DEVELOPMENT OF ARTIFICIAL NEURAL NETWORK BASED DESIGN TOOL FOR AIRCRAFT ENGINE BOLTED FLANGE CONNECTION SUBJECT TO COMBINED AXIAL AND MOMENT LOAD

\author{
A THESIS SUBMITTED TO \\ THE GRADUATE SCHOOL OF NATURAL AND APPLIED SCIENCE \\ $\mathrm{OF}$ \\ THE MIDDLE EAST TECHNICAL UNIVERSITY
}

BY

TAHIR VOLKAN SANLI

\begin{abstract}
IN PARTIAL FULFILLMENT OF THE REQUIREMENTS
FOR

THE DEGREE OF MASTER OF SCIENCE

IN

THE DEPARTMENT OF AEROSPACE ENGINEERING
\end{abstract}

JANUARY 2018 

Approval of the thesis:

\section{DEVELOPMENT OF ARTIFICIAL NEURAL NETWORK BASED DESIGN TOOL FOR AIRCRAFT ENGINE BOLTED FLANGE CONNECTION SUBJECT TO COMBINED AXIAL AND MOMENT LOAD}

submitted by TAHIR VOLKAN SANLI in partial fulfillment of the requirements for the degree of Master of Science in Aerospace Engineering Department, Middle East Technical University by,

Prof. Dr. Gülbin Dural Ünver

Dean, Graduate School of Natural and Applied

Science

Prof. Dr. Ozan Tekinalp

Head of Department, Aerospace Engineering

Prof. Dr. Altan Kayran

Supervisor, Aerospace Engineering Dept., METU

\section{Examining Committee Members:}

Assoc. Prof. Dr. Demirkan Çöker

Aerospace Engineering Dept., METU

Prof. Dr. Altan Kayran

Aerospace Engineering Dept., METU

Prof. Dr. Mehmet Ali Güler

Mechanical Engineering Dept., TOBB

Assoc. Prof. Dr. Ercan Gürses

Aerospace Engineering Dept., METU

Assoc. Prof. Dr. D. Funda Kurtuluş

Aerospace Engineering Dept., METU

Date: 30.01 .2018 
I hereby declare that all information in this document has been obtained and presented in accordance with academic rules and ethical conduct. I also declare that, as required by these rules and conduct, I have fully cited and referenced all material and results that are not original to this work.

Name, Last name : Tahir Volkan Sanl1

Signature 


\title{
ABSTRACT \\ DEVELOPMENT OF ARTIFICIAL NEURAL NETWORK BASED DESIGN TOOL FOR AIRCRAFT ENGINE BOLTED FLANGE CONNECTION SUBJECT TO COMBINED AXIAL AND MOMENT LOAD
}

\author{
Sanl1, Tahir Volkan \\ MSc., Department of Aerospace Engineering \\ Supervisor: Prof. Dr. Altan Kayran
}

January 2018, 104 pages

In this thesis, a design tool using artificial neural network (ANN) is developed for the bolted flange connections, which enables the user to analyze typical aircraft engine connections subjected to combined axial and bending moment in a fast yet very accurate way. The neural network trained for the design tool uses the database generated by numerous finite element analyses for different combinations of parametric design variables of the bolted flange connection. The defined parameters are the number of bolts, the bolt size, the shaft thickness, the flange thickness, the pretension load acting on the bolt and the combined external axial force and bending moment. The outputs gathered from total $12000 \mathrm{FE}$ analyses are the bolt reaction force and the average flange stress, which are collected to be used as database for the ANN training process together with the input design parameters. The results of the trained ANN are then compared with the FEA results. The comparison proves that the neural network shows great compliance with the non-linear FEA within the range of design parameters. As the last step, a graphical user interface is developed to turn the neural network into a user-friendly bolted flange design tool. It is believed that the developed design tool can replace the non-linear finite element analysis and be 
used very effectively in an optimization framework for the weight minimization of cylindrical bolted flange connections of aircraft engines.

Keywords: Artificial Neural Network, Bolted Flange Connection, Finite Element Analysis, Contact, Design Tool 


\title{
EKSENEL VE MOMENT YÜKÜ ALTINDAKİ FLANŞLAR İÇİN YAPAY SINIIR AĞINA DAYALI CIVATALI FLANŞ TASARIM ARACI GELISTTIRILMESI
}

\author{
Sanl1, Tahir Volkan \\ Yüksek Lisans, Havacılık ve Uzay Mühendisliği Bölümü \\ Tez Yöneticisi: Prof. Dr. Altan Kayran
}

Ocak 2018, 104 sayfa

Bu çalışma, kullanıcının, bileşik eksenel yük ve eğme momenti etkisindeki tipik uçak motoru bağlantılarını hızlı ve doğru bir biçimde analiz etmesini sağlayan, yapay sinir ağı (YSA) tabanlı bir tasarım aracı geliştirilmesi üzerine yapılmıştır. Tasarım aracı için geliştirilen sinir ağı, seçilen tasarım parametreleri permütasyonları sonucu ortaya çıkan, binlerce sonlu eleman analizinin çıktısını veri tabanı olarak kullanmıştır. Tanımlanan tasarım parametreleri cıvata sayısı, cıvata çapı, gövde kalınlı̆̆ı, flanş kalınlığı, cıvatalara uygulanan önyükleme kuvveti ve bileşik eksenel kuvvet ile eğme momentinden oluşmuştur. Toplam 12000 sonlu eleman analizinden cıvata reaksiyon kuvveti ve flanş gerilimi çıktı olarak toplanmıştır. Bu çıktılar, tasarım girdileri ile bir araya getirilerek yapay sinir ağı geliştirme aşamasında kullanılmıştır. Geliştirilen yapay sinir ağı, daha sonra sonlu eleman analizlerinin çıktılarıyla karşılaştırılmıştır. $\mathrm{Bu}$ karşılaştırma sonucunda yapay sinir ağının sonlu eleman analizleri ile büyük uyum gösterdiği görülmüştür. Son olarak, yapay sinir ağını kullanıcı dostu bir tasarım aracına çevirmek amacıyla grafik kullanıcı ara yüzü yazılmıştır. Bu tasarım aracının uçak motorlarındaki silindirik cıvatalı flanş bağlantıları için, sonlu eleman 
analizlerinin yerini alarak, kuvvetli bir en iyileme analiz arac1 olarak kullanılması amaçlanmıştır.

Anahtar Kelimeler: Yapay Sinir Ağı, Cıvatalı Flanş Tasarımı, Tasarım Aracı Geliştirme, Grafik Kullanıcı Ara yüzü 
To All The Freedom,

Yet to Come 


\section{ACKNOWLEDGMENTS}

First of all, I would like to thank my supervisor, Prof. Dr. Altan Kayran for giving me the opportunity to work with him.

Besides my supervisor, I would like to thank Assoc. Prof. Dr. Demirkan Çöker and Assoc. Prof. Dr. Ercan Gürses for all their help and contributions to this study.

I would also like to thank my wife for bearing with me during the whole process, and my cat, Çükübik, for the emotional support during the breaks.

To Kocatepe Kahvecisi; without them, this study would never start. 
TABLE OF CONTENTS

ABSTRACT

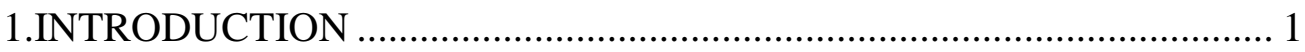

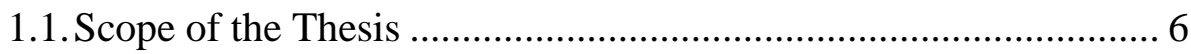

2.FINITE ELEMENT ANALYSIS OF BOLTED FLANGE

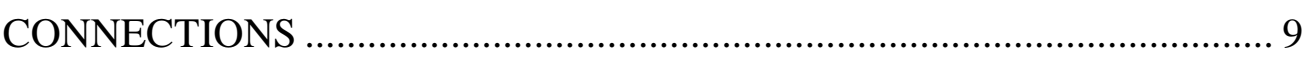

2.1. Finite Element Modeling and Geometry ......................................... 9

2.1.1. The analysis geometry ................................................. 9

2.1.2. Finite element modeling ............................................ 14

2.1.3. Loads and boundary conditions ................................. 20

2.2. The Application of Bending Moment ............................................ 22

2.3. Application of the Shear Force …………………………….......... 30

2.4. The Effect of the Shear Force ………………………………......... 36

3.PARAMETRICAL ANALYSES AND DATABASE CONSTRUCTION 45

3.1. The Selection of Input Parameters .................................................. 45

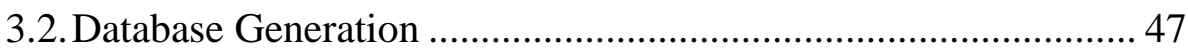

3.3. The Parametric Finite Element Analysis Results.......................... 54

4.SETUP OF ARTIFICIAL NEURAL NETWORK AND RESULTS..........59

4.1. The Modeling of Artificial Neural Network ................................. 59

4.2. The Training Results of the Artificial Neural Network ................ 61 
4.3.Comparison of Artificial Neural Network and Finite Element Analysis Results 65

4.4.The Graphical User Interface of the Bolted Flange Design Tool. 70

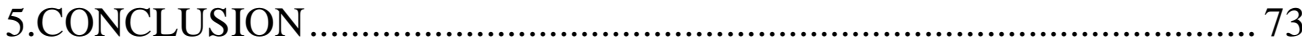

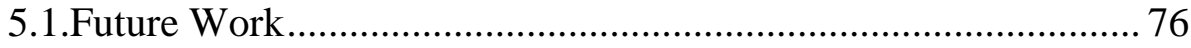

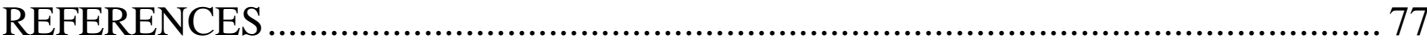

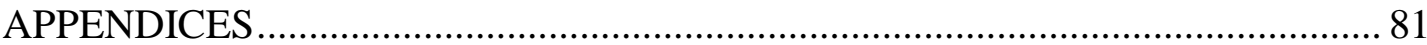

A. JUSTIFICATION OF EQUATION FOR AXIAL FORCE DUE TO

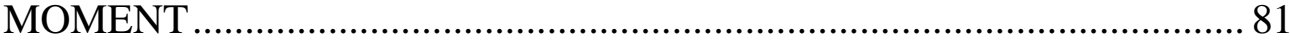

B. ARTIFICIAL NEURAL NETWORK TRAINING CODE .................... 83

C. CREATING THE GRAPHICAL USER INTERFACE .......................... 85

D. BOLTED FLANGE DESIGN TOOL GRAPHICAL USER INTERFACE

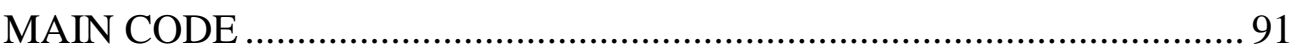

E. BOLTED FLANGE DESIGN TOOL GRAPHICAL USER INTERFACE

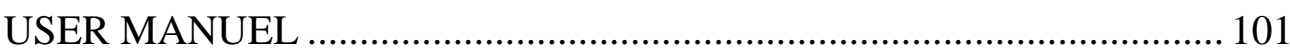

F. THEORETICAL BOLT STRESS CALCULATION CODE - ESDU ... 103 


\section{LIST OF TABLES}

\section{TABLES}

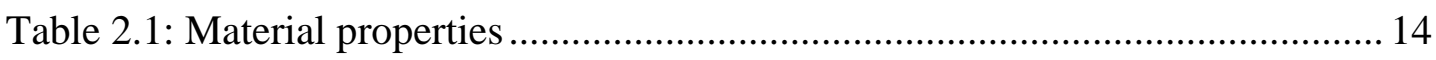

Table 2.2: Contact definitions between parts …..................................................... 15

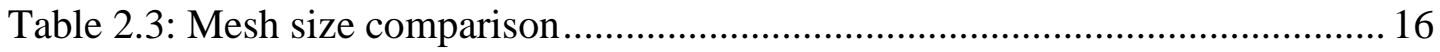

Table 2.4: Sample load set acting upon the whole assembly of bolted flange

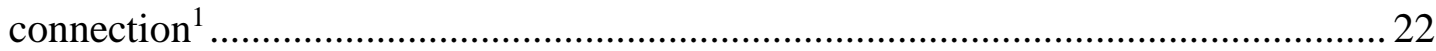

Table 2.5: Average normal stresses for preload case only ...................................... 27

Table 2.6: Average normal stresses for the combined preload and bending moment

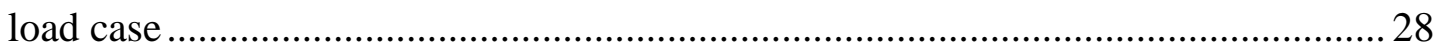

Table 2.7: Average normal stresses for the combined preload bending moment load case with bending moment 10 times magnified ....................................................... 30

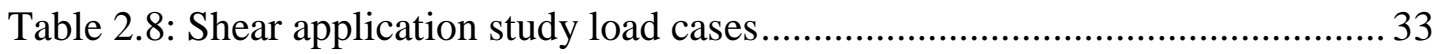

Table 2.9: Studied cases for the shear force effect on the bolt and flange shear stress

Table 3.1: Geometrical input parameters of the bolted flange connection ................ 46

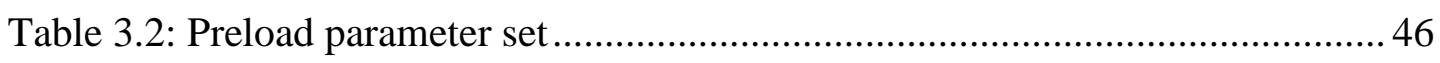

Table 3.3: Combined bending moment load parameter set ..................................... 47

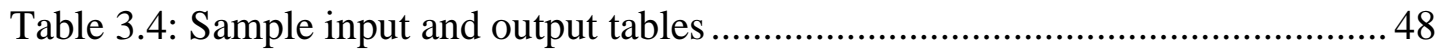

Table 3.5: Sample average equivalent von-Mises stress calculation for DP1 in Table

Table 3.6: Average bolt reaction forces on each bolt group ..................................... 55

Table 3.7: Average flange stresses for each bolt group ...........................................56

Table 3.8: Maximum tensile stresses on each bolt cross-section..............................57

Table 4.1: RMSE for each bolt group and combined RMSE for all bolt groups along

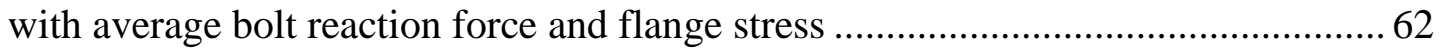

Table 4.2: Random design points used in the training of the ANN ..........................66

Table 4.3: Comparison of the ANN and the FEA results for the selected design points

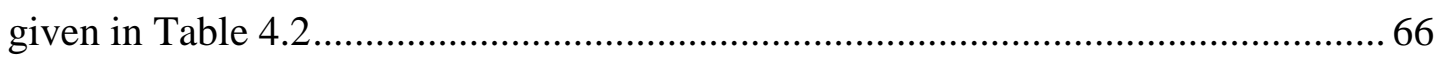

Table 4.4: Input variables of intermediate design points ....................................... 67 
Table 4.5: Comparison of the ANN and the FEA results for the intermediate design

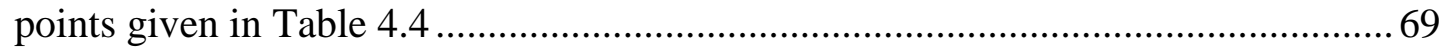




\section{LIST OF FIGURES}

\section{FIGURES}

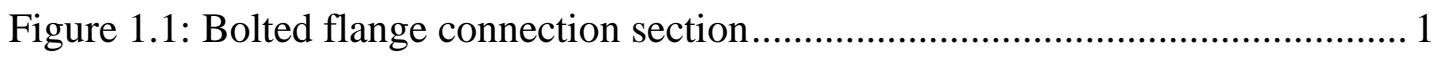

Figure 1.2: Sample ANN structure with three layers including three input and two outputs

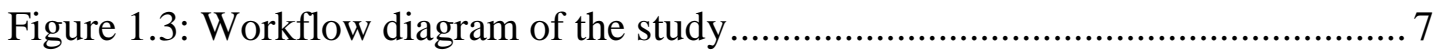

Figure 2.1: Bolted flange connection assembly ...................................................... 10

Figure 2.2: Segment model representing the bolted flange assembly....................... 10

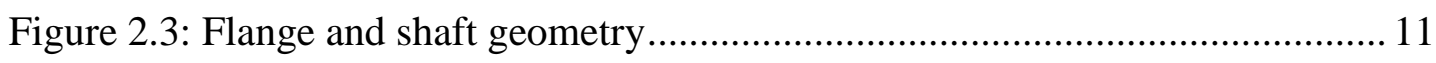

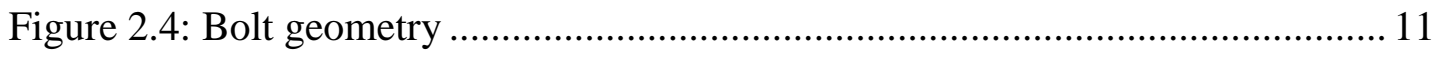

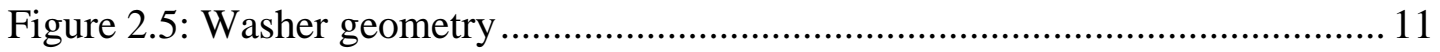

Figure 2.6: Effective diameter calculation for the bolt-nut geometry ....................... 12

Figure 2.7: Relations between the geometrical input parameters ........................... 13

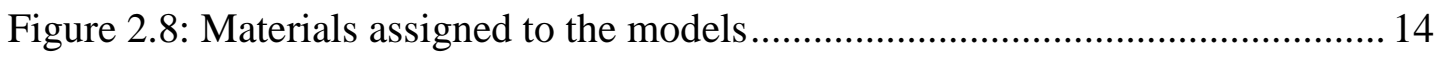

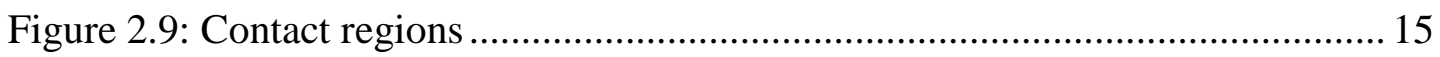

Figure 2.10: The meshed bolt-nut geometry with the edge sizing .......................... 17

Figure 2.11: The meshed flange geometry with edge sizing and multi-zone method

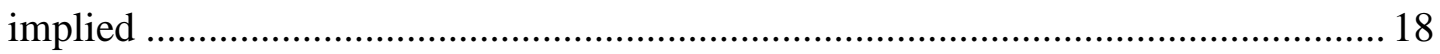

Figure 2.12: The meshed washer geometry with implemented edge sizing ............. 19

Figure 2.13: Partial model with the medium-fine mesh......................................... 20

Figure 2.14: Boundary conditions of the segment model ...................................... 21

Figure 2.15: Application surfaces of the boundary conditions ............................... 21

Figure 2.16: Full model with 30 bolt/nut pairs ..................................................... 23

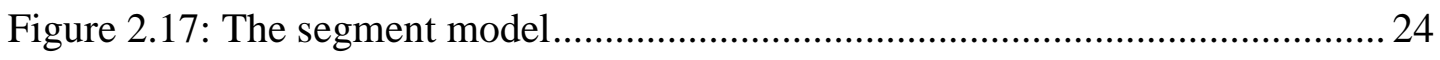

Figure 2.18: The load and boundary conditions on the full model ........................... 24

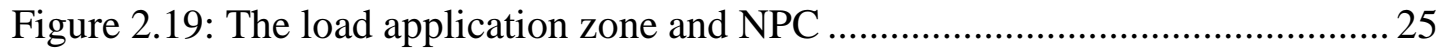

Figure 2.20: The load and boundary conditions of the segment model .................... 26

Figure 2.21: (a) Normal stress distribution of the segment model for the preload application without any bending moment (upper figure), (b) normal stress distribution of the full model at the same case (lower figure) 
Figure 2.22: (a) Normal stress distribution of the segment model for the combined preload and bending moment load case (upper figure), (b) normal stress distribution of the full model for the same case (lower figure) .28 Figure 2.23: (a) Normal stress distribution in the bolt of the segment model for the combined load case with bolt pretension and bending moment (upper figure), (b) normal stress distribution of the full model for the same case (lower figure);

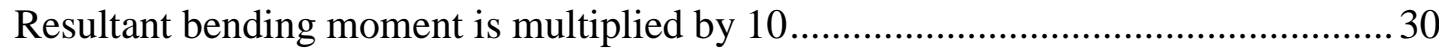
Figure 2.24: A simplified bolted flange connection model used in the case study.... 31 Figure 2.25: The boundary condition and the load application used for the first case in the study 32

Figure 2.26: The load application regions and load direction used in the case study 33 Figure 2.27: The defined shear stress path and the bolt under maximum shear load 34 Figure 2.28: The comparison of the shear stresses along the path for each load case 34 Figure 2.29: The comparison of the shear stresses around the 3rd bolt on the midpath 35

Figure 2.30: Mesh structure of the geometry used in the shear force case study........36 Figure 2.31: Load and boundary conditions used in the shear force case study .........37

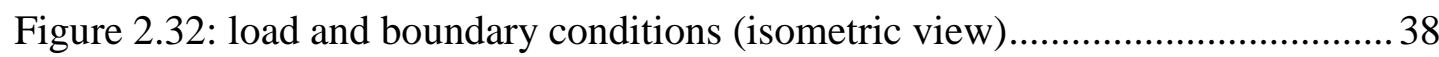
Figure 2.33:Shear stress path and the bolt region under the influence of maximum

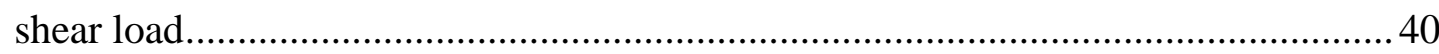

Figure 2.34: Shear stress vs. distance along the path ............................................... 40 Figure 2.35: The effect of preload on the shear stresses on the flange and the bolt near the center of the path, 1,3 and $5^{\text {th }}$ cases 41 Figure 2.36: The effect of friction on the shear stresses on the flange and the bolt near the path center .42

Figure 3.1: Bolt reaction force for DP1 configuration in Table 3.4 49

Figure 3.2: The equivalent von-Mises stress distribution on flange geometry for DP1 configuration in Table 3.4 .49

Figure 3.3: The equivalent von-Mises stress distribution on the bolt-nut geometry for DP1 configuration in Table 3.4 .50 Figure 3.4: The normal stress distribution at the center cross-section of the bolt-nut geometry for DP1 configuration in Table 3.4 .51 
Figure 3.5: The equivalent von-Mises stress distribution of bolted flange connection assembly for DP1 configuration in Table 3.4

Figure 3.6: The equivalent von-Mises stress distribution at the $\mathrm{X}$ cross-section of the bolted flange connection assembly for DP1 configuration in Table 3.4 ....................52

Figure 3.7: Contact status between the flanges ....................................................... 53

Figure 3.8: The frictional stress distribution on the contact surface of flanges ......... 53

Figure 3.9: The equivalent von-Mises stress collection points ................................ 53

Figure 3.10: Average bolt reaction forces on each bolt group .................................. 55

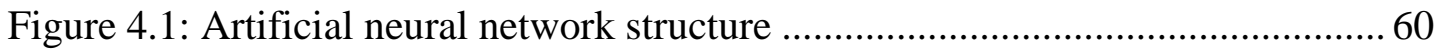

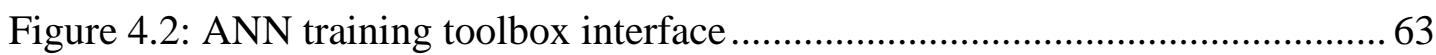

Figure 4.3: Error histogram comparing ANN and FEA results of the (4.826-5) bolt

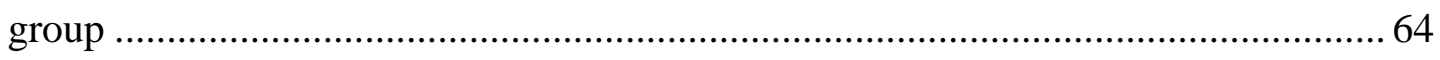

Figure 4.4: Graphical user interface of the bolted flange design tool ....................... 71

Figure A.1: Shaft section with 8-bolt configuration ............................................... 81

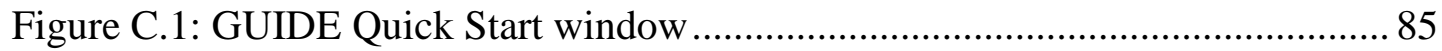

Figure C.2: Empty fig file and the main GUI elements …....................................... 86

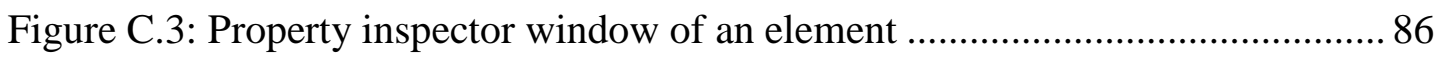

Figure C.4: Sample graphical user interface …..................................................... 87

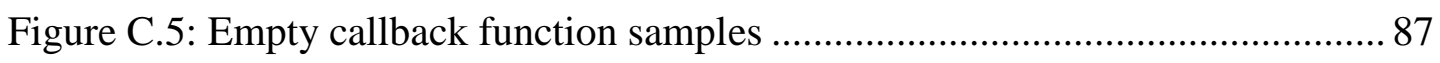

Figure C.6: Preliminary GUI for bolted flange design tool ..................................... 88

Figure C.7: Execute pushbutton callback function ................................................ 89

Figure E.1: Graphical user interface sections .................................................... 101

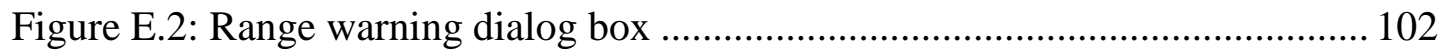

Figure E.3: Integer warning dialog box .......................................................... 102 


\section{LIST OF ABBREVIATIONS}

$\begin{array}{ll}\text { ANN } & \text { Artificial neural network } \\ \text { DP } & \text { Design point } \\ \text { FE } & \text { Finite element } \\ \text { FEA } & \text { Finite element analysis } \\ \text { FEM } & \text { Finite element method } \\ \text { GUI } & \text { Graphical user interface } \\ \text { MSE } & \text { Mean square error } \\ \text { RMSE } & \text { Root mean square error } \\ \text { RS } & \text { Response surface } \\ \mathbf{R}^{2} & \text { Coefficient of determination }\end{array}$




\section{CHAPTER 1}

\section{INTRODUCTION}

In the industry, bolted flange connections are one of the most widely encountered joint types. A bolted flange joint consists of two pipe or shaft sections connected with bolts through the flanges located on the ends. Figure 1.1 shows a typical industrial bolted flange connection section.

These type of connections, generally, have three main purposes in the industry. Depending on the application area, these purposes vary from preventing leakages to being an interface for transferring loads from one part of the structure to another, while the common purpose is to keep the structural integrity [1].

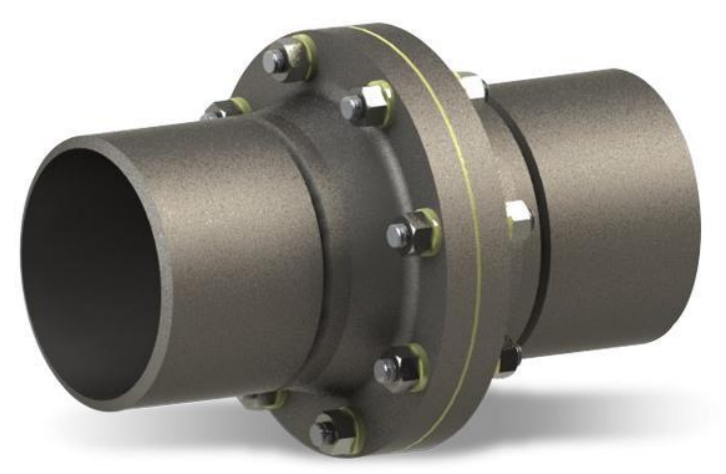

Figure 1.1: Bolted flange connection section 
In the aircraft industry, bolted flange connections are mostly seen in the engine zone. Within the aircraft engine structure, their main purpose is to transfer acting loads to the other parts of the engine.

In aerospace applications, one of the most important aspects is to keep the weight of the structure minimum without sacrificing the integrity of the structure. To achieve this purpose, the analysis of the structure has to be handled carefully in order to keep the margin of safety minimum. An optimum aircraft design, which needs a balance between structural integrity and the weight limitations, requires many critical analyses, repetitively conducted to reach an optimum configuration.

For the bolted flange connection analysis, two main analysis methods are used commonly; finite element analysis and the simplified theoretical calculations. Theoretical calculations require the simplification of the analysis geometry, along with the load and boundary conditions applied to it. As a result of these simplifications, analytical methods usually tend to give fast results. However, minimum weight requirement is hard to achieve with the theoretical calculations, as they are inclined to give over-safe outcomes [2]. As an example, ASME standard [3] and ESDU [4] are two of the most commonly used analytical calculation methods used in the analysis process of the bolted flange connections. Finite element method (FEM), on the other hand, is a better analysis method for the bolted flange joint analysis in order to achieve the optimum weight. Since only simple assumptions are made for the simplification purposes during the modeling stage of the analysis, the finite element analysis tends to give more realistic and accurate results compared to the theoretical calculations. However, due to the non-linear nature of the structure model, resulting from the contact definitions which are have to made, finite element analysis method requires significant amount of computational effort, which make is unsuitable for repetitive analyses.

As a result of the disadvantages of both common methods, a new alternative analysis tool is needed combining the good aspects of both theoretical calculations and the finite element analysis. This new method is aimed to achieve optimum design parameters with instant calculations. In order to satisfy such needs, initially, two main approaches are thought to be utilized for the development of this design and 
analysis tool. Those are the artificial neural network (ANN) and the response surface (RS) approaches. Both response surface and the artificial neural network methods satisfy the need for accurate and fast outcomes for non-linear problems. However, according to the conducted comparisons, artificial neural network seems to have broader application area than the response surface approach $[5,6]$.

The artificial neural network is basically an artificial structure, composed of artificial computational cells, referred as neurons. It is usually utilized to solve complex, nonlinear problems. The concept of artificial neural network is derived from the nervous system of human brain [7], and simulating the biological system, it has the capability of organizing, classifying, generalizing and learning data [5]. As in the biological case, each neuron in an artificial network is connected to all other neurons located in the defined artificial layers, as can be seen in Figure 1.2 [8].

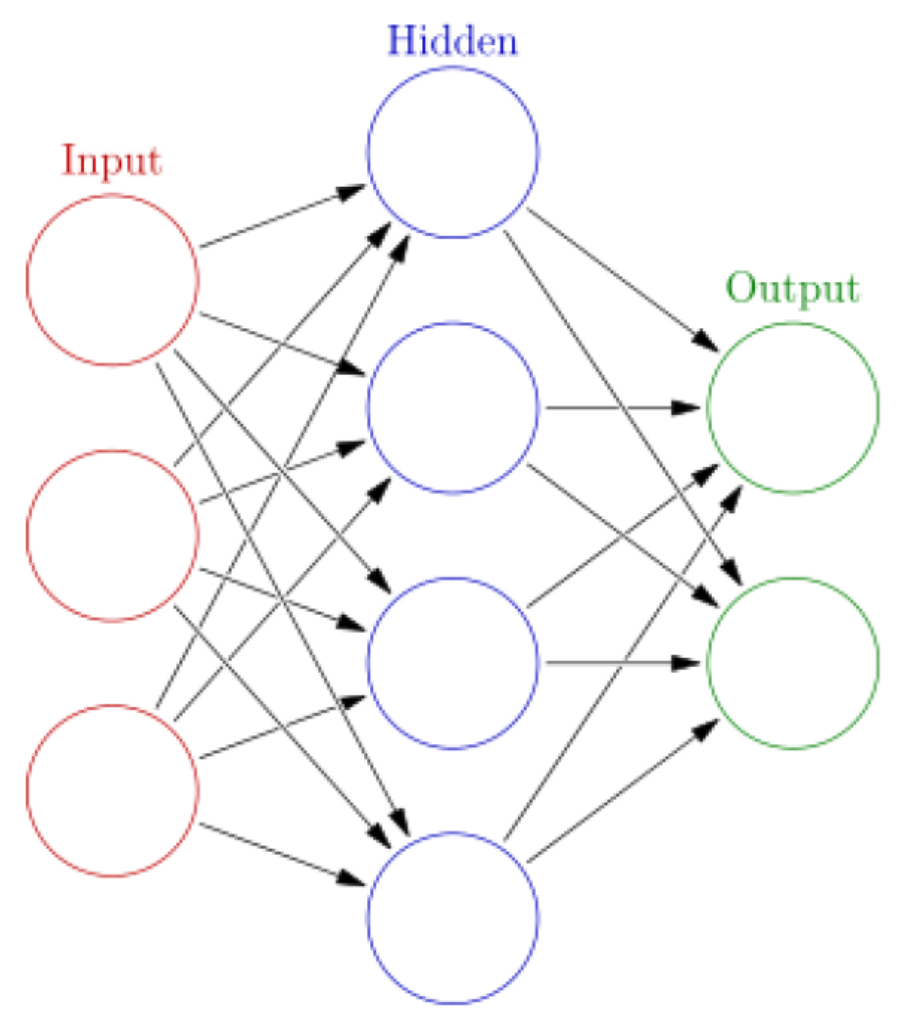

Figure 1.2: Sample ANN structure with three layers including three input and two outputs 
ANN can be utilized and trained to solve variety of problems either by using the experimental or analysis data as an initial database. For complex, non-linear problems, ANN can be trained to produce very accurate models within the range of the design variables. Muliana et al. compared the performance of a model created by the utilized artificial neural network with a model created with finite element approach in order to predict the response of material with non-linear property [8]. In this study, an artificial network is trained including wide range of materials and geometrical parameters, and the load-displacement curves are calculated with the help of the trained ANN. It has been shown that the ANN is capable of accurately estimating the behavior of the non-linear finite element model.

Concerning the behavior of bolted flange connections, there are number of studies and methodologies, each built on a different approach to the problem. As mentioned before, ESDU [4] and ASME [3] sources are among the most respected reference sources in the field. ESDU source approaches to the problem structure under axial load by beam assumption. It models the bolted flange connection assembly as an assembly of springs representing the flange and bolt groups, as Shigley explains in detail [9]. The stiffness of each spring representing each group is calculated utilizing the geometrical parameters and the material properties. Using the created parallel spring model and considering the external axial loads, the bolt and flange loads are calculated. This approach can also consider the prying effect resulting from the separation under the bolt head due to the external loads.

ASME Boiler and Pressure Vessel Code Section VIII [3] approaches to the bolted flange connections with very detailed theoretical calculations. This code contains methodology for complex flange designs having several aspects. It suggests design solutions to complicated problems including gaskets and internal pressure. As Schaaf et al. states in ASME conference proceeding, EN13445, which is a European standard for flange calculation, is based on ASME code [10].

Another methodology, based on finite element analysis, is described by Coro [2] for bolted flange connection design. As stated, the utilization of finite element approach significantly increases the accuracy of the analysis, compared to the theoretical beam theory approach. The mentioned commercial flange-design tool, which analyzes 
different flange connections under different loads, is said to give very precise results compared to the finite element analysis solutions.

Azim [11] investigates an analytical approach for bolted flange connections working under bending moments. Azim compares the effect of design parameters, such as flange thickness and number of bolts, on the bolt loads using both classical beam theory approach and finite element method. In this study, it is stated that the theoretical approach is only applicable to some geometries, and it is not reliable when the geometry begins to alter from them, as the error increases. Therefore, it is not applicable to the cases differing from the standard condition. The finite element analysis approach should be preferred for such complicated geometries in order to obtain low error compared to the theoretical calculations.

Couchaux et al. investigated a theoretical model for the bolted flange connections under combined axial and bending moment loads [12]. They considered ductile and non-ductile failure modes while proposing the analytical model in order to determine the plastic bending moment of the structure. Later, they validated their findings with a numerical model [13] and observed a good agreement with the numerical solution.

Stamatopoulos [14] studied behavior of the circular bolted flange connections under static compressive and tensile loads, using a segment model of the structure. The methodology used in the study is based on the failure pattern classifications. Stamatopoulos, as a result, plotted the M-N curves for the bolted flange connections. The analytical approach is, then, compared to the finite element analysis results, and good agreement between the models are observed. In this study, the ultimate bearing capacity of the full model of the bolted flange connection is derived by extending the behavior of the segment model. The effects of the parameters, such as flange and shaft thicknesses, bolt size and location, magnitude of the external load and the material properties, are investigated.

Tafheem et al. conducted a study on the bolt tension of the bolted flange connections subjected to bending moment [15]. This study is conducted on the finite element model of full circular bolted flange connection. Tafheem et al. aimed to conduct a parametric correlation study and clear the effect of each design parameter on the bolt 
loads. In this study, it is seen that the parameters such as flange thickness and width and bolt diameter significantly affect the tensile bolt reaction.

Fei et al. trained an ANN utilizing the results of two dimensional finite element analysis to predict the bolt force in a bolted flange connection [16]. Y1ldırım [17] and Yildırım et al. [18] performed a similar study to the current study and developed an ANN based design tool for bolted flange connections. However, in the study of Yildirım et al. the external load is on the bolted flange connection is limited to axial load only.

In this study, swift yet very accurate, design and analysis tool, based on the artificial neural network (ANN), for the typical aircraft engine bolted flange connection is aimed to be developed for joints acting under the combined axial and bending moment service loads.

\subsection{Scope of the Thesis}

In this thesis study, a fast and accurate, artificial neural network based design and analysis tool is developed for an aircraft engine bolted flange connection subjected to the combined axial and moment loads, using a database created by repetitive finite element analyses conducted on a segment model representing the circular bolted flange connection assembly acting under the same load condition.

In the Chapter 2, the analysis geometry is defined and various design parameters are selected which are thought to be critical. The finite element model is created using a medium-fine mesh density, derived from the comparison study conducted among various mesh densities. After the modeling stage, general loads acting on a typical aircraft engine bolted flange connection and the boundary conditions of the segment model representing such connection are defined. The application of the bending moment to the segment model is investigated by conducting series of analyses comparing the full bolted flange connection model acting under the bending moment and the segment model loaded with an axial load derived from the bending moment. Furthermore, the application region of the global shear load is studied, followed by an investigation about the effect of the shear force on the flange and bolt stresses, in order to decide whether shear load is negligible, or not. 
In the Chapter 3, the geometrical and load input parameters are selected. The selection of these design parameters resulted in different design points, which then are used to create the artificial neural network. For each combination of the design parameters, finite element analyses are conducted with the set boundary conditions. The database is generated, using the finite element analysis results for each design point. Some intermediate finite element analysis results are presented.

In the Chapter 4 of the thesis, an artificial neural network is modeled using the database created with the results of parametric finite element analysis, which is the crucial step for the development of the design tool. The results calculated by the trained neural network are then compared and verified with the finite element analysis results for each design point and the intermediate design points. Finally, a user-friendly graphical user interface is developed using the trained and verified artificial neural network, and the design tool for the bolted flange connections is created. For the design and the analysis stage of the thesis, ANSYS [19] Workbench software is used as it enables the user to conduct parametrical analysis. MATLAB [20] Neural Network and GUI toolboxes are used for the training stage of the artificial neural network and the development stage of the graphical user interface for the ANN based bolted flange design tool. Figure 1.3 demonstrates the workflow of the followed process.

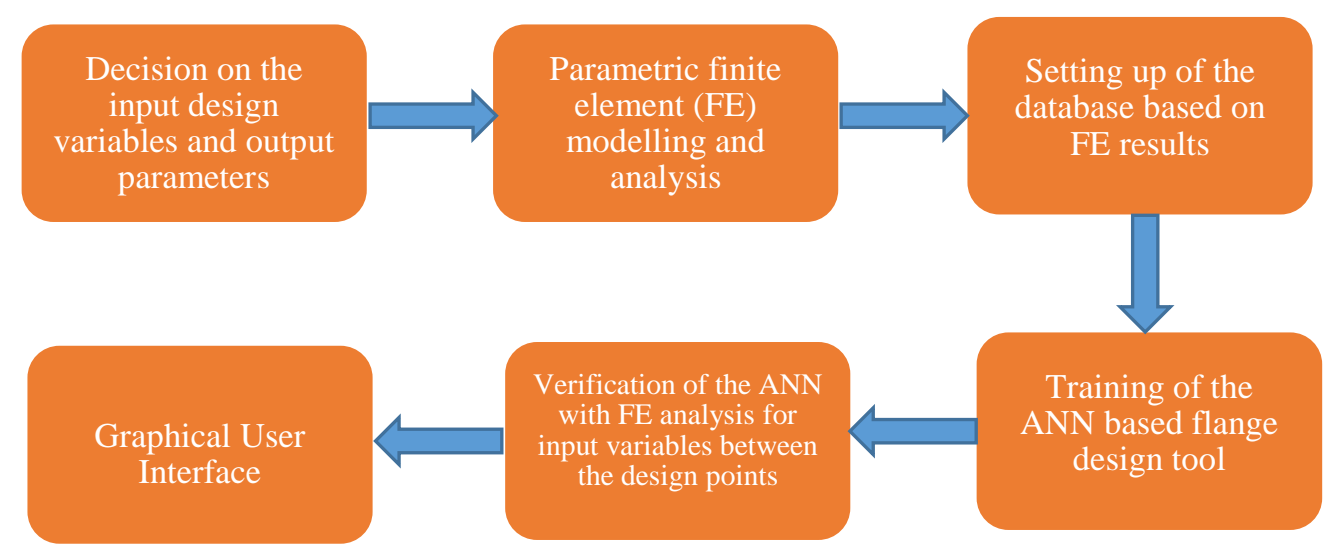

Figure 1.3: Workflow diagram of the study 


\section{CHAPTER 2}

\section{FINITE ELEMENT ANALYSIS OF BOLTED FLANGE CONNECTIONS}

\subsection{Finite Element Modeling and Geometry}

\subsubsection{The analysis geometry}

The cylindrical bolted flange connection assembly consists of two flanged shaft section, selected number of bolt and nut pairs and a couple of washers for each bolt. Figure 2.1 shows the full model of cylindrical bolted flange connection assembly. Analyzing this full model assembly with a non-linear finite element method is too much time consuming, as the modeling requires many contact definitions for each bolt-nut couple and their washers. Concerning this study, as training the artificial neural network requires a database derived from many design points, the computational expense becomes a serious problem. In order to eliminate this problem, it is decided to use a segment model representing the full assembly model for the parametric analyses. Figure 2.2 represents the segment model of the bolted flange connection used in the analyses. Figures 2.3, 2.4 and 2.5 show the components that build up the segment model assembly.

In the modeling stage of the segment model, four design parameters are decided to be used as independent parametric design inputs. The rest of the design parameters are modeled to be dependent on them, except for the inner shaft diameter, which is kept constant. These four design inputs are the bolt size (A), the number of bolts (B), the shaft thickness (C) and the flange thickness (D). The bolt sizes used in the thesis are chosen among the industrial standard bolt sizes which are used for the similar aircraft 


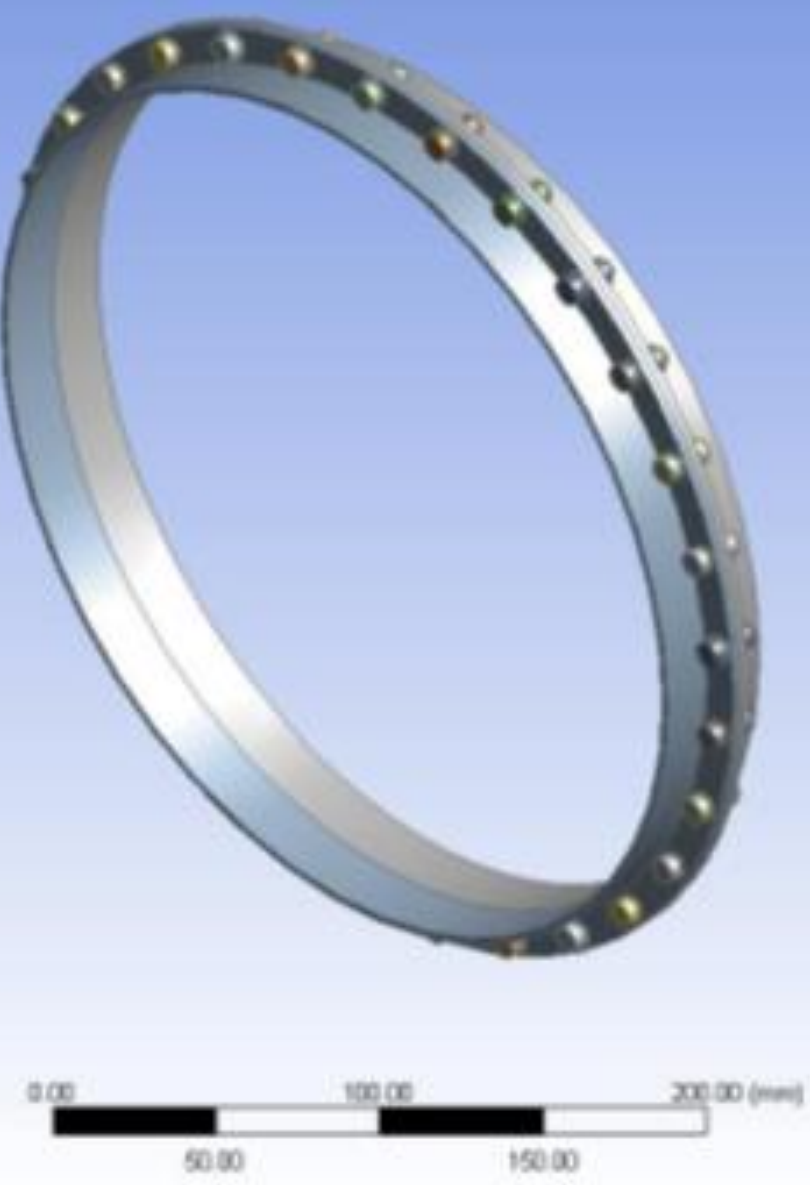

Figure 2.1: Bolted flange connection assembly

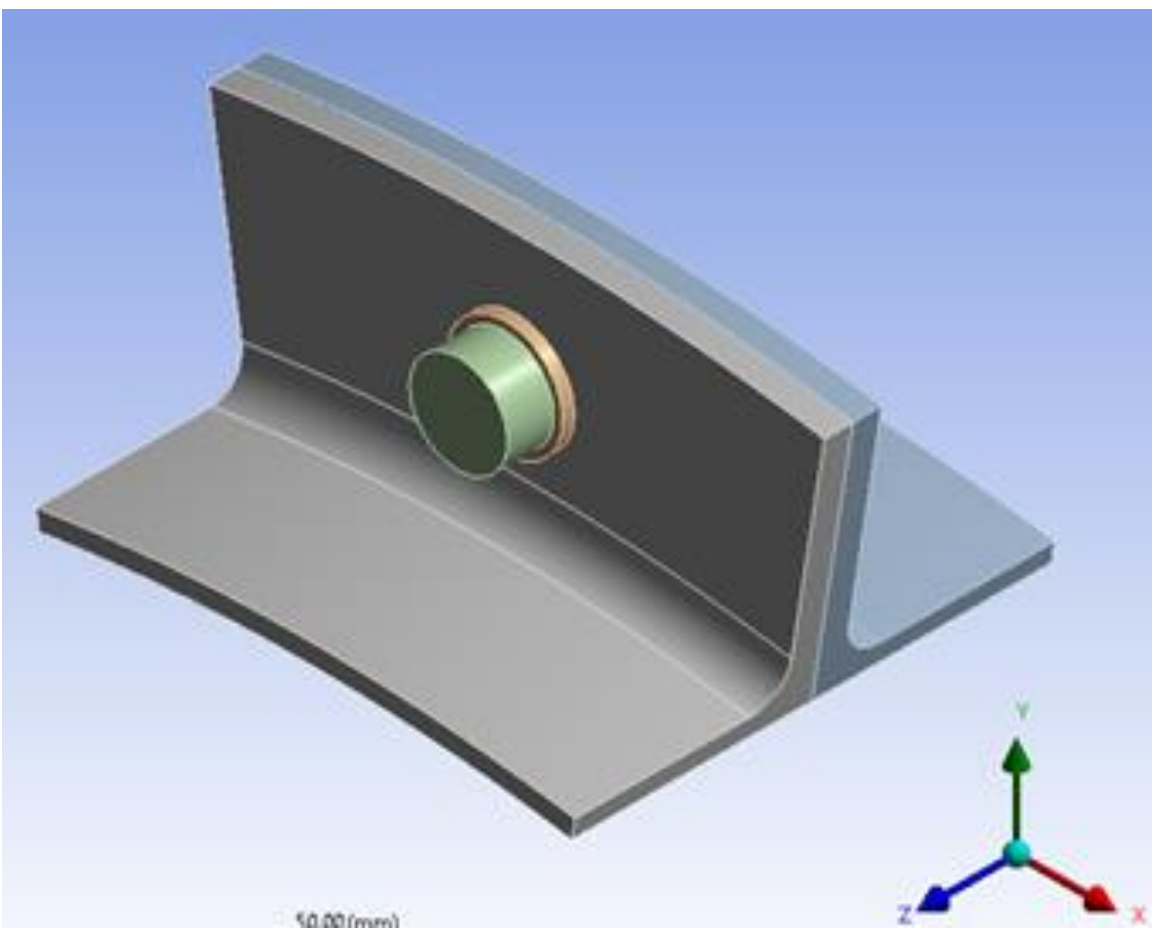

Figure 2.2: Segment model representing the bolted flange assembly 


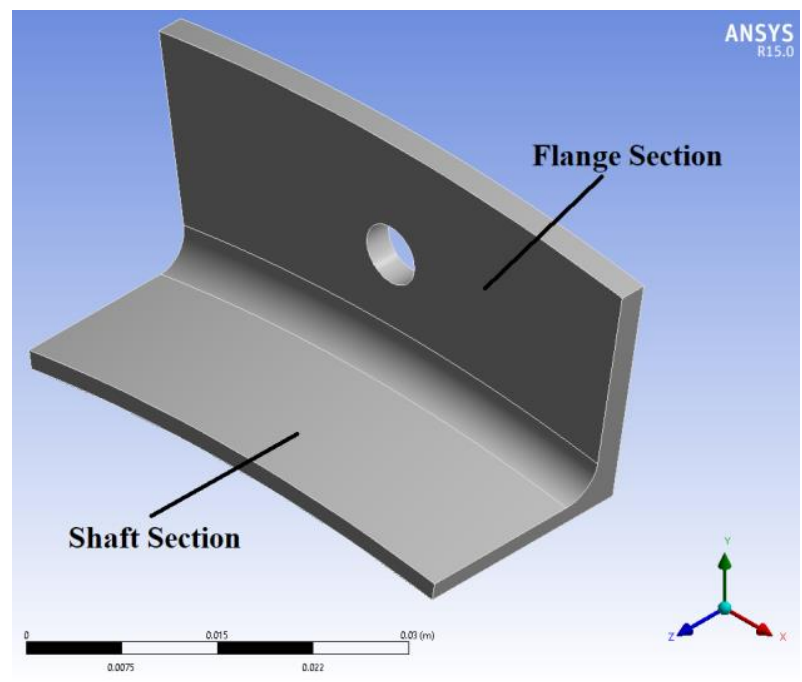

Figure 2.3: Flange and shaft geometry

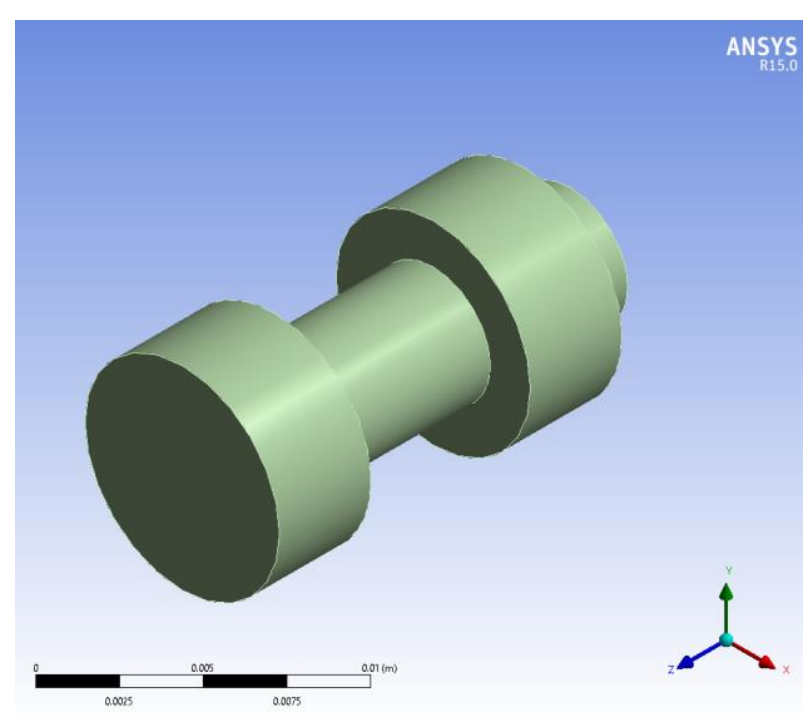

Figure 2.4: Bolt geometry

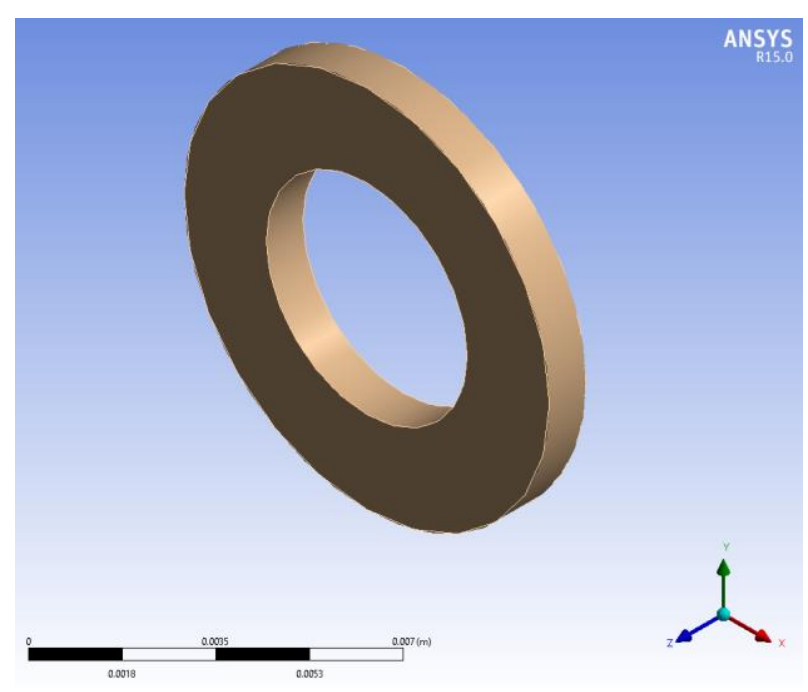

Figure 2.5: Washer geometry 
engine shafts. While modeling the bolt and nut pair, some assumptions are made in order to simplify the model for parametric analyses. First of all, the bolt and the nut bodies are modeled as one body. By doing so, one of the contact definitions, which is the bonded contact between the nut and the bolt thread, is eliminated, which in turn reduced the computational effort significantly. As the bonded contact, in definition, considers the bodies in contact as one, this assumption did not affect the analysis results in a bad way, on the contrary, it made the analysis provide a more realistic bolt reaction force. Another simplification made on the bolt-nut pair was to model bolt head and the nut as circular, instead of the traditional hexagonal shape. This assumption, again, saved some computational time by eliminating the need for finemeshing at the sharp corners of the bolt head and the nut. The circular bolt head and the nut diameters are modeled with the effective diameter, which is the average of the diameters of the circles enclosing the head and enclosed by the hexagonal head, as shown in Figure 2.6. The effective diameter changing automatically for each parametric analysis is taken as 1.7 times the bolt diameter, whereas the bolt head and nut thicknesses are formulated as 0.8 times the bolt size.

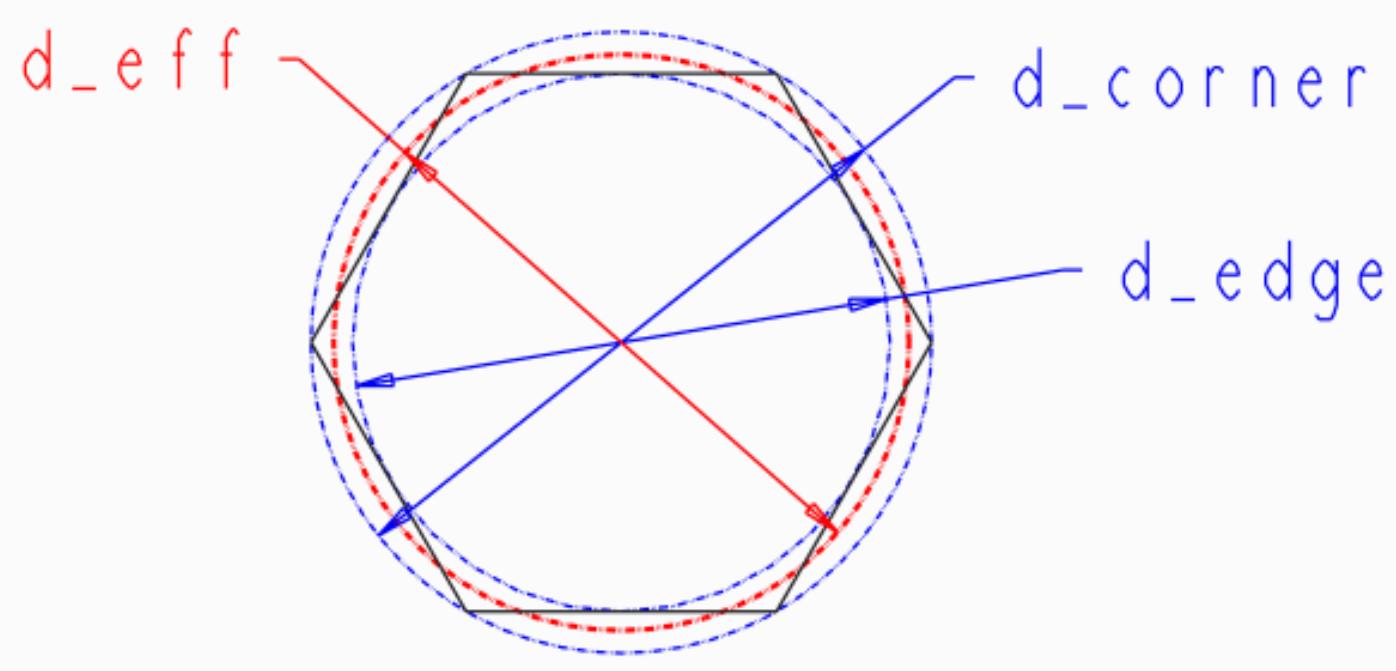

Figure 2.6: Effective diameter calculation for the bolt-nut geometry 
The bolt size parameter is then used to define the edge distances on the flange of the segment model. The distance from the center of the bolt to the free outer edge of the flange is calculated as 2 times metric bolt diameter plus 1 millimeter, and the distance from the center to the inner edge of the flange is taken as the bolt diameter plus 2 millimeters. The bolt diameter is also used to define the washer dimensions and the hole diameter on the flange. The washer thickness is taken as 0.2 times bolt diameter whereas the inner and outer diameters of the washer are 1.1 and 2 times bolt diameter, respectively. The hole diameter is also taken as 1.1 times bolt diameter. The parameter representing the number of bolts is used to define the angular segment of the partial model. It divides the full model such that the partial model contains only one bolt-nut pair. The shaft thickness and the flange thickness are selected based on the typical aircraft engine bolted flange connection design. Figure 2.7 shows the cross section of the segment model and the relations and dependencies between the input parameters.

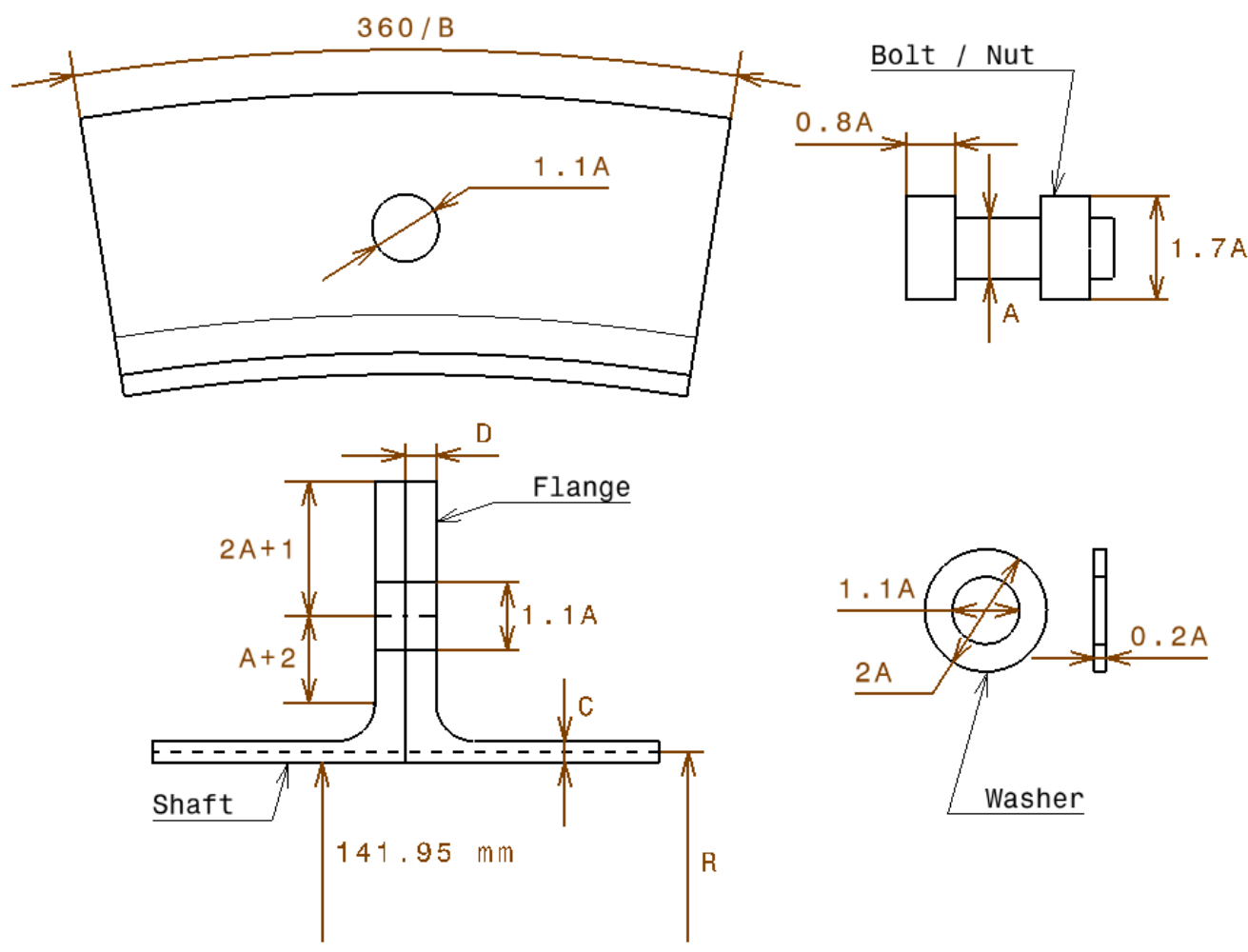

Figure 2.7: Relations between the geometrical input parameters 


\subsubsection{Finite element modeling}

In order to prepare the modeled geometry for the parametric finite element analyses, some preliminary works are done. Materials are assigned to the parts, the contacts between the parts are defined and the geometry is meshed. Both of the flange bodies are defined as aluminum alloy, which is readily available in the ANSYS material database. On the other hand, structural steel is assigned to the bolt-nut pair and the washers as in the industrial applications. Table 2.1 shows the assigned materials and the material properties and Figure 2.8 shows the visual representation of the materials assigned to the models. The friction coefficients of the contacts defined are taken depending on the material properties of the bodies in contact as explained in Table 2.2. Figure 2.9 shows the regions in the assembly where the contacts are defined.

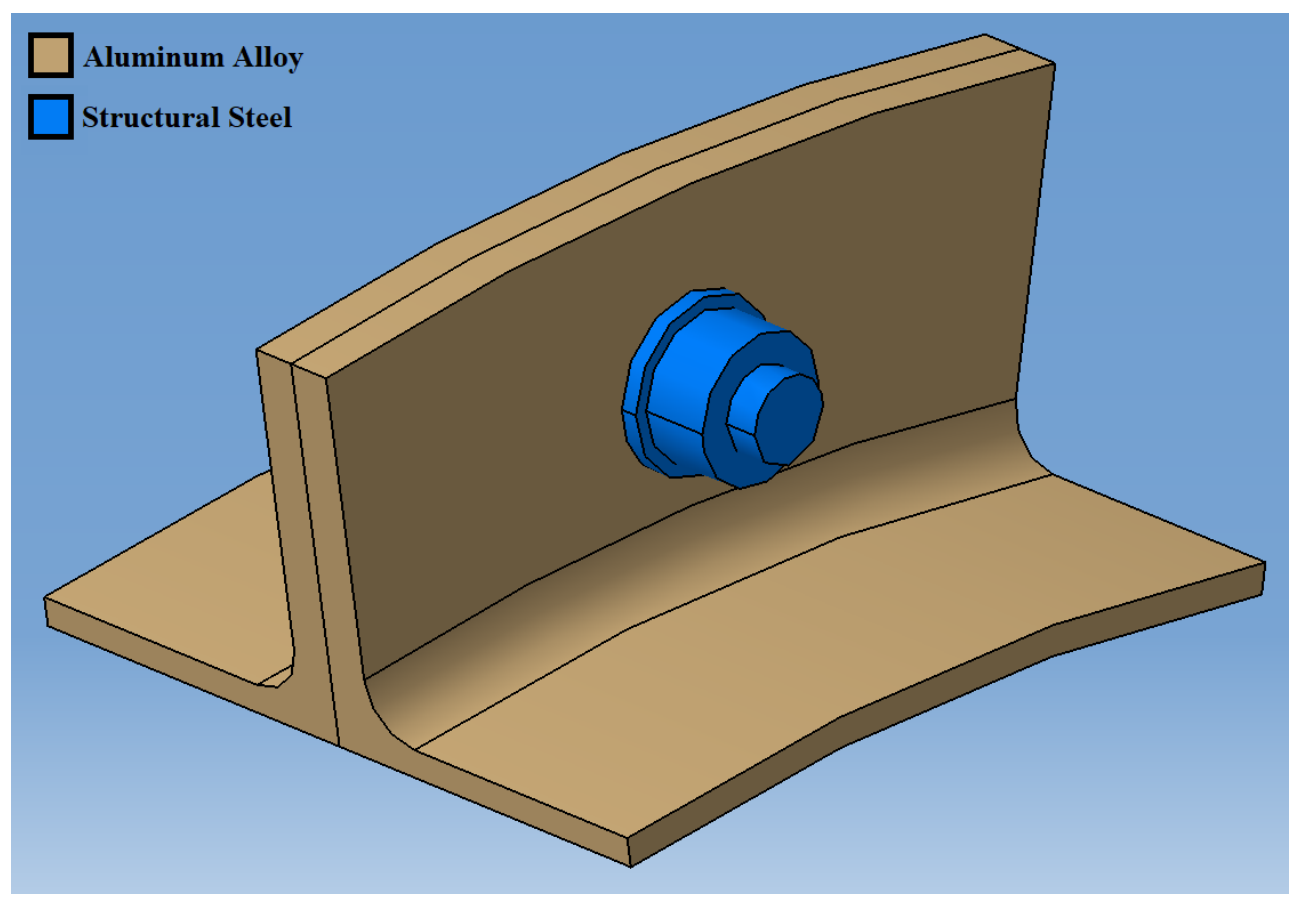

Figure 2.8: Materials assigned to the models

Table 2.1: Material properties

\begin{tabular}{|l|l|c|c|}
\hline Component & Material & E [GPa] & $\boldsymbol{v}$ \\
\hline flanges & Aluminum alloy & 72 & 0,3 \\
\hline bolt/nut/washer & Structural Steel & 204 & 0,3 \\
\hline
\end{tabular}


Table 2.2: Contact definitions between parts

\begin{tabular}{|l|c|c|}
\hline Parts in Contact & Contact Type & Static Friction Coeff. \\
\hline Flange - Flange & Frictional & 1.2 \\
\hline Flange - Washer & Frictional & 0.61 \\
\hline Bolt Head/Nut - Washer & Frictional & 0.74 \\
\hline Bolt Shank - Flange & Friction-less & N/A \\
\hline Bolt Shank - Washer & Friction-less & N/A \\
\hline
\end{tabular}

${ }^{1}$ For further information refer to reference [21]

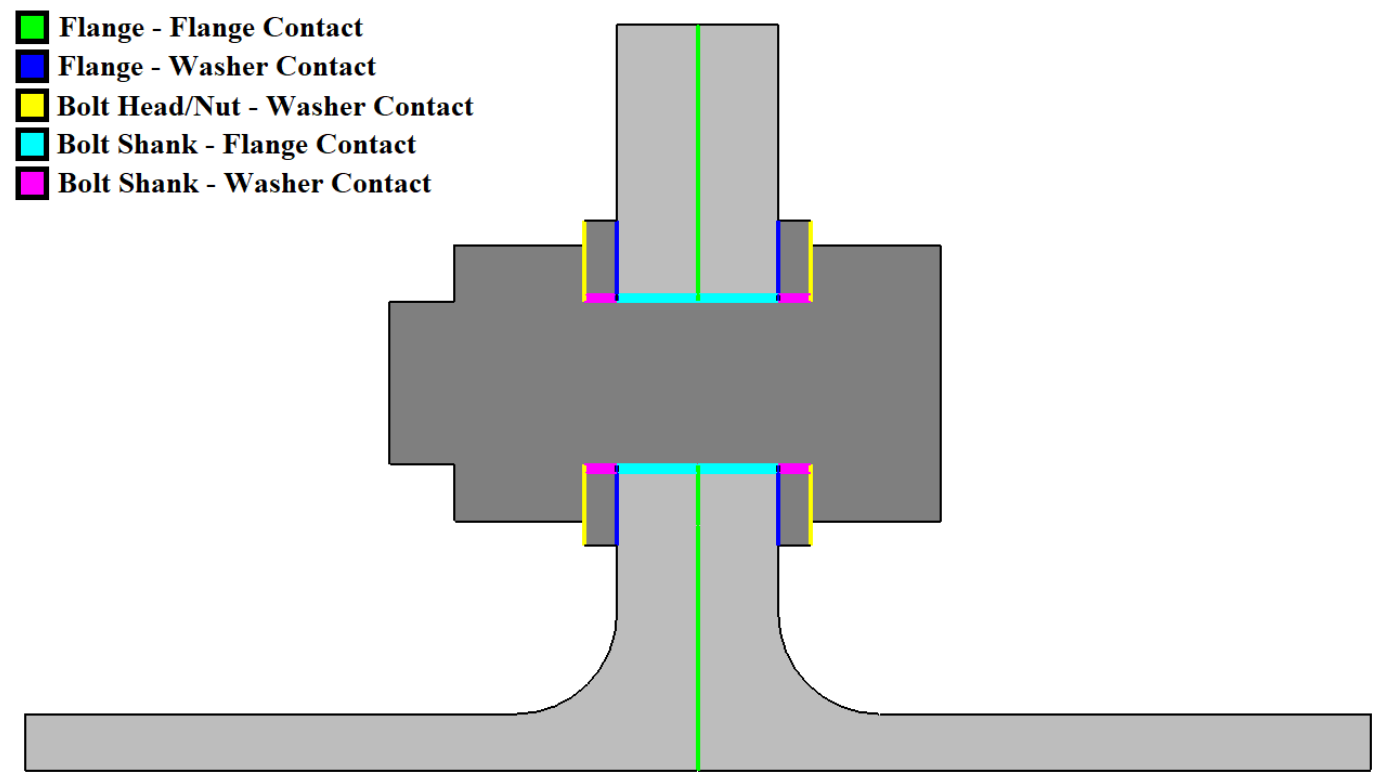

Figure 2.9: Contact regions

When the contacts between the parts are defined, the segment model of the bolted flange connection is meshed. The determination of the correct mesh size is a critical issue, as the mesh size is directly related to the computational effort that the finite element analysis need. The density of the mesh applied to the models has to be handled carefully, so that the parametrical analysis uses a reasonable amount of computational power without sacrificing the accuracy of the results. In order to determine the suitable mesh size, a comparison between five different mesh densities is conducted. Table 2.3 shows the different mesh sizes compared in order to determine the suitable mesh size. Five assembly models are created with mesh densities varying from coarse to very fine. The course meshed model consists of 
1354 elements having 3524 nodes, while very fine meshed assembly model consists of 28477 elements with 39072 nodes. Five cases are compared in terms of the elapsed time during the analysis, the bolt reaction force obtained from the center plane of the bolt geometry and the average equivalent von-Mises flange stress occurred on the contact surface of the flanges. The results gathered from the very fine meshed model are considered as the nomimal values and the rest is compared to them. In terms of the bolt reaction force, all the mesh densities are considered acceptable as the deviation from the nominal value stays within the acceptable limit of error for all the mesh densities, $0.08-0.54 \%$. On the other hand, it is observed that the deviation of the flange stress is around $1 \%$ for the medium-fine and fine mesh cases while the error is around $2 \%$ for the other two mesh sizes. Thus, the possible suitable mesh densities are narrowed down to three mesh sizes.

Table 2.3: Mesh size comparison

\begin{tabular}{|c|c|c|c|c|c|c|}
\hline $\begin{array}{c}\text { Mesh } \\
\text { Size }\end{array}$ & $\begin{array}{c}\text { Number } \\
\text { of } \\
\text { Elements }\end{array}$ & $\begin{array}{c}\text { Number } \\
\text { of } \\
\text { Nodes }\end{array}$ & $\begin{array}{c}\text { Element } \\
\text { Quality }\end{array}$ & $\begin{array}{c}\text { Elapsed } \\
\text { Time } \\
(\mathbf{s})\end{array}$ & $\begin{array}{c}\text { Bolt } \\
\text { Reaction } \\
\text { Force } \\
(\mathbf{N})\end{array}$ & $\begin{array}{c}\text { Average } \\
\text { Flange } \\
\text { Stress } \\
\text { (Mpa) }\end{array}$ \\
\hline Coarse & 1354 & 3524 & 0.747 & 44.00 & 5796.83 & 137.91 \\
\hline Medium & 1854 & 4397 & 0.827 & 46.00 & 5801.46 & 138.91 \\
\hline Medium-Fine & 4608 & 8346 & 0.882 & 127.00 & 5818.64 & 134.45 \\
\hline Fine & 18125 & 26215 & 0.940 & 307.00 & 5822.70 & 134.76 \\
\hline Very Fine & 28477 & 39072 & 0.952 & 491.00 & 5827.42 & 135.91 \\
\hline
\end{tabular}

In order to make the final decision, the computational times and mesh element qualities are compared for remaining three cases. It can be seen on the Table 2.3 that the element quality increases from 0.88 to 0.952 when the mesh density increases 
from medium-fine to very fine. Although the element quality of the fine meshed analysis model is higher than the medium-fine meshed model, and closer to the very fine meshed model, when the elapsed time is considered, it is concluded that duration of a single analysis is too much for fine and very fine meshed models, especially when it is considered that there will be many parametrical analysis in order to create a database for the artificial neural network training. Therefore, it is decided to use the medium-fine mesh size, in order to consume more reasonable amount of computational resources without sacrificing the accuracy of the results.

After deciding the suitable mesh density, hexahedral elements with 8 nodes are used. Multi-zone method is utilized for each part in order to obtain a high quality mesh structure. Mesh sizing restrictions are imposed in order to improve the mesh quality. For the bolt-nut pair, bolt head and the nut outer diameters are divided into 20 segments while the maximum element size is restricted as $0.004 \mathrm{~mm}$. Figure 2.10 shows the meshed bolt-nut geometry with the implemented edge sizing.

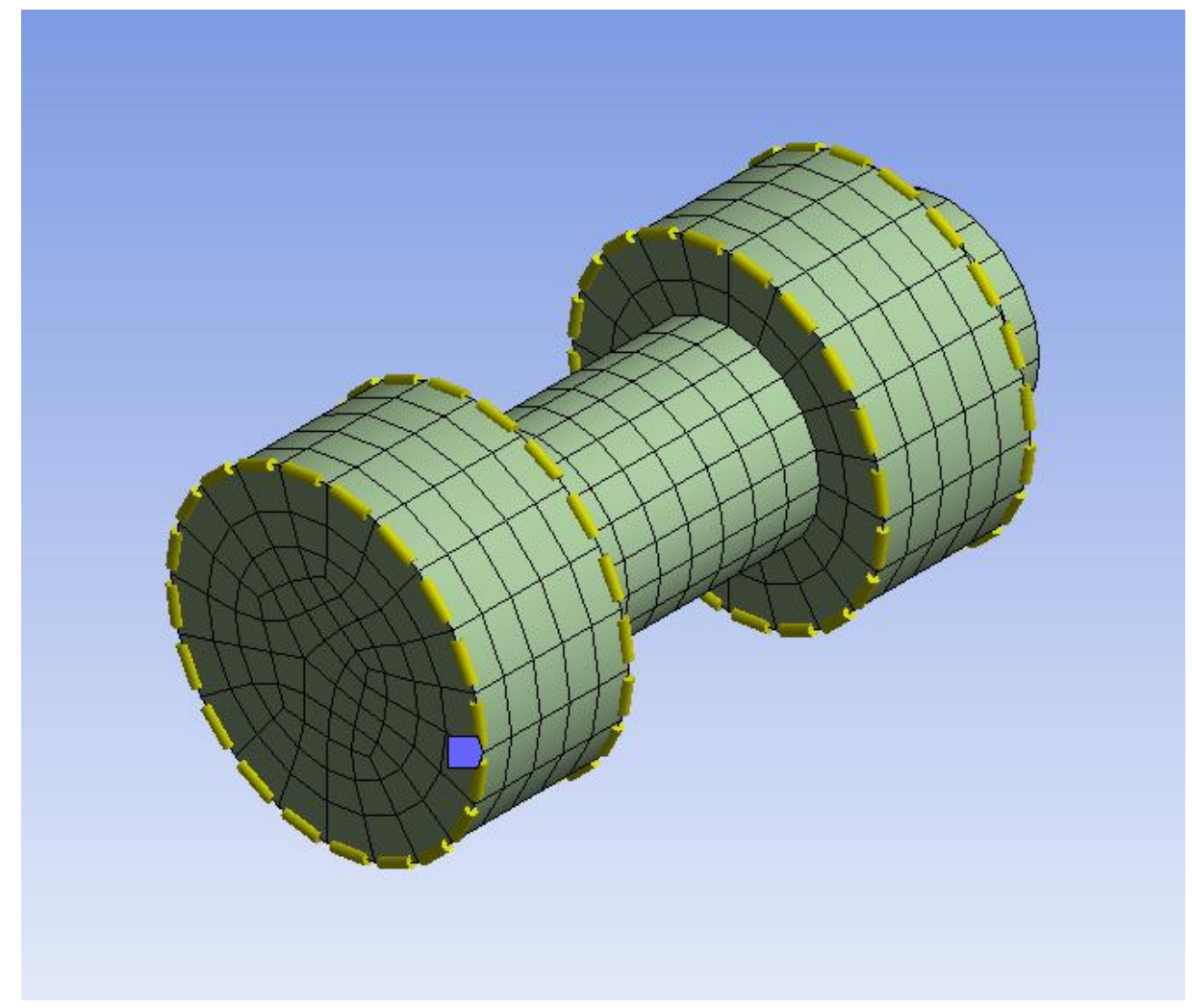

Figure 2.10: The meshed bolt-nut geometry with the edge sizing 
Edges of the holes on the flanges are divided into 24 segments. Sides of the contact surfaces of the flanges, axial cross-sectional surfaces of both shafts and the remaining radial edges of the flange geometries are restricted with a maximum element size of $0.0018 \mathrm{~mm}$. Figure 2.11 illustrates the implemented edge sizing and multi-zone method on the flange geometry along with the mesh structure. Red surfaces on the flange geometry indicates the source surfaces for the multi-zone method applied on the flanges.

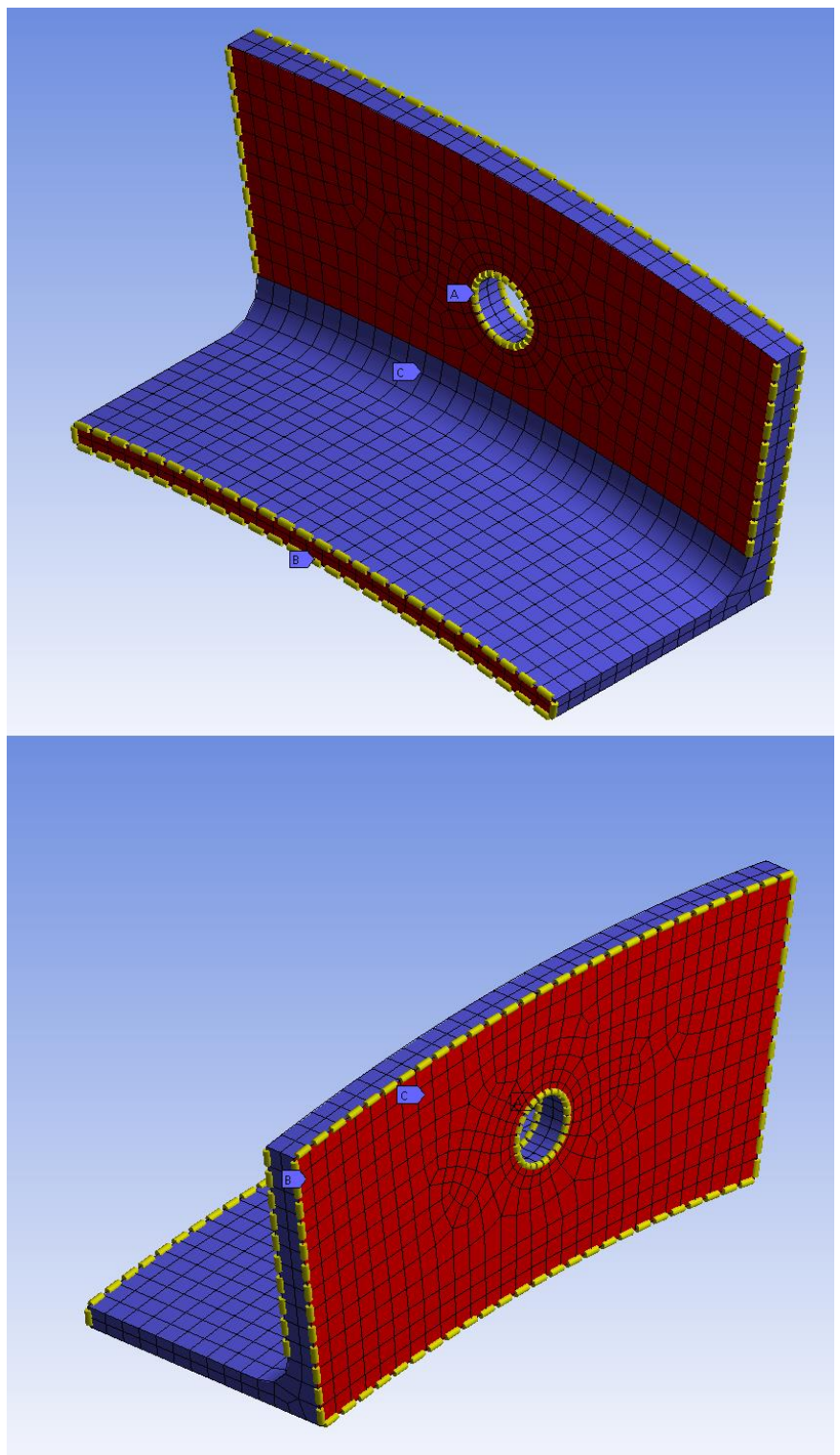

Figure 2.11: The meshed flange geometry with edge sizing and multi-zone method implied 
Finally, the inner and outer edges of the washers are divided into 24 elements. Figure 2.12 represents the meshed washer geometry with the edge sizing composed of 24 elements.

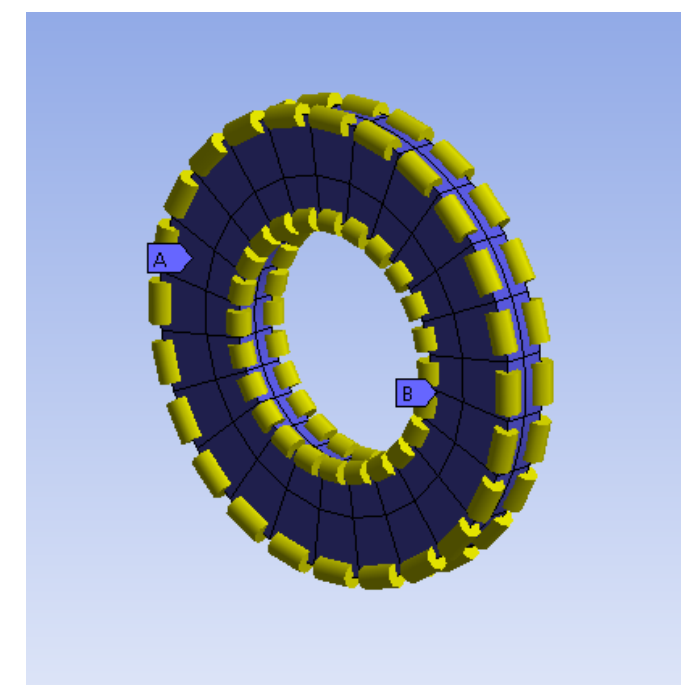

Figure 2.12: The meshed washer geometry with implemented edge sizing

All parts except the washers are meshed without the mid-side nodes. Mid-side nodes on the washers are used because of the convergence problem occurred during the analysis stage. With all the limitations and the sizing applied, finite element model of the segment model of the bolted flange connection is composed of total number of 4608 elements and 8346 nodes. Figure 2.13 shows the analysis model with the medium-fine mesh. 


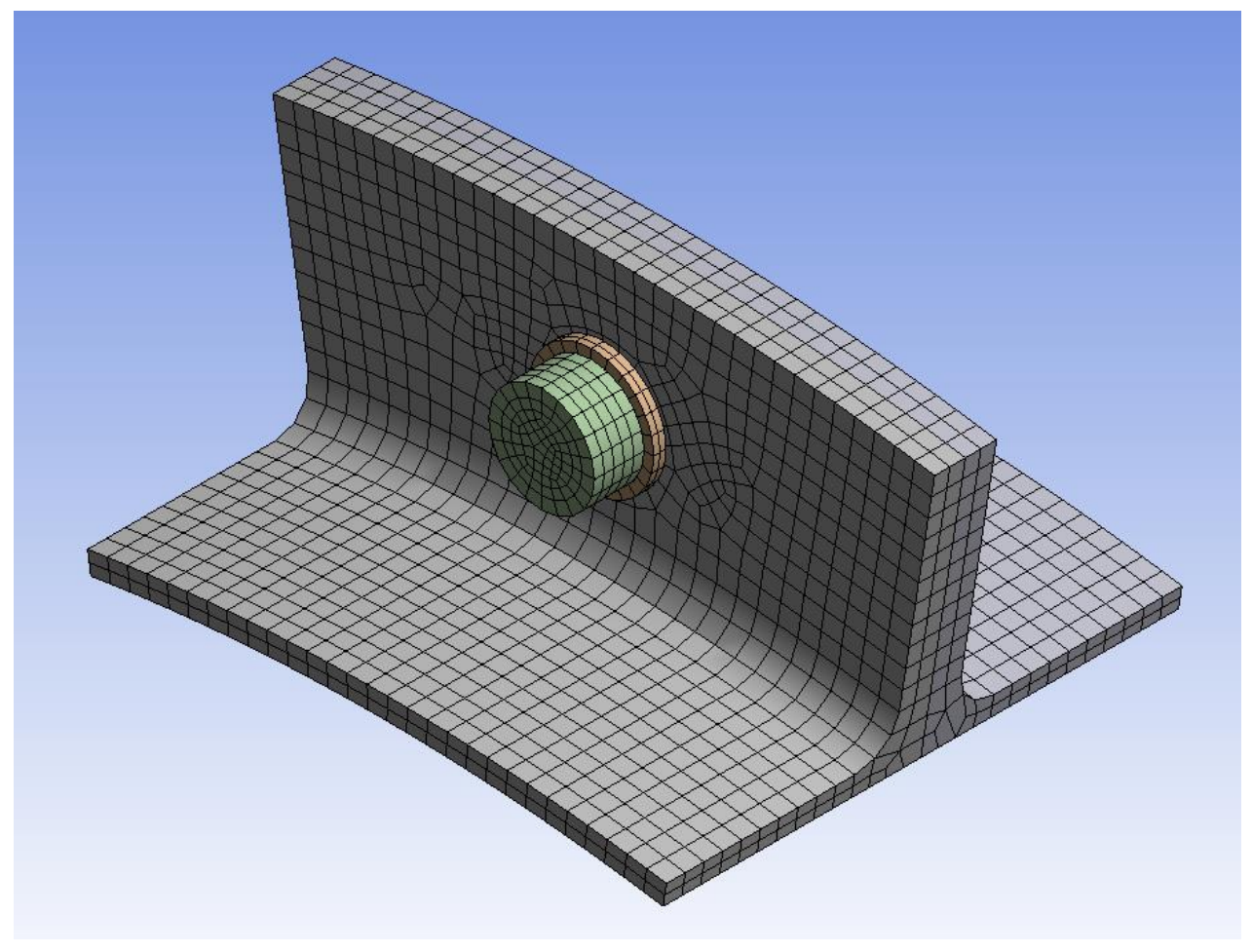

Figure 2.13: Partial model with the medium-fine mesh

\subsubsection{Loads and boundary conditions}

Although it was decided to use a segment model for the parametric analysis for the simplification and computational time reasons, the representation of the full model characteristics with the partial geometry is still a critical issue. The previous study $[13,18]$ conducted on the effect of different boundary conditions showed that it possible to reproduce the conditions of the full model with the segment geometry of the bolted flange connection modeled with appropriate boundary conditions. As a result of that study, the axial cross-sectional surface (A) of one of the shafts is fixed in all degrees of freedom, while the cross-sectional surface (C) of the opposing shaft is set to move freely in only one degree of freedom, which is the axial direction $\mathrm{z}$ shown in Figure 2.15. Furthermore, tangential cross-sectional surfaces (B) of both flange geometries are set free in all degrees of freedom except the tangential direction, which is kept fixed. Figure 2.14 represents the boundary conditions implied on the partial geometry, and the Figure 2.15 shows the application zones of the boundary conditions on the 3-D model. 


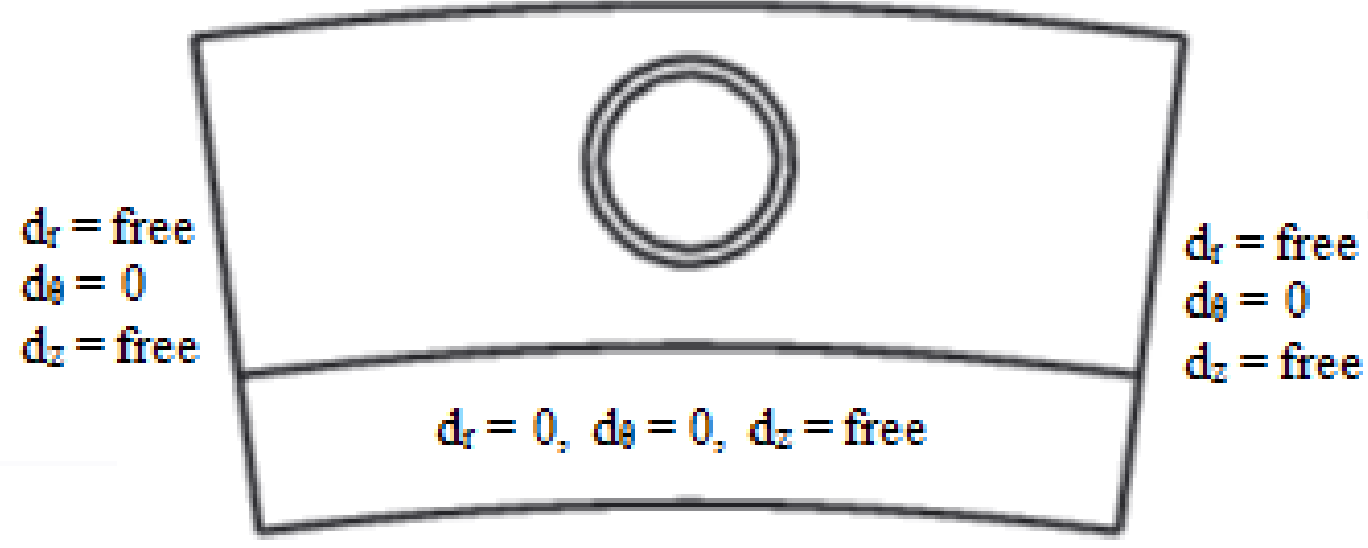

Figure 2.14: Boundary conditions of the segment model

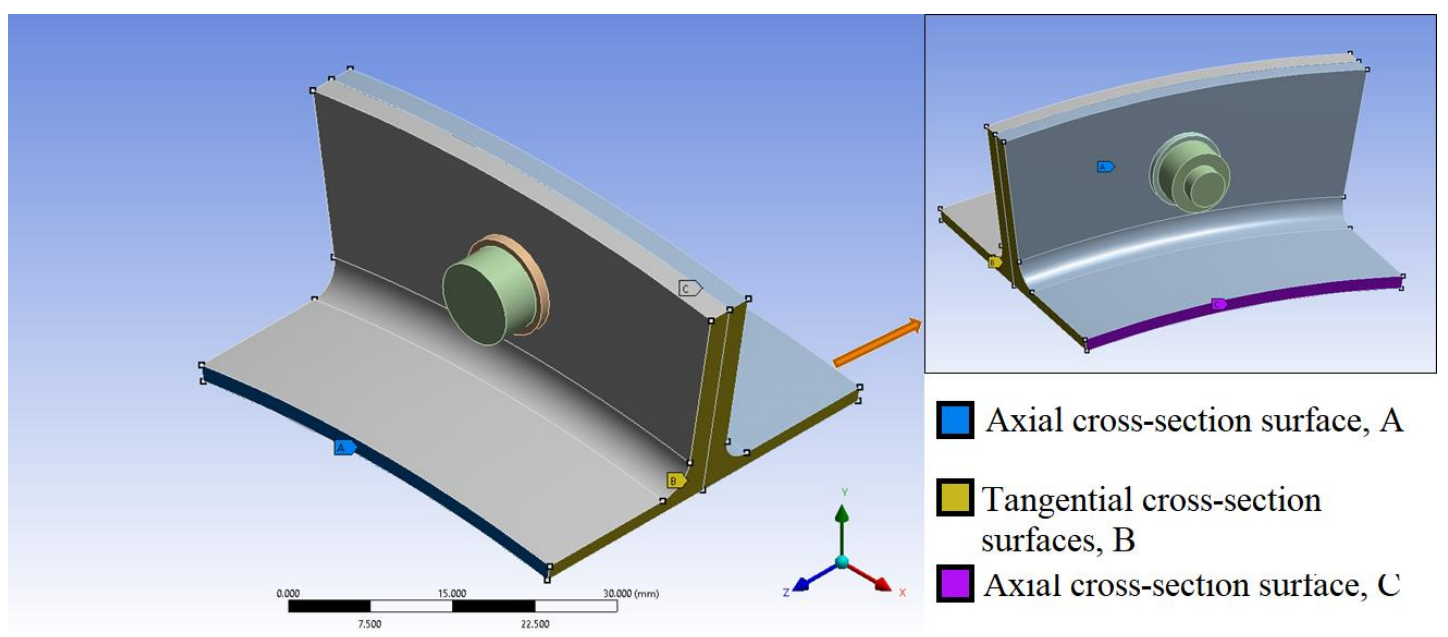

Figure 2.15: Application surfaces of the boundary conditions

In Table 2.4, the sample load set used in the thesis study is shown. This sample load set is acquired from the loads acting on a typical aircraft engine of a similar size. In the beginning of the study, torsional moment is excluded since the magnitude of the torque is very low compared to the bending moment, and the study began with the axial and shear forces and the combined bending moment. In addition to the external loads acting on the structure, for each bolt size, a proper preload is applied to the bolts in accordance with the aircraft industry. 
Table 2.4: Sample load set acting upon the whole assembly of bolted flange connection $^{1}$

\begin{tabular}{|l|c|c|c|c|c|c|}
\hline & $\begin{array}{c}\text { Fx } \\
(\mathbf{N})\end{array}$ & $\begin{array}{c}\text { Fy } \\
(\mathbf{N})\end{array}$ & $\begin{array}{c}\text { Fz } \\
(\mathbf{N})\end{array}$ & $\begin{array}{c}\text { Mx } \\
(\mathbf{N} . m m)\end{array}$ & $\begin{array}{c}\text { My } \\
(\mathbf{N} . m m)\end{array}$ & $\begin{array}{c}\text { Mz } \\
(\mathbf{N} . m m)\end{array}$ \\
\cline { 2 - 7 } & $\begin{array}{c}\text { Shear } \\
\text { Load }\end{array}$ & $\begin{array}{c}\text { Shear } \\
\text { Load }\end{array}$ & $\begin{array}{c}\text { Axial } \\
\text { Load }\end{array}$ & $\begin{array}{c}\text { Bending } \\
\text { Moment }\end{array}$ & $\begin{array}{c}\text { Bending } \\
\text { Moment }\end{array}$ & Torque \\
\hline Max. & 1934.52 & 366.947 & 463.751 & 215599 & 868455.5 & 1809.91 \\
\hline Min & -1524.82 & -302.678 & -349.759 & -180241 & -1105355 & -1798 \\
\hline
\end{tabular}

${ }^{1}$ For the $\mathrm{x}-\mathrm{y}-\mathrm{z}$ directions refer to

Figure 2.2

Further into the study, some additional pre-investigations are conducted about the loading conditions before initializing the parametric analyses. First, the investigation is done about the application of bending moment to the full model, and then it is adapted to the segment model. Moreover, the application of the shear force is examined in order to decide where to apply the shear force on the geometry for more realistic analysis, and, the effect of the shear force on the bolt reaction and the flange stress is inspected, and then the final load sets and conditions for the parametric analyses are determined.

\subsection{The Application of Bending Moment}

Alongside the implemented boundary conditions, which resolves the geometrical side of the problem by correctly representing the behavior of the full model, transfer of the loads from the full assembly to the segment model also has to be appropriate for the sake of having a precise and reliable analysis and design tool. In order to accomplish the purpose of accurate load transfer, comparison of the responses of the full model and the segment model has to be made.

Initially, a study is done about the implementation of the bending moment. The effect of bending moment on the segment model, to which the moment is transferred as an axial force as shown in Figure 2.20, is compared to the effect of the moment on the full assembly. First, a full assembly model of the bolted flange connection with 30 bolt-nut pairs is created, along with a segment model of the bolted flange connection. 
Metric bolt with a diameter of $5 \mathrm{~mm}$ is used in the assembly. Flange and shaft thicknesses are modeled as $3 \mathrm{~mm}$ and $2.1 \mathrm{~mm}$, respectively. The full model and the segment model are shown in Figure 2.16 and Figure 2.17. On top of modeling of the geometry, all the contact definitions are defined as described in the previous section, and all the bolts are initially loaded with a pretension load with a magnitude of 5000 $\mathrm{N}$. As a boundary condition of the full model, axial cross-section surface of one of the shafts is fixed in all degrees of freedom, while the mirror surface of the other shaft is kept free for the moment application as can be seen in Figure 2.18.

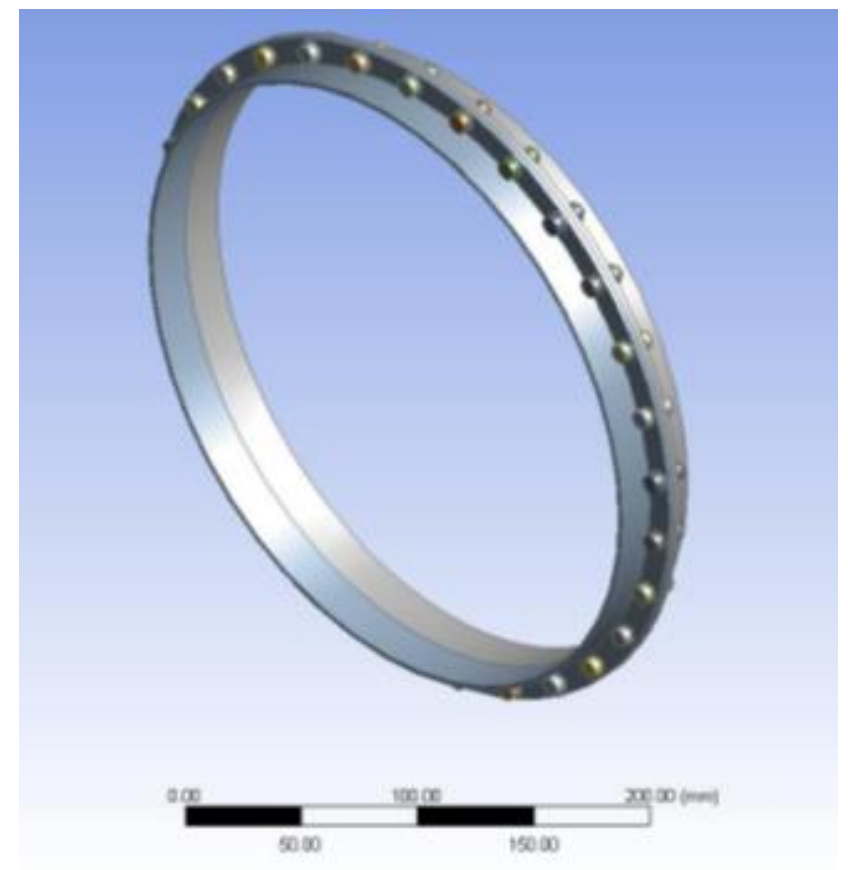

Figure 2.16: Full model with 30 bolt/nut pairs 


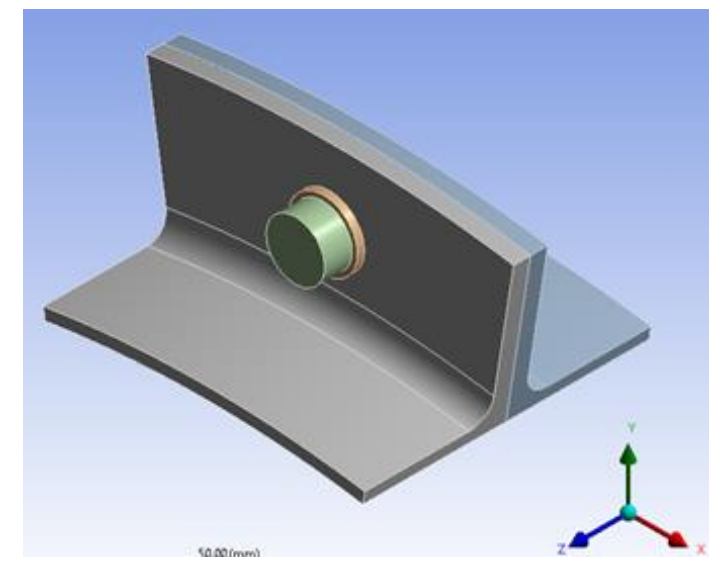

Figure 2.17: The segment model

The resultant of the bending moments given in Table 2.4 is applied to the model, such that the maximum tensile load due to the bending moment coincides with a bolt creating a worst-case scenario. For the full assembly model, the bending moment is applied to the cross-section surface through a neutral clamped point (NPC). This neutral clamped point is defined at the center of the shaft on that cross-section plane, connected to the surface. The load application and the boundary conditions are shown in Figure 2.18 and Figure 2.19.

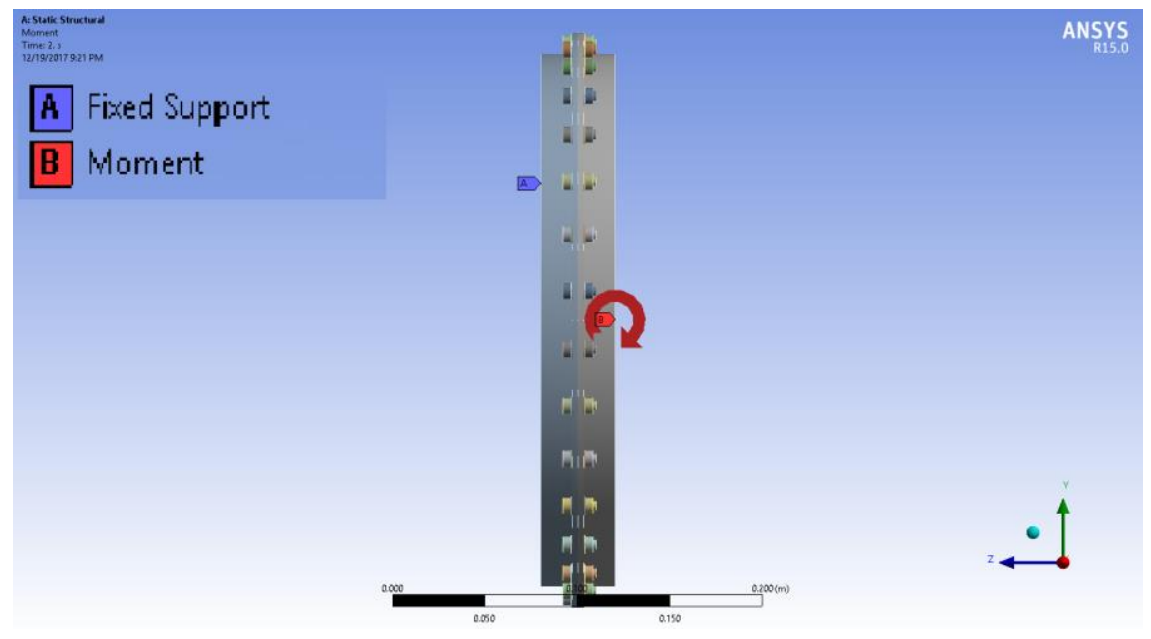

Figure 2.18: The load and boundary conditions on the full model 


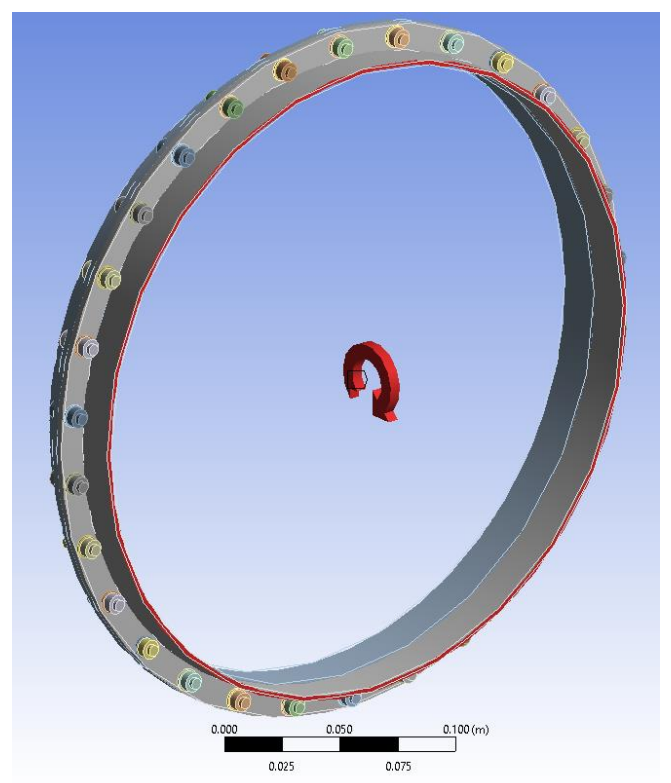

Figure 2.19: The load application zone and NPC

In order to conduct the analysis on the segment model, the bolt-nut pair in the segment model is assumed to carry the maximum tensile load resulting from the bending moment. The bending moment is converted to an axial force through the approximate relation Equation 2.1 (See Appendix A), and the application of the axial load is shown in Figure 2.20.

$$
F_{M}=\frac{2 M}{B R}
$$

In Equation 2.1, M stands for the resultant bending moment, while B corresponds to the total number of bolt in a full assembly model as stated in Table 3.1 and $\mathrm{R}$ is the average shaft radius as shown in Figure 2.7. 


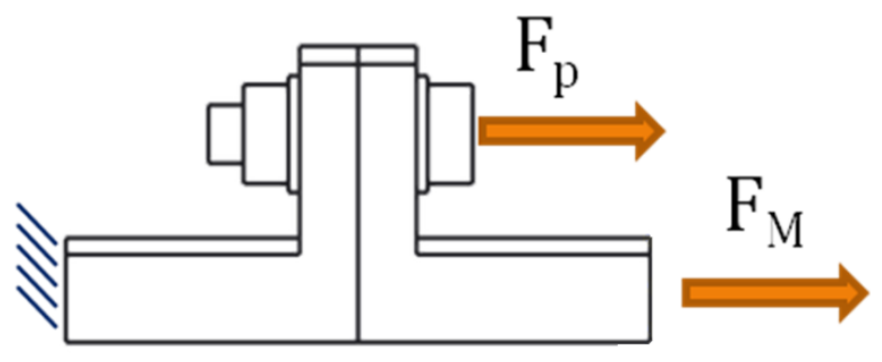

Figure 2.20: The load and boundary conditions of the segment model

Three distinct load cases are investigated, and then the average normal bolt stresses gathered from the center cross-sectional plane of the bolts, are compared for both full model and partial model analyses. Firstly, only the preload case, without any bending moment, is studied. With this case, it is aimed to create a base for the other cases and to check the boundary condition assumptions. Figure 2.21 shows the normal stress distributions in the center plane of the bolts for both full model and the segment model analyses.

Stress distribution of the segment model is shown in the Figure 2.21a, while the normal stress distribution on the bolt subjected to the maximum tensile load in the full model is represented in Figure 2.21b. Tabulated stress results along with the analytically calculated bolt stress under given loads are presented Table 2.5. As can be seen from the results, for both full model and the segment model, the average normal stresses on bolts are compatible with each other as well as the analytically calculated normal stress. Thus, the boundary conditions applied to the segment model are proven to represent the behavior of full assembly model successfully.

Analytical normal bolt stress is calculated using a code (See Appendix F) based on ESDU 85021 source [4]. 


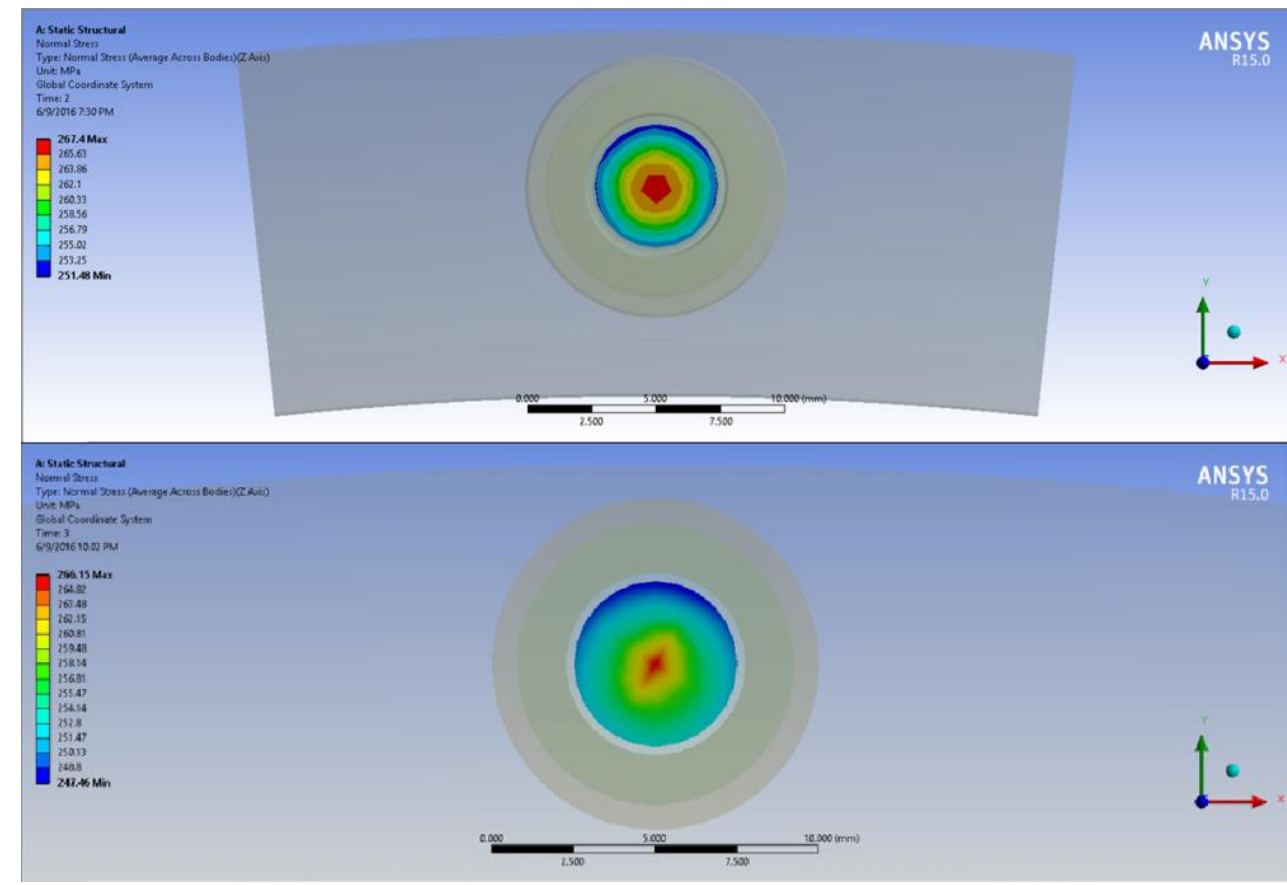

Figure 2.21: (a) Normal stress distribution of the segment model for the preload application without any bending moment (upper figure), (b) normal stress distribution of the full model at the same case (lower figure)

Table 2.5: Average normal stresses for preload case only

\begin{tabular}{|c|c|c|c|}
\hline & Unit & Full Model & Segment Model \\
\hline Preload & $N$ & \multicolumn{2}{|c|}{5000} \\
\hline Bending Moment & $N m m$ & 0 & - \\
\hline Axial Force due to Moment $^{\mathbf{1}}$ & $N$ & - & 0 \\
\hline Average Normal Stress & $M P a$ & 254.63 & 258.88 \\
\hline ESDU Analytical Bolt Stress $^{2}$ & $M P a$ & \multicolumn{2}{|c|}{254.65} \\
\hline
\end{tabular}

${ }^{1}$ Calculated with Equation 2.1

${ }^{2}$ See Appendix F

After the confirmation of the boundary conditions for the preload case, combined preload and bending moment load case is investigated. For the full and the partial model, the average bolt axial stresses resulting from the application of the combined load are compared. Figure 2.22 shows the axial stress distributions on the bolt for both full model and segment model. In Figure 2.22a, bolt stress distribution in the partial model is presented, while the stress distribution obtained from the full model 
analysis is shown in Figure 2.22b. The average normal bolt stresses of both models are collected in Table 2.6 alongside the analytical normal bolt stress for the given load case.

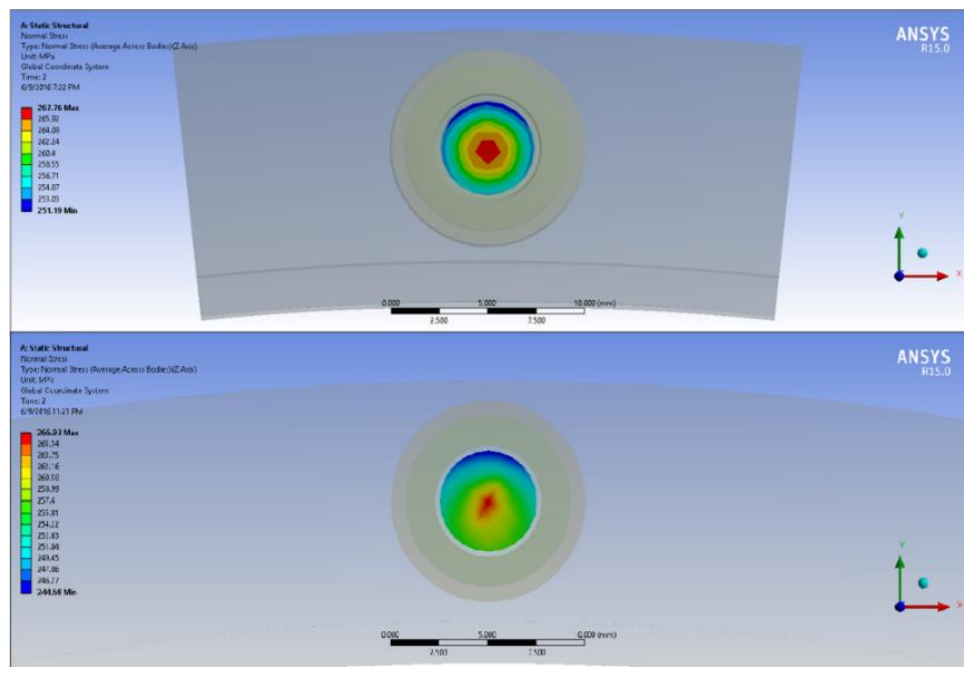

Figure 2.22: (a) Normal stress distribution of the segment model for the combined preload and bending moment load case (upper figure), (b) normal stress distribution of the full model for the same case (lower figure)

Table 2.6: Average normal stresses for the combined preload and bending moment load case

\begin{tabular}{|c|c|c|c|}
\hline & Unit & Full Model & Segment Model \\
\hline Preload & $N$ & \multicolumn{2}{|c|}{5000} \\
\hline Bending Moment & $N m m$ & 1126184.8 & - \\
\hline Axial Force due to Moment $^{\mathbf{1}}$ & $N$ & - & 525.03 \\
\hline Average Normal Stress & $M P a$ & 255.44 & 259.26 \\
\hline ESDU Analytical Bolt Stress $^{\mathbf{2}}$ & $M P a$ & \multicolumn{2}{|c|}{258.12} \\
\hline
\end{tabular}

${ }^{1}$ Calculated with Equation 2.1

${ }^{2}$ See Appendix F

As the obtained results suggest, it can be concluded that the conversion of the bending moment to an axial force is successfully achieved, considering the normal average bolt stresses for both finite element models show good agreement. However, as the results given in Tables 2.5 and 2.6 show, the effect of the bending moment on the bolt stress is relatively low, as the bending moment and the resultant axial force 
due to the bending moment are low in magnitude compared to the dominant pretension load on the bolt. Moreover, it can also be seen that, although it is relatively close, the theoretically calculated normal bolt stress is slightly diverged from the finite element result. Due to the conservative nature of the theoretical calculation, the estimated analytical stress appears to be over-safe, as expected.

Last of all, in order to confirm the findings of the second case study, in the third case study,bending momentis multiplied by 10 and finite element analysis of the full and the segment models are performed. In this study, it is aimed to show the agreement between two finite element models without the dominance of pretension load. The normal stress distributions on the center cross-section surfaces of the bolts for both models are shown in Figure 23. Figure 2.23a gives the axial stress distribution in the bolt for the segment model, and Figure 2.23b gives the axial stress distribution for the full assembly model.

The average normal stresses gathered from both models are tabulated in Table 2.7. Tabulated results confirms the agreement on the average normal bolt stresses for both finite element models, thus, proves that the assumption about the adaptation of the bending moment from the full model to the partial model is effective, as assumed. As a result of this investigation about the application of bending moment to the partial bolted flange connection model, the bending moment load input parameter set is created to be used in the parametric analyses. 


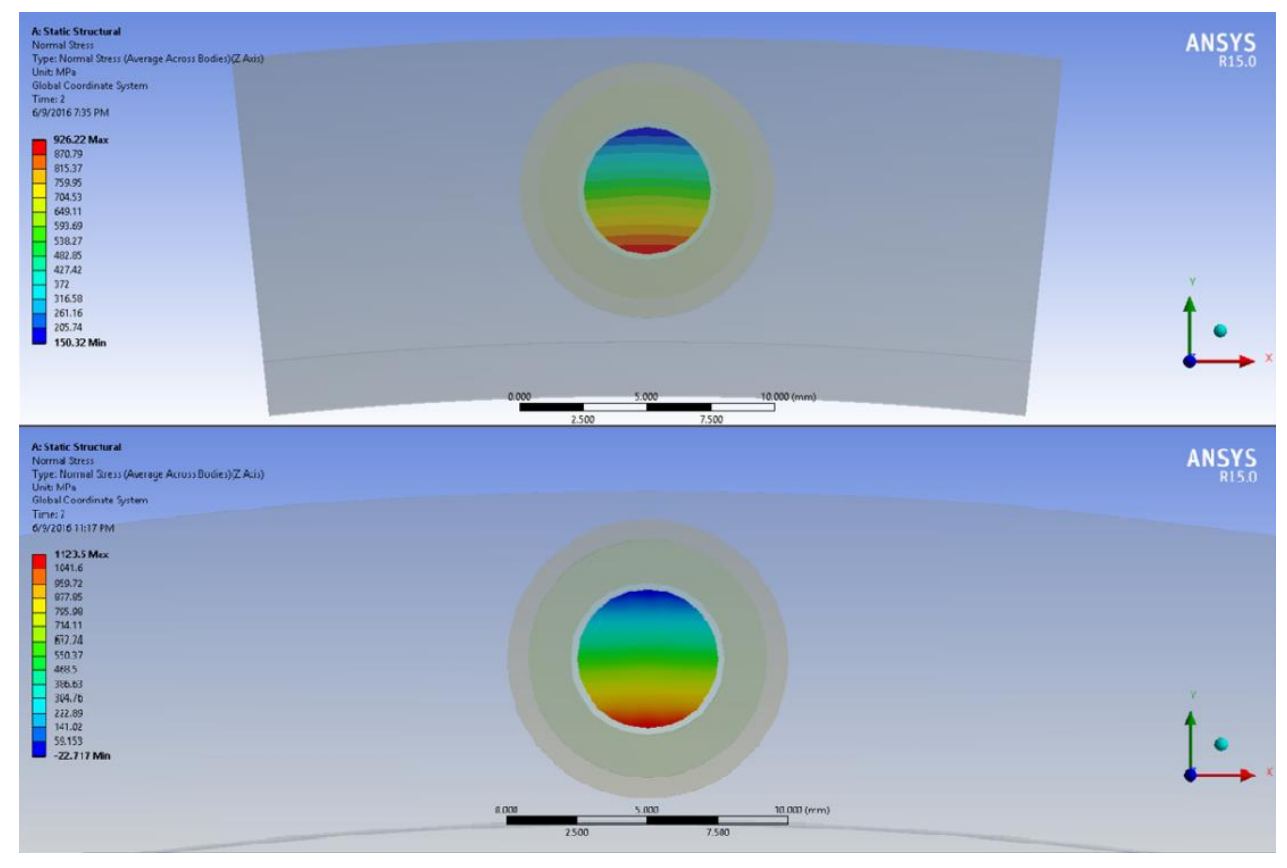

Figure 2.23: (a) Normal stress distribution in the bolt of the segment model for the combined load case with bolt pretension and bending moment (upper figure), (b) normal stress distribution of the full model for the same case (lower figure);

Resultant bending moment is multiplied by 10

Table 2.7: Average normal stresses for the combined preload bending moment load case with bending moment 10 times magnified

\begin{tabular}{|c|c|c|c|}
\hline & Unit & Full Model & Segment Model \\
\hline Preload & $N$ & \multicolumn{2}{|c|}{5000} \\
\hline Bending Moment & $N m m$ & 11261848 & - \\
\hline Axial Force due to Moment $^{\mathbf{1}}$ & $N$ & - & 5250.3 \\
\hline Average Normal Stress & $M P a$ & 559.54 & 547.79 \\
\hline ESDU Analytical Bolt Stress $^{2}$ & $M P a$ & \multicolumn{2}{|c|}{533.58} \\
\hline
\end{tabular}

${ }^{1}$ Calculated with Equation 2.1

${ }^{2}$ See Appendix F

\subsection{Application of the Shear Force}

After the successful adaptation of the bending moment to the partial model, further study is conducted on the shear force application. Before deciding on the terms of the application of the shear force on the segment model, an investigation is done about the location of the shear force application on the full model. In order to convey this 
study, a simplified cylindrical bolted flange connection model is created in Figure 2.24 .

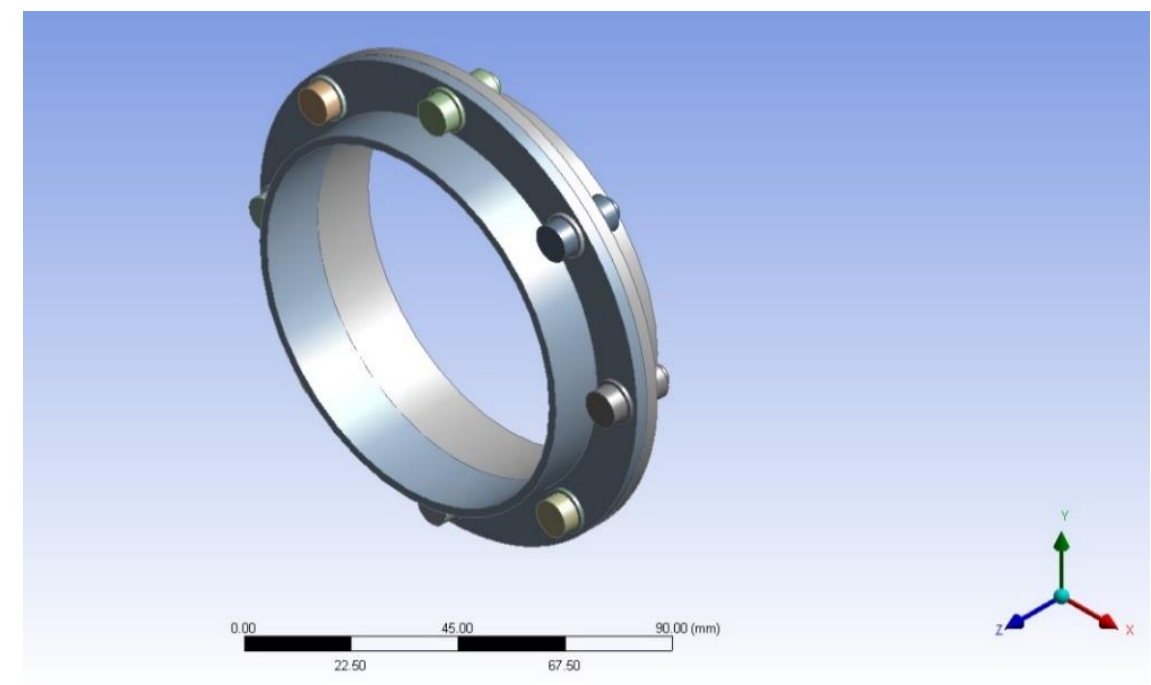

Figure 2.24: A simplified bolted flange connection model used in the case study

The simplified model used in this case study is constructed with 8 bolt-nut pairs and with an inner flange radius of $41.95 \mathrm{~mm}$. All the materials and the contact definitions between the parts are defined as explained in the previous sections, and the meshing of the structure is done accordingly. Metric bolts of $5 \mathrm{~mm}$ in diameter are used. The pretension force of $5000 \mathrm{~N}$ in magnitude is loaded on the bolt geometries. As in the previous studies, axial cross-sectional surface of one of the shafts is fixed in all the directions, while the opposite shaft/flange geometry is used for the shear load application. Figure 2.25 shows the boundary condition and load application example used in the study. 


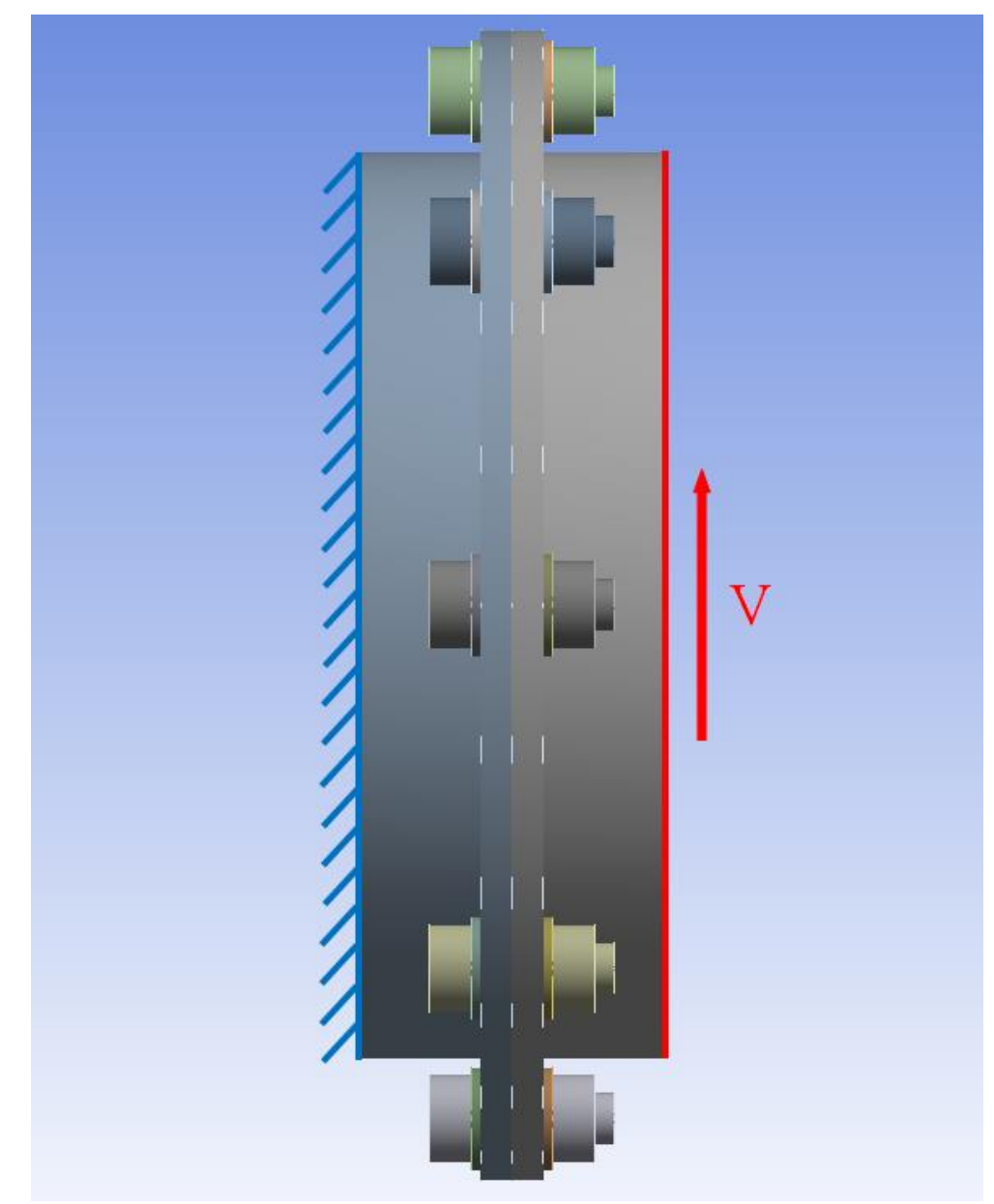

Figure 2.25: The boundary condition and the load application used for the first case in the study

Four different load cases are selected for the case study. For the first case, the shear load is applied to the axial cross-sectional surface of the free shaft. For another case, the load is applied on the same region, but an additional displacement boundary condition is defined on the same surface. The cross-section surface is fixed on the axial direction, letting the surface to move only in-plane directions. For the other two cases, the shear force is loaded on the inner surface of the shaft geometry and the outer surface of the flange geometry. The load cases are summarized in Table 2.8. In order to be able to see the effect of the application zone of the shear force clearly, an amplified shear force of $8000 \mathrm{~N}$ is loaded on the structure in y direction, for each case. The application regions on the bolted flange connection geometry are shown in green in Figure 2.26. 
Table 2.8: Shear application study load cases

\begin{tabular}{|c|l|}
\hline Load Case & \multicolumn{1}{c|}{ Definition } \\
\hline 1 & Load applied to the axial cross-section surface \\
\hline 2 & $\begin{array}{l}\text { Load applied to the axial cross-section surface with } \\
\text { displacement boundary condition }\end{array}$ \\
\hline 3 & Load applied to the inner surface of the shaft \\
\hline 4 & Load applied to the outer surface of the flange \\
\hline
\end{tabular}

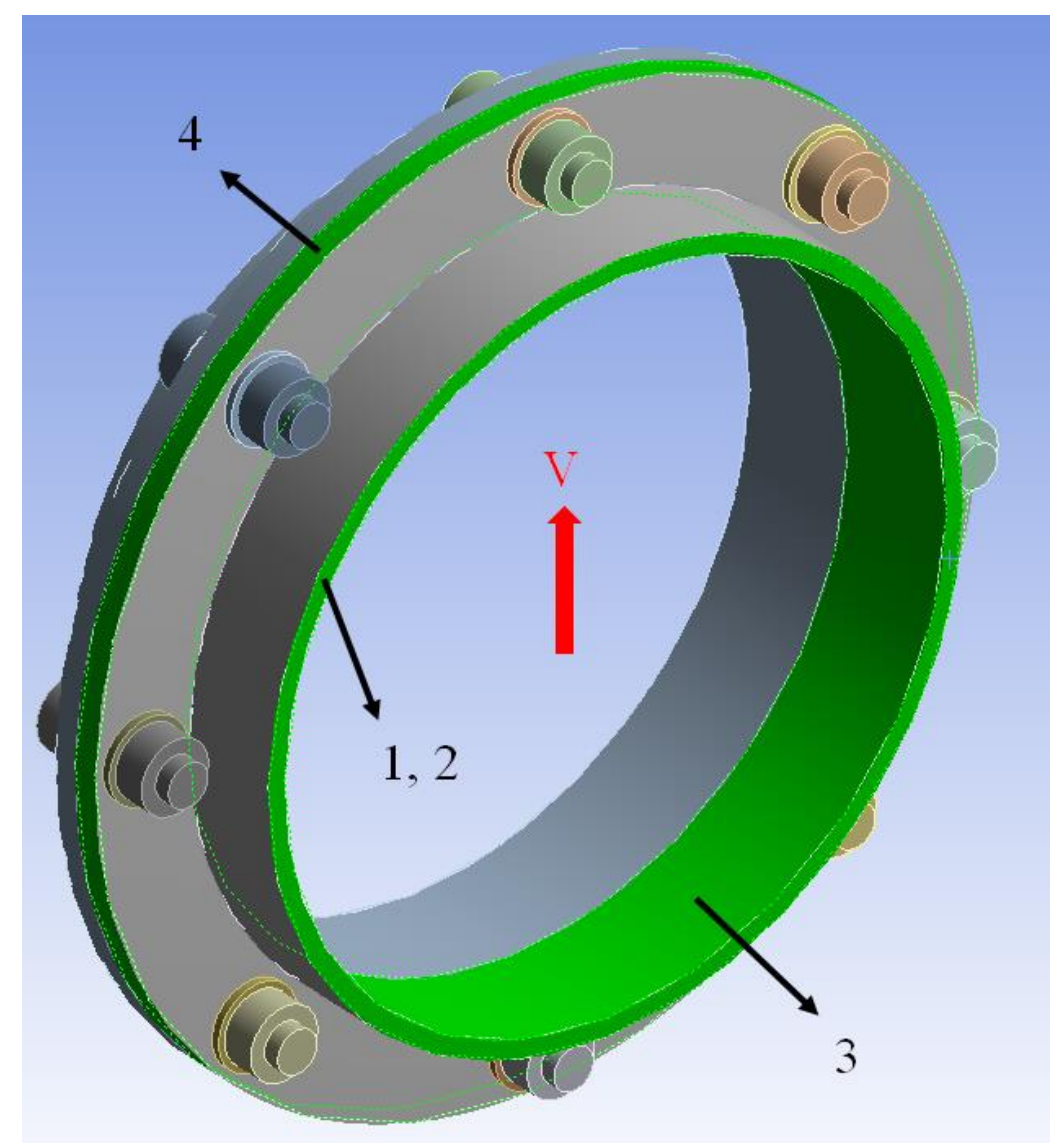

Figure 2.26: The load application regions and load direction used in the case study

For all cases, a path on the contact surface of the flanges is defined, and on this path flange and bolt stresses are gathered. A semi-circular path concentric with the shaft is created, such that, it starts from the center of the top bolt, passes through consecutive bolt centers and ends at the center of the bottom bolt. A semi circular path is used due to the symmetry of the shear stress with respect to the application direction, which is y-axis. Figure 2.27 shows the path defined for each load case. 


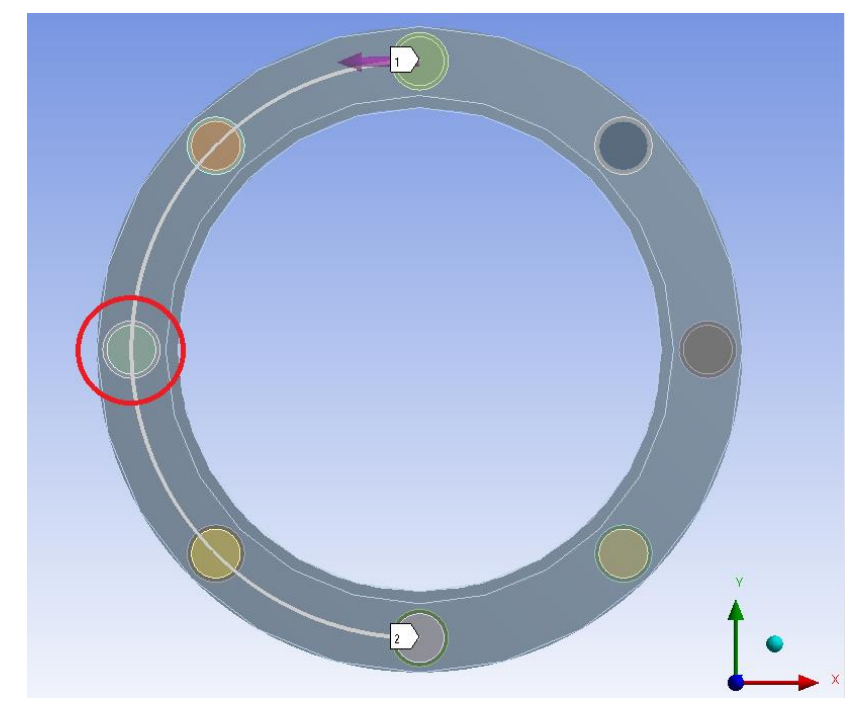

Figure 2.27: The defined shear stress path and the bolt under maximum shear load

After the analyses are done for the four different loading cases, the results are gathered to form a graph of a shear stress distribution along the path. Figure 2.28 gives the comparison of the shear stresses along the path for each load case. For a better comparison, Figure 2.29 shows the shear stress distributions concentrated around the third bolt on the path, where the effect of the shear force is maximum.

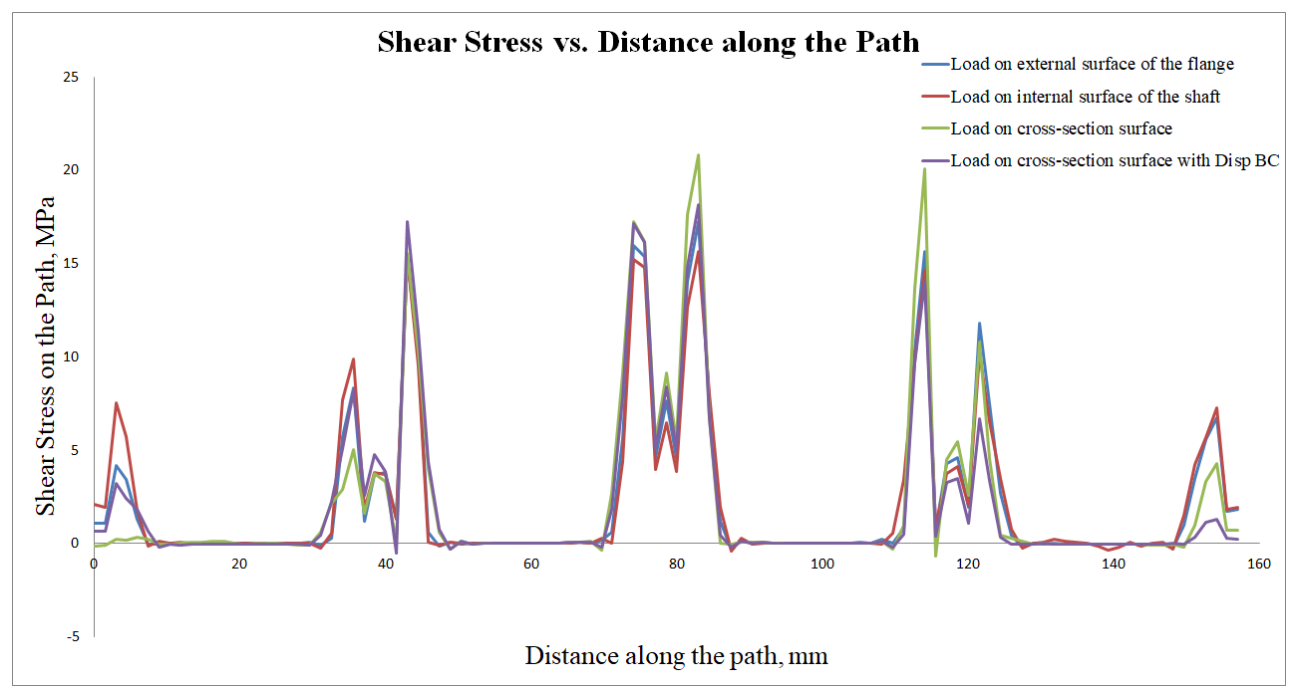

Figure 2.28: The comparison of the shear stresses along the path for each load case 


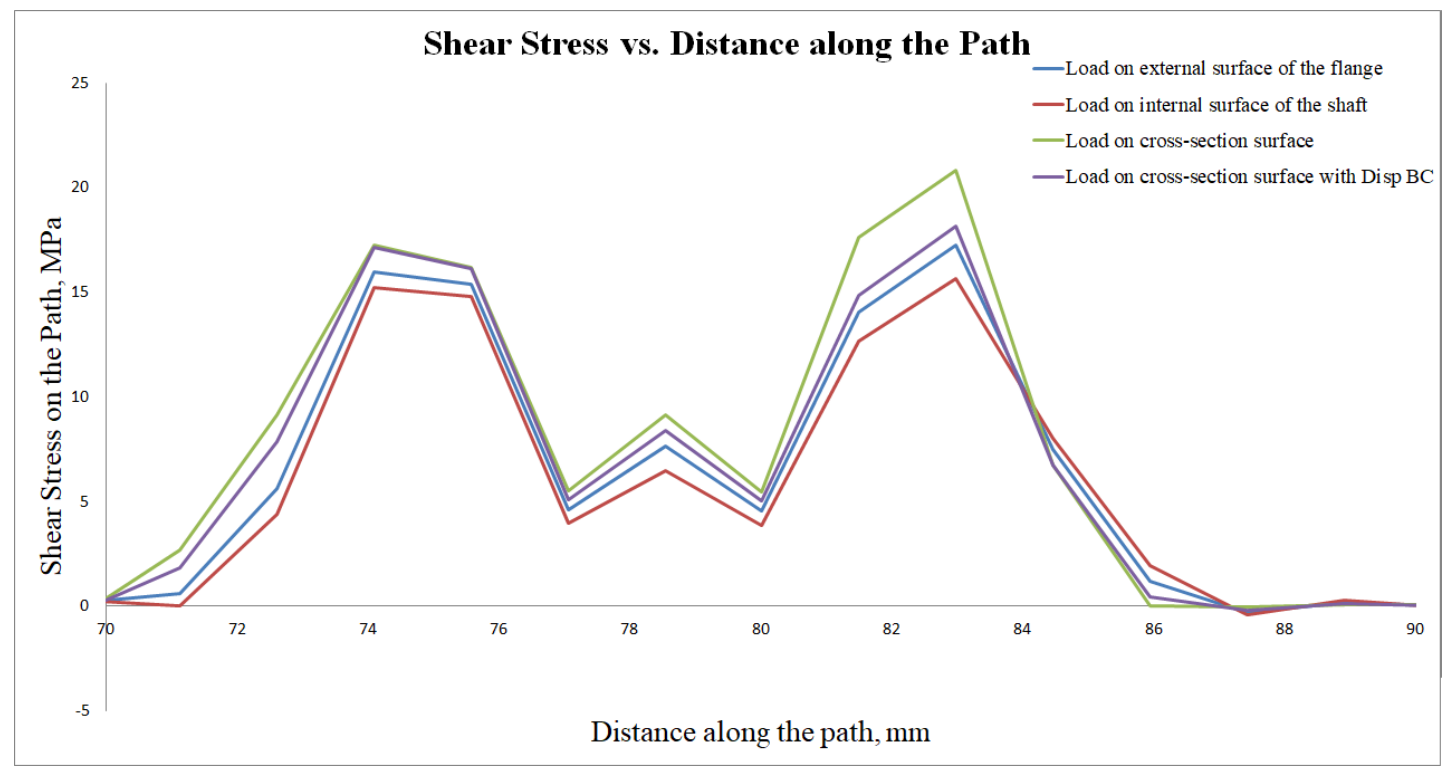

Figure 2.29: The comparison of the shear stresses around the 3rd bolt on the midpath

As a result the study on the comparison of different loading conditions on the full bolted flange connection geometry, it is concluded that, although there seems a $30 \%$ difference between the first and third load cases, concerning the amplified shear loads and low shear stress responses, there are no significant differences between each application zones for the shear force loading, as the shear stress distribution trends are similar to each other. However, the case study draw attention to the effect of the shear force on the geometry. Although, the shear force applied to the model is exaggerated in order to be able to see the effect clearly, it is seen that the magnitude of the shear stress is very low compared to the material properties of the defined flange and bolt materials. Concerning this issue, an additional study is conducted on the effect of the prescribed resultant shear force on the flange and bolt stresses. For this case study, to be on the safe side shear force is applied to the axial cross-section of the shaft as in the first load case studied, since this gives the highest shear stress. 


\subsection{The Effect of the Shear Force}

In this study, full model of a typical double flange joint of an aircraft engine with 30 bolts, having $5 \mathrm{~mm}$ diameters, shown in Figure 2.1 is analyzed for different preload values acting on bolt-nut geometries and friction coefficients between the two flanges. The shear stress results in the bolts and in the flange, collected along a path passing through them, are compared. The purpose of the study is to determine if the shear load effect is negligible or not.

For the analyses, resultant of the absolute maximums of $F_{X}$ and $F_{Y}$ loads, shown in Table 2.4, is used. The resultant force is calculated as $1969 \mathrm{~N}$. This load is applied in positive y direction for simplicity. In addition to the shear load, pretension force of $5000 \mathrm{~N}$ is applied to each bolt, as a base study. Later, in order to compare the effect of preload on the shear stress, this value is doubled. Mesh structure of the geometry used in this study as well as the material properties and the contact definitions are modeled as described in the previous sections. Figure 2.30 shows the mesh structure of the modeled geometry.

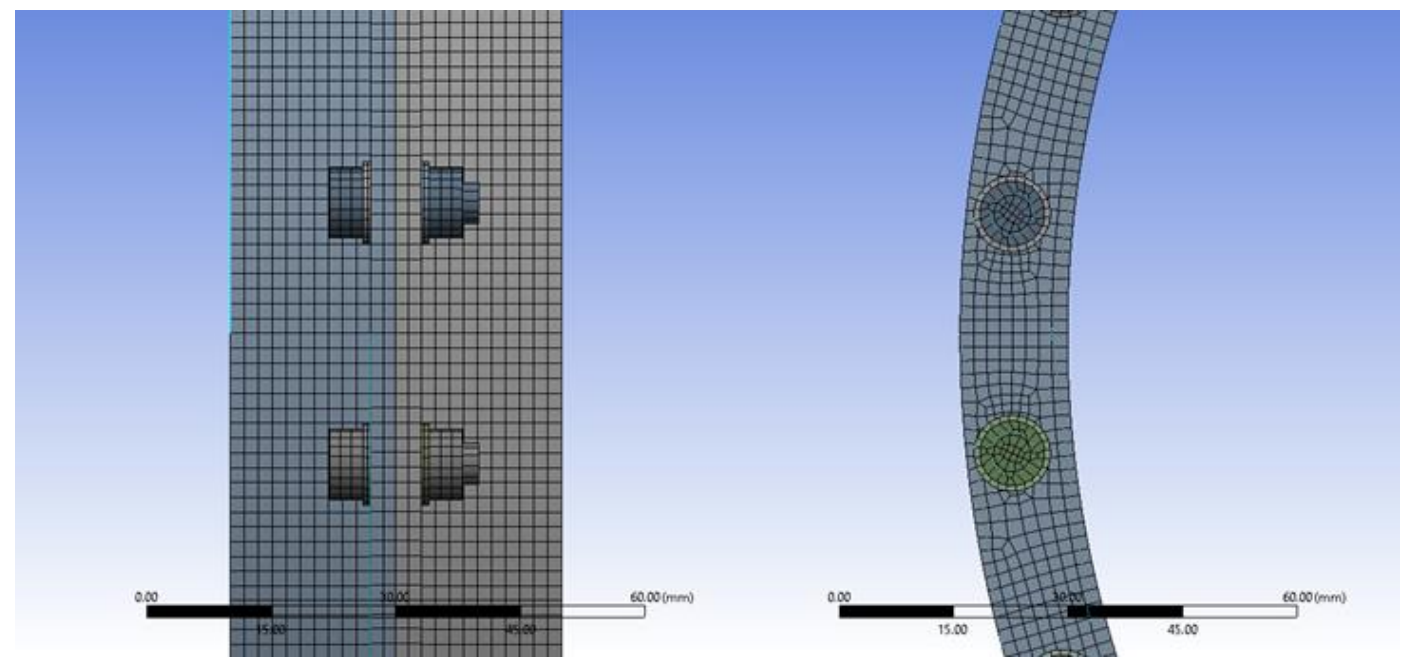

Figure 2.30: Mesh structure of the geometry used in the shear force case study 
Load and boundary conditions are defined as described in the previous case study where the application of the shear force is investigated. Boundary condition and load applications are shown in Figure 2.31 and Figure 2.32. As can be seen in Figure 2.31 and Figure 2.32, cross-section surface of the one of the shafts is defined as fixed support, and the shear load is applied to the cross-section surface of the other shaft. Preload is defined on each bolt.

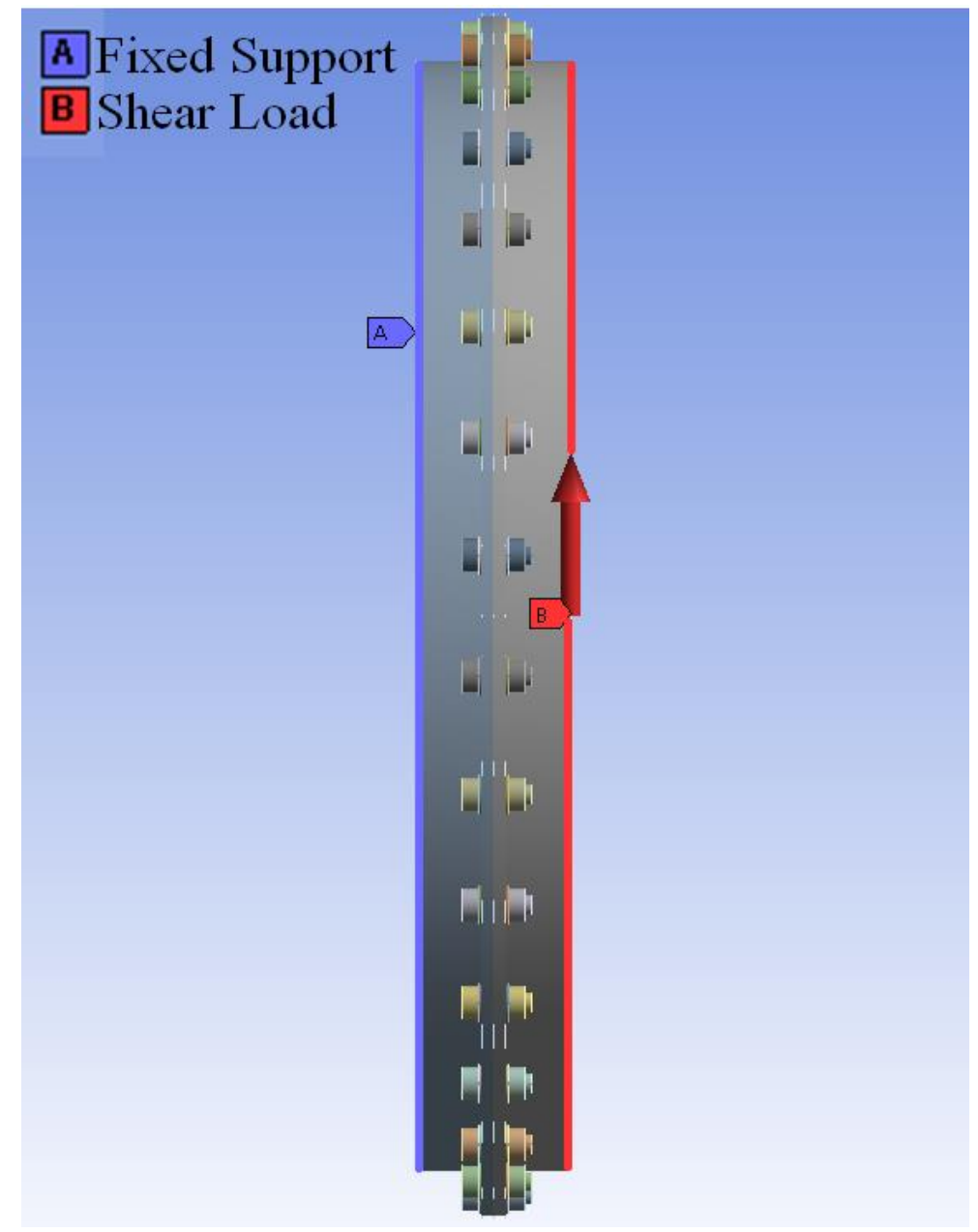

Figure 2.31: Load and boundary conditions used in the shear force case study 


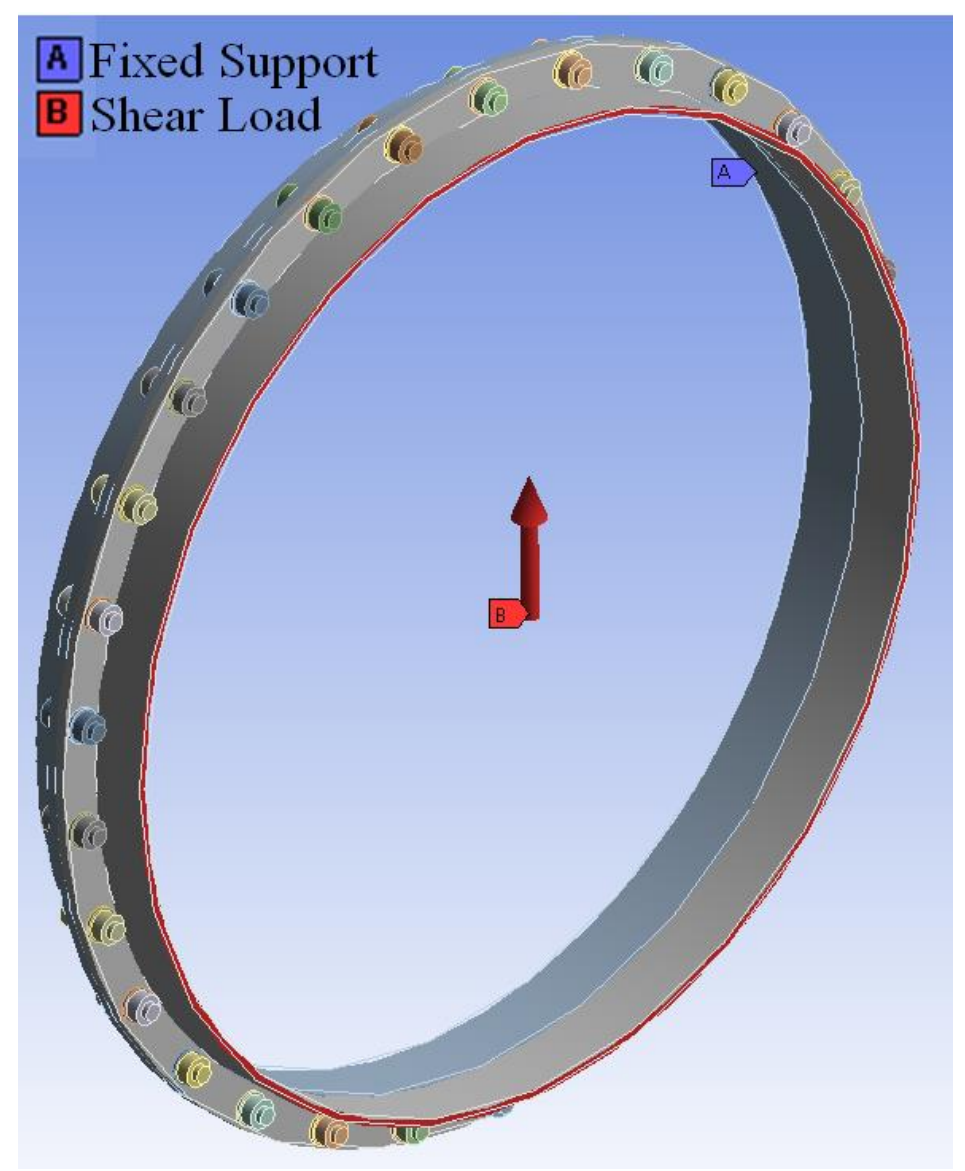

Figure 2.32: load and boundary conditions (isometric view)

Full model analyses are done for 5 different cases. As a base study, $1969 \mathrm{~N}$ shear force is applied to geometry with $5000 \mathrm{~N}$ preload on each bolt and friction coefficient of 1.2 is used between the flanges. All the other contact definitions, such as contacts between bolt head and washer, and washers and flanges, are defined as described in Table 2.2. Following this study, to investigate the effect of friction; first, the coefficient of friction between the flanges is reduced to half and then the contact between the flanges is defined as frictionless. Then, in order to see the effect of pretension force, preload is doubled. As a final case, an analysis is made with double preload and frictionless contact. Table 2.9 shows the studied cases for this investigation. 
Table 2.9: Studied cases for the shear force effect on the bolt and flange shear stress

\begin{tabular}{|c|l|}
\hline Case & \multicolumn{1}{|c|}{ Description } \\
\hline 1 & $\begin{array}{l}\text { Preload }=5000 \mathrm{~N}, \text { Shear force=1969 N, Coefficient of } \\
\text { friction }=1.2\end{array}$ \\
\hline 2 & $\begin{array}{l}\text { Preload }=5000 \mathrm{~N}, \text { Shear force=1969 N, Coefficient of } \\
\text { friction }=0.6\end{array}$ \\
\hline 3 & $\begin{array}{l}\text { Preload }=10000 \mathrm{~N}, \text { Shear force=1969 N, Coefficient } \\
\text { of friction =1.2 }\end{array}$ \\
\hline 4 & $\begin{array}{l}\text { Preload =5000 N, Shear force=1969 N, Coefficient of } \\
\text { friction =0 }\end{array}$ \\
\hline 5 & $\begin{array}{l}\text { Preload }=10000 \mathrm{~N}, \text { Shear force=1969 N, Coefficient } \\
\text { of friction =0 }\end{array}$ \\
\hline
\end{tabular}

For each analysis, shear stresses on the bolts and the flange on which the shear force is applied is gathered along a path. The path is created on the contact plane of the flanges and starts from the center of the top bolt cross-section. Being concentric with flanges the path passes through the center of each bolt, and ends at the bottom bolt center. Figure 2.33 shows the path along which the shear stress results are gathered and the bolt region amenable to maximum shear load.

Figure 2.34 illustrates the stress curves gathered from each analysis case. Shear stresses are plotted with respect to the distance along the path. As can be seen, maximum stresses occur near the center of the path. In order to be able to make more clear comparison, closer look is taken on the center bolt which is shown in Figure 2.33 . 


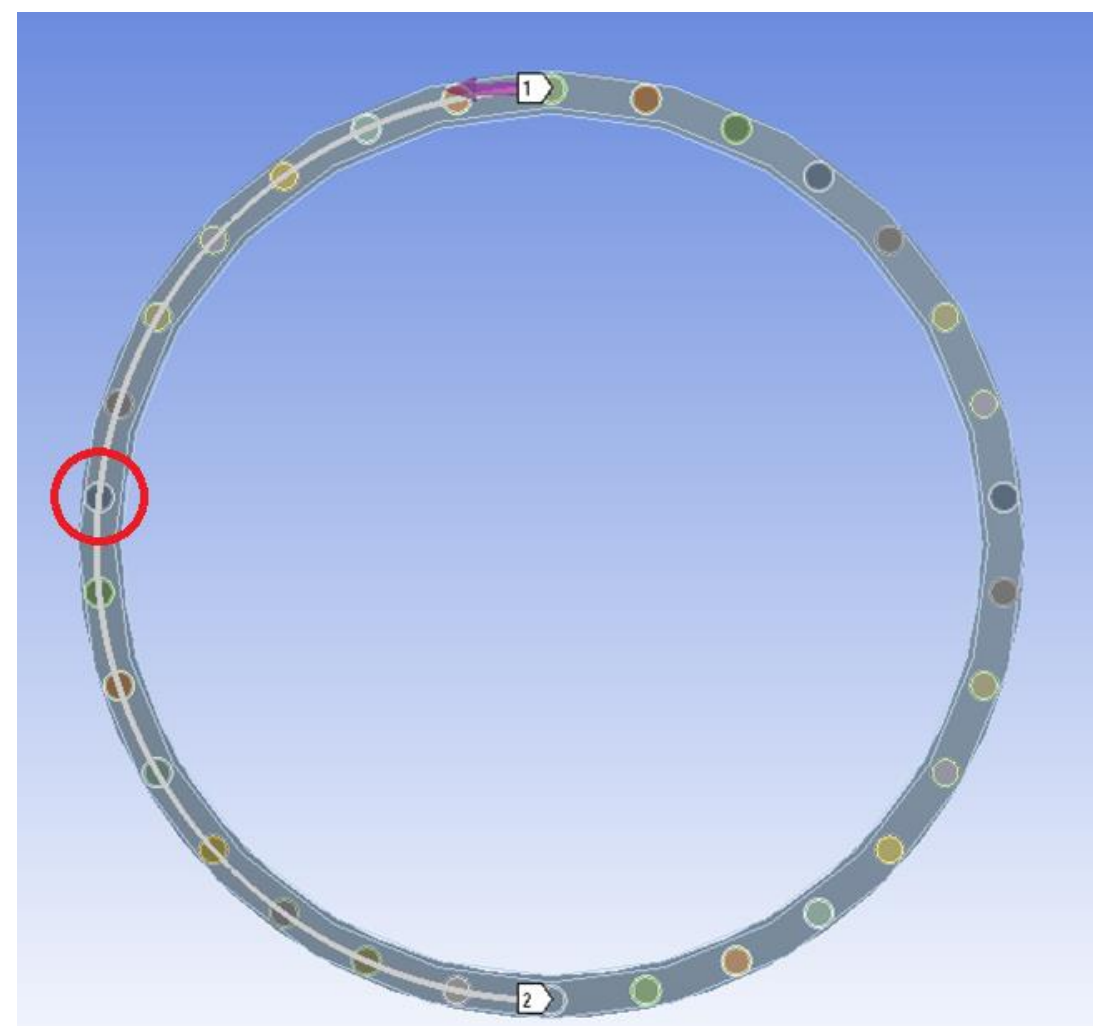

Figure 2.33:Shear stress path and the bolt region under the influence of maximum shear load

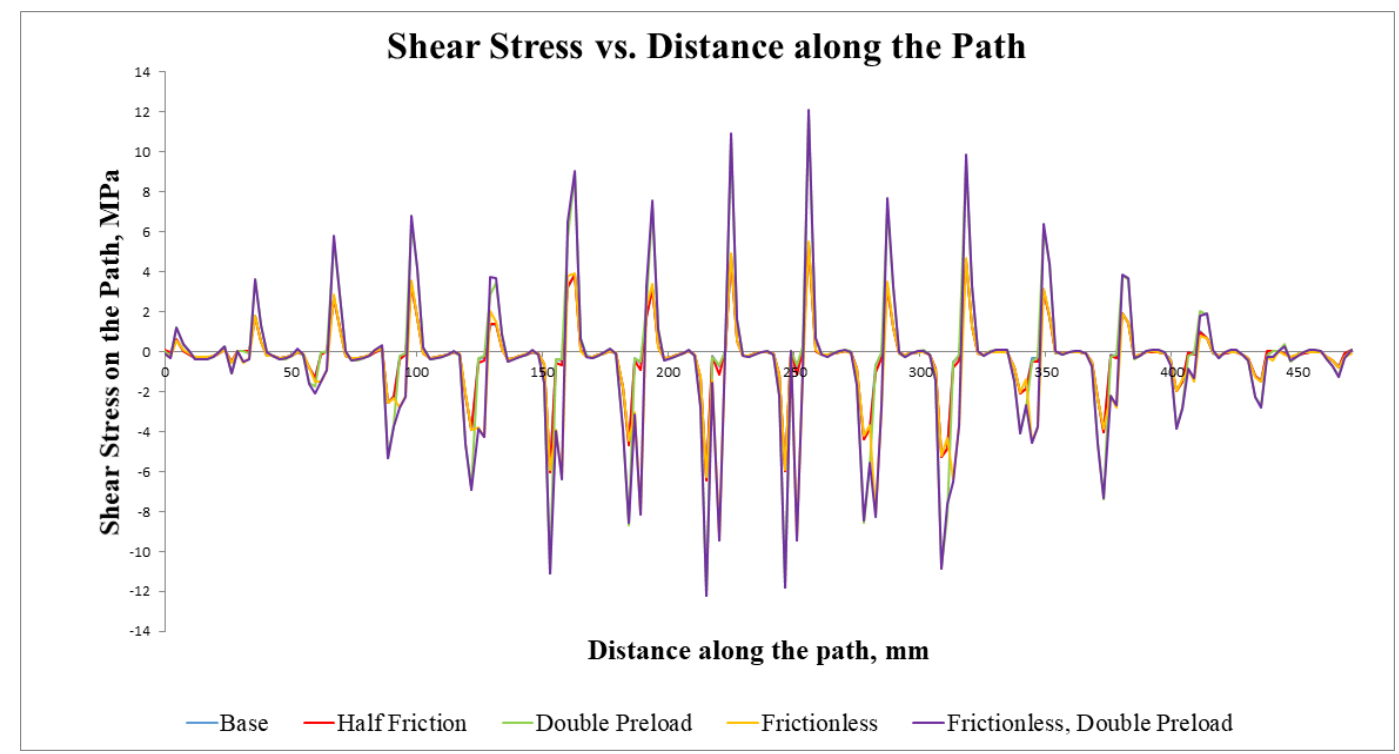

Figure 2.34: Shear stress vs. distance along the path 
Figure 2.35 shows the shear stress plots around the center bolt for base case, double preload case and the frictionless double preload case, in order to illustrate the effect of changing preload value on the shear stress occurring on the flange and the bolt. As it can be seen, with changing preload, the shear stress on the flange section changes, as well. When the preload is doubled, the shear stress is also doubled. However, the change of preload has almost no effect on the bolt stress. The shear stress on the bolt section is only affected by the change in coefficient of friction.

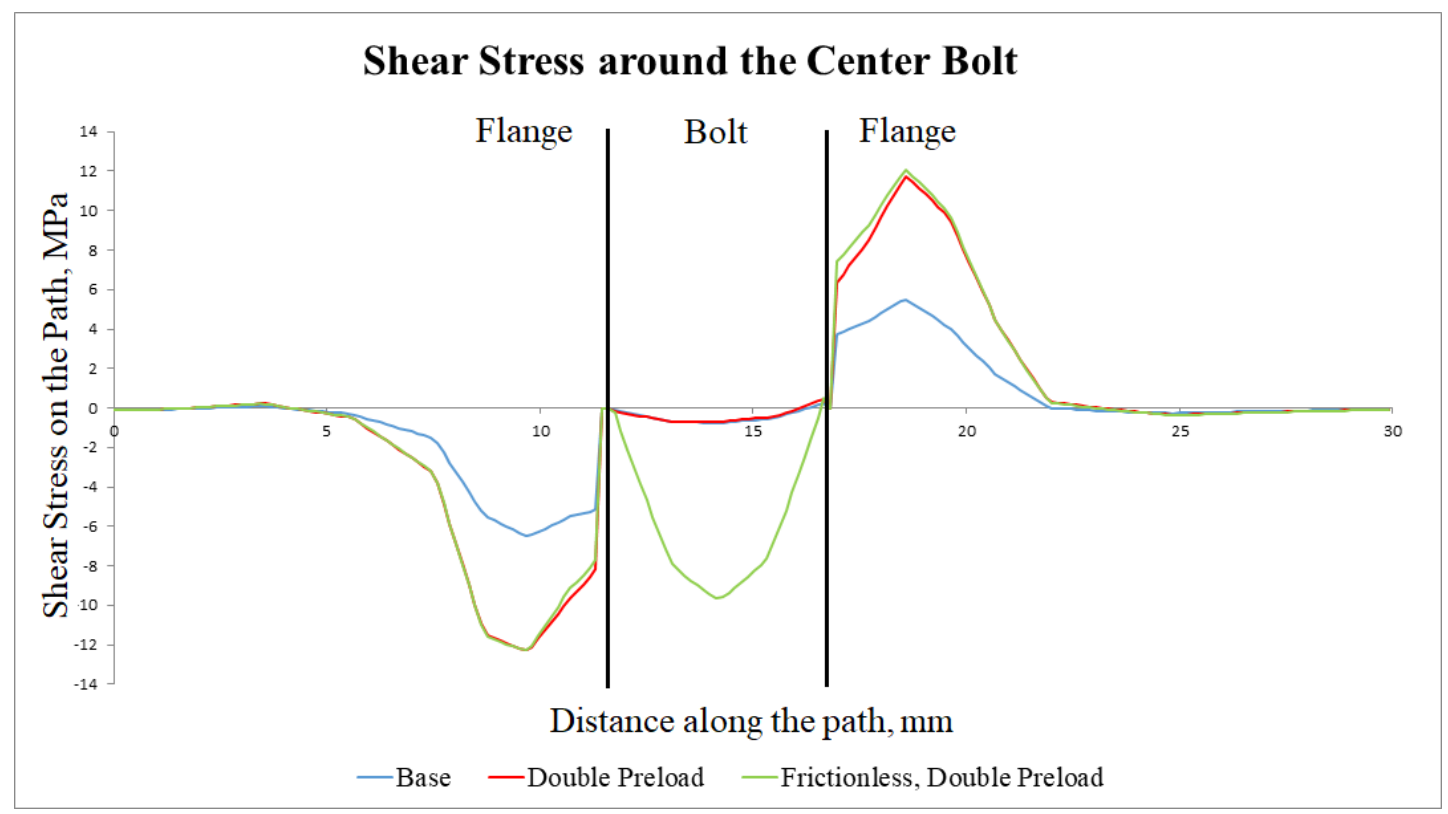

Figure 2.35: The effect of preload on the shear stresses on the flange and the bolt near the center of the path, 1,3 and $5^{\text {th }}$ cases

Figure 2.36 shows the shear stress plots around the center bolt for base case, half friction case and the frictionless case, in order to highlight the effect of the friction coefficient on the shear stress. 


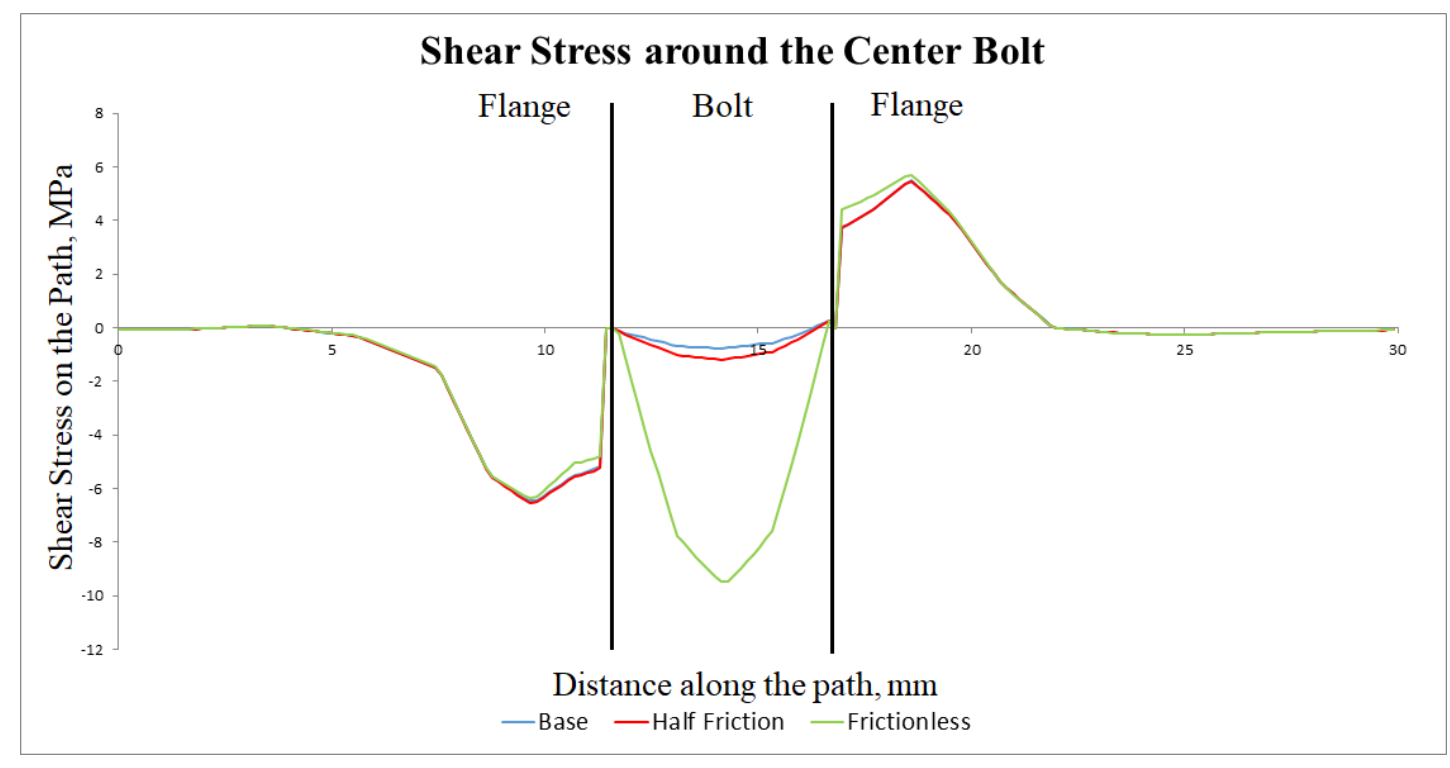

Figure 2.36: The effect of friction on the shear stresses on the flange and the bolt near the path center

The first and the last sections in Figure 2.35 and Figure 2.36 show the stress concentrations on the flange along the path. Middle portion of the curves indicate stresses occurring on the bolt. For the base, frictionless and half friction analyses, maximum shear stress on the flange is around $6 \mathrm{MPa}$. On the other hand, for the double preloaded and double preloaded with the frictionless contact analyses, this value goes up to $12 \mathrm{MPa}$. Maximum shear stress on the bolt is around $0.8 \mathrm{MPa}$ for base and double preloaded analyses. This value slightly increases to 1.2 for the half friction case and jumps up to 9.5 MPa for both frictionless contact cases.

The results presented in Figure 2.35 shows that driving factor for the flange stress is preload. When the preload is doubled, it is observed that, flange stress near the hole doubles, too. On the other hand, it is seen that friction has almost no influence on flange stress (Figure 2.36). It can also be seen that apart from the near hole locations, there exist no shear stress on the flange at all, regardless of which case it is. So, under the given loads, it can be concluded that there is no significant effect of the shear load on the flange. 
As a result of the findings of this case study, it can also be clarified that for the base and the double preload cases, where the standard friction coefficient is used, the given load value creates almost no shear stress on the bolt, considering that the material is structural steel (Figure 2.35). When the analysis is done with half friction coefficient, although there exists a slight increase in shear stress, it is still very low compared to the material properties of steel (Figure 2.36). The reason is believed to be that with the base friction coefficient and $5000 \mathrm{~N}$ preload acting on each bolt, there occurs such a friction between flanges that shear load is almost completely compensated by it and does not act on the bolts. Amplifying the preload contributes to the friction so that the same situation appears. Even after decreasing the coefficient value to half, friction is still so high with the acting preload that, still, no drastic increase of bolt shear stress is observed. As expected, after assuming that the contact is frictionless, a jump in the bolt shear stress is observed as the friction force between the flanges is zero and the shear load is transferred to the bolts (Figure 2.35, 2.36). Although the load is carried by the bolts, it is shared by 30 bolts, and with the given load values, it creates no significant shear stress even on the highest loaded bolt.

All in all, this study showed that, specified shear loads for the particular aircraft engine are so low that they create no remarkable effect on the given joint geometry even when the highest possible shear loads acting together is considered. Even for the worst case possible, where the shear load is maximum and the coefficient of friction is zero, the shear loads could not create any remarkable effect on the both flange and bolt geometries, for the region around the highest loaded bolt. Therefore, in the present study, it is decided to neglect the shear loads acting on the bolted flange connectionin order to reduce the number of design points and analysis cost for the final study which includes combined loading. 


\section{CHAPTER 3}

\section{PARAMETRICAL ANALYSES AND DATABASE CONSTRUCTION}

\subsection{The Selection of Input Parameters}

Success of the artificial neural network, which is the core element of the bolted flange design tool, heavily depends on the number of design points selected in order to create the database for training the neural network. These design points are derived from the parametric input values and the number of design points resulting from the permutations of different parametric inputs. Initially, the geometrical design input points are decided. In this respect, for the geometric design variables given in the Figure 2.7, for the bolt size parameter (A) 9 different standard bolt sizes is used while 4 different total number of bolts (B) is defined, and 5 different thicknesses are chosen for the shaft (C) and flange (D) thicknesses. Lower and upper limits of the number of bolts and flange and shaft thicknesses are selected based on the typical values used in the flange connection of the aircraft engine. Table 3.1 shows the tabulated geometrical input parameters used in the thesis.

Apart from the geometrical input parameters, load parameter values are selected in order to create different design points. Initially, the pretension load input parameter is chosen. Selected pretension loads, which are applied to the bolt-nut pairs, are chosen among the preload values used in the industry depending on each bolt size. For similar bolt size pairs, which is created by dividing the bolt sizes into four different groups, same preload values are used in the parametric analysis phase. For each group of bolts, three different preload parameters are selected as the first load input parameter. Table 3.2 represents the applied pretension loads for each bolt size group. 
Table 3.1: Geometrical input parameters of the bolted flange connection

\begin{tabular}{|l|c|c|c|c|c|c|c|c|c|}
\hline Bolt Size & $\begin{array}{c}\text { A } \\
(\mathrm{mm})\end{array}$ & 4.83 & 5.00 & 6.00 & 6.35 & 7.00 & 7.94 & 9.00 & 9.53 \\
\hline Number of Bolts & $\begin{array}{c}\mathrm{B} \\
(-)\end{array}$ & 20 & 24 & 30 & 36 & - & - & - & - \\
\hline Shaft Thick. & $\begin{array}{c}\mathrm{C} \\
(\mathrm{mm})\end{array}$ & 1.68 & 1.89 & 2.10 & 2.31 & 2.52 & - & - & - \\
\hline Flange Thick. & $\begin{array}{c}\mathrm{D} \\
(\mathrm{mm})\end{array}$ & 2.40 & 2.70 & 3.00 & 3.30 & 3.60 & - & - & - \\
\hline
\end{tabular}

Table 3.2: Preload parameter set

\begin{tabular}{|l|c|c|c|c|c|c|c|c|c|}
\hline \multirow{2}{*}{$\begin{array}{c}\text { Preload } \\
\text { for each }\end{array}$} & $\mathrm{A}(\mathrm{mm})$ & 4.83 & 5.00 & 6.00 & 6.35 & 7.00 & 7.94 & 9.00 & 9.53 \\
\cline { 2 - 8 } bolt size & $\mathrm{P}(\mathrm{N})$ & 6700.00 & 10000.00 & 16000.00 & 27000.00 \\
& & 6500.00 & 11150.00 & 19000.00 & 29500.00 \\
& & 6300.00 & 22000.00 & 32000.00 \\
\hline
\end{tabular}

As the load input parameter, the bending moment acting on the bolted flange connection is selected. The maximum resultant bending moment, which is the resultant of the maximum $\mathrm{MX}_{\mathrm{X}}$ and $\mathrm{M}_{\mathrm{Y}}$ moments given in Table 2.4, $1126185 \mathrm{Nmm}$, is taken as the minimum bending moment load parameter as the magnitude of the axial load created by the bending moment is low compared to the pretension load. Afterwards, the bending moment load set is generated with 5 different bending moment loads, defined as the increments of the minimum bending moment in order to take the safety factor into account. Table 3.3 gives the final bending moment load input parameters. 
Table 3.3: Combined bending moment load parameter set

\begin{tabular}{|c|c|c|c|c|c|c|}
\hline $\begin{array}{c}\text { Bending } \\
\text { Moment }\end{array}$ & $\begin{array}{c}\mathrm{M} \\
(\mathrm{Nmm})\end{array}$ & 1126185 & 1689277 & 2252370 & 2815462 & 3378555 \\
\hline
\end{tabular}

Apart from the pretension load and the bending moment, no other load input is used as a parametric load input. As mentioned in the previous chapter, the acting shear load is excluded from the study as it has no significant effect on the bolt and flange stresses. Beside that, axial load, stated as $\mathrm{F}_{\mathrm{Z}}$ in Table 2.4, is assumed to be very low compared to the pretension load and the axial force created by the acting bending moment. Due to that, it is decide to keep the axial load constant at the maximum value of $463.75 \mathrm{~N}$ for all the design point analyses, without defining it as a design input parameter.

\subsection{Database Generation}

Using the selected geometrical and load input parameters, the number of design points is determined by taking permutations of each input parameter. Eight bolt diameters, four total number of bolts in a full bolted flange connection, five varying thicknesses for flange and shaft geometries, along with the preload ranges containing three different pretension loads for each similar bolt size group and five different resultant bending moment acting on the bolted flange connection resulted in a total number of twelve thousand specific design points. In order to create the database for the artificial neural network containing input and output values for each configuration, parametric finite element analyses are conducted for each twelve thousand design point. These parametric analyses are handled in twenty four distinct groups, each consists of five hundred different design points based on each bolt sizepreload pair. Bolt reaction forces gathered from the center plane cross-section of bolt geometries and the equivalent von-Mises flange stresses collected from the contact face of the flanges for each design point analysis are brought together in order to include as output values in the neural network database. Sample database segment is presented in Table 3.4. 
Table 3.4: Sample input and output tables

\begin{tabular}{|l|c|c|c|c|c|c|}
\hline & $\begin{array}{c}\text { Bolt } \\
\text { Size } \\
(\mathbf{m m})\end{array}$ & $\begin{array}{c}\text { \# of } \\
\text { Bolts } \\
(-)\end{array}$ & $\begin{array}{c}\text { Shaft } \\
\text { Thick. } \\
(\mathbf{m m})\end{array}$ & $\begin{array}{c}\text { Flange } \\
\text { Thick. } \\
(\mathbf{m m})\end{array}$ & $\begin{array}{c}\text { Bending } \\
\text { Moment } \\
(\mathbf{N m m})\end{array}$ & Preload \\
$\mathbf{( N )}$ \\
\hline DP1 & 4.83 & 20 & 1.68 & 2.40 & 1126185.00 & 5700.00 \\
\hline DP2 & 4.83 & 24 & 1.68 & 2.40 & 1126185.00 & 5700.00 \\
\hline DP3 & 4.83 & 30 & 1.68 & 2.40 & 1126185.00 & 5700.00 \\
\hline DP4 & 4.83 & 36 & 1.68 & 2.40 & 1126185.00 & 5700.00 \\
\hline DP5 & 4.83 & 20 & 1.89 & 2.40 & 1126185.00 & 5700.00 \\
\hline
\end{tabular}

\begin{tabular}{|c|c|c|}
\cline { 2 - 3 } \multicolumn{1}{c|}{} & $\begin{array}{c}\text { Bolt } \\
\text { Reaction } \\
\text { Force } \\
(\mathbf{N})\end{array}$ & $\begin{array}{c}\text { Flange } \\
\text { Stress }\end{array}$ \\
\hline DP1 & 5818.64 & $(\mathbf{M P a})$ \\
\hline DP2 & 5771.95 & 134.45 \\
\hline DP3 & 5738.58 & 121.84 \\
\hline DP4 & 5727.08 & 110.64 \\
\hline DP5 & 5809.46 & 100.42 \\
\hline
\end{tabular}

Figure 3.1 shows the visualization of bolt reaction force on the bolted flange connection geometry. Upper part of the figure illustrates the total force reaction occurring in the center cross-sectional plane of the bolt geometry, for design point 1 , given in Table 3.4. Lower portion of the Figure 3.1 represents the corresponding force graph for each loading step. The external loads are applied to the geometry in two loading steps, in order to represent the real-life applications where, first, the bolts are preloaded on the assembly line, and then the external loads are applied during the product life. At the first step, the pretension force is loaded on the bolt-nut geometry, and then it is locked. After that at the second step, the external axial force due to the bending moment is applied to the corresponding surface on the bolted flange connection geometry. Figure 3.2 shows the equivalent von-Mises stress distribution on the flange and shaft sections, for DP1. 


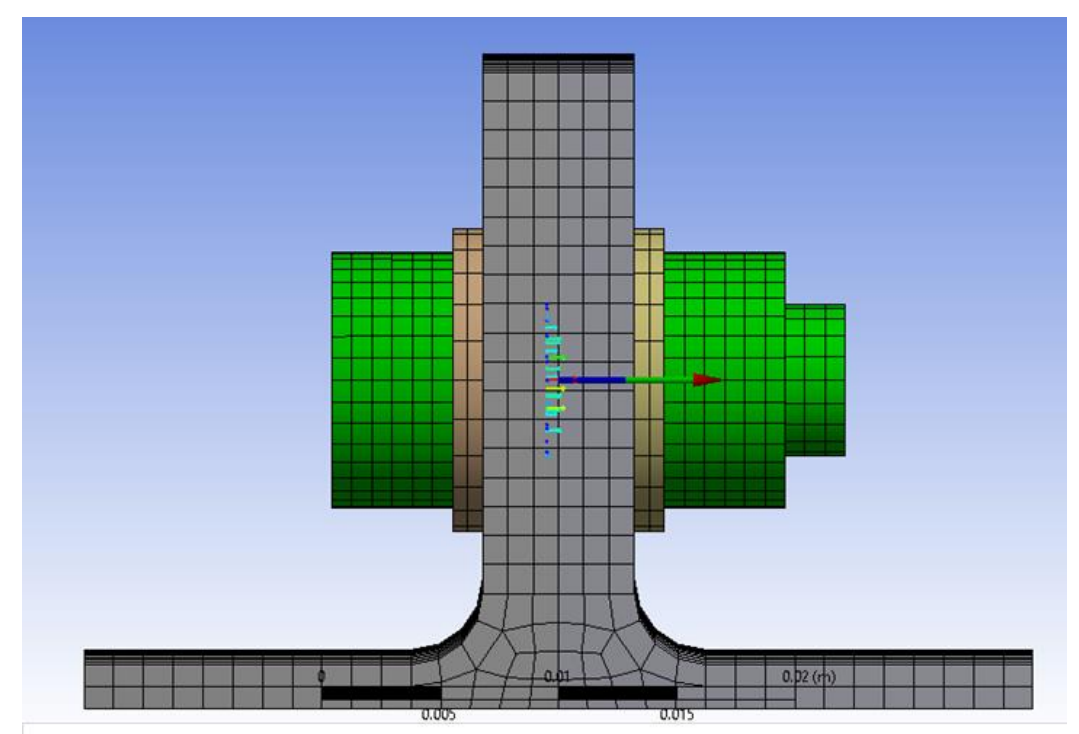

Bolt Reaction Force at Each Loading Step

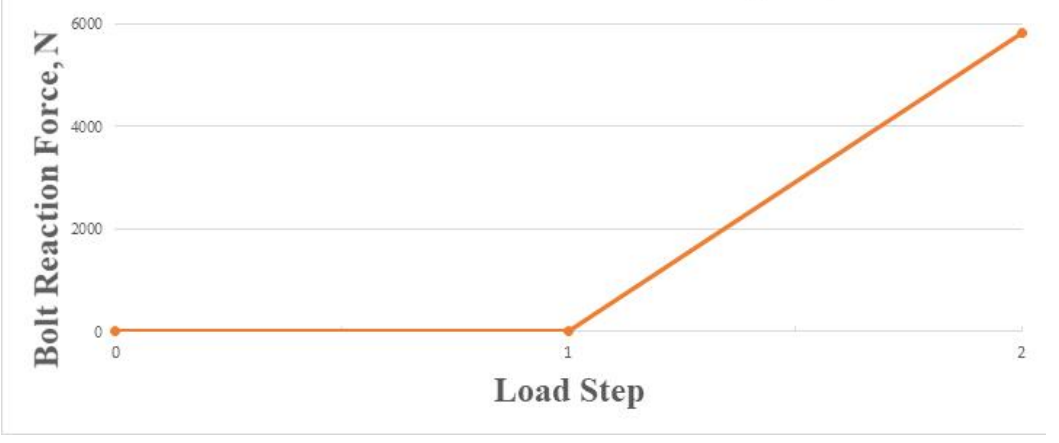

Figure 3.1: Bolt reaction force for DP1 configuration in Table 3.4

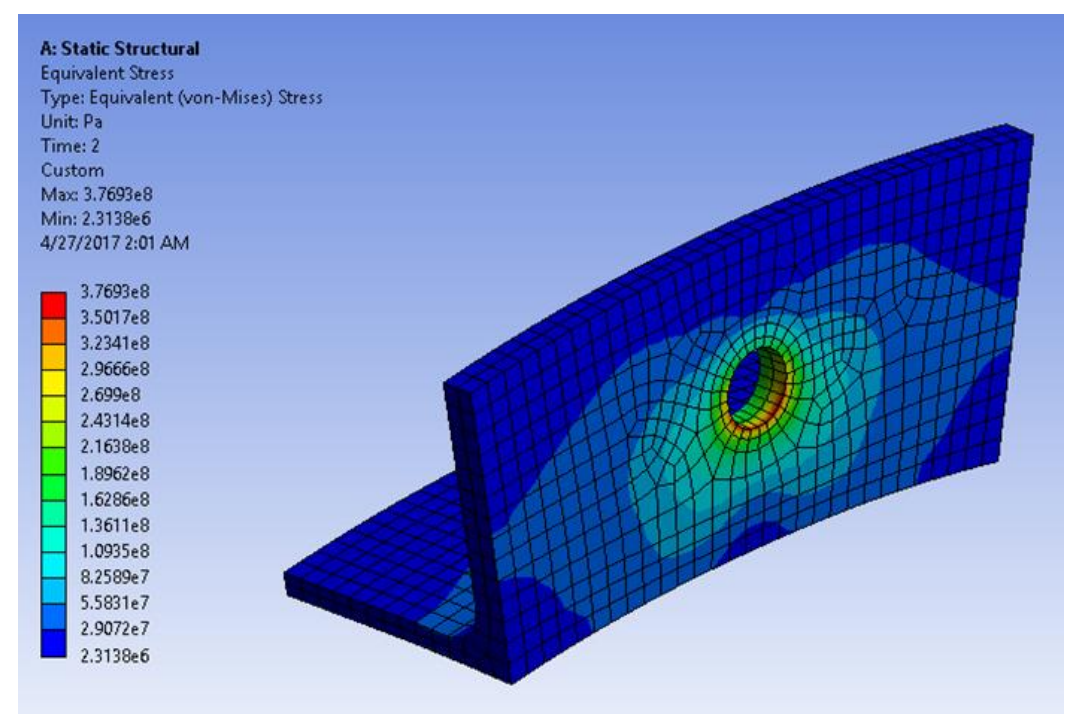

Figure 3.2: The equivalent von-Mises stress distribution on flange geometry for DP1 configuration in Table 3.4 
The equivalent von-Mises stress distribution of the bolt-nut geometry is shown in Figure 3.3. In addition to that, normal stress distribution in the principle $\mathrm{Z}$-axis at the center cross-section of the bolt is presented in Figure 3.4, with the average stress of 318.1 MPa.

$$
\sigma_{z}=\frac{F_{Z}}{A_{\text {cross-section }}}
$$

Using Equation 3.1, the normal reaction force at the center plane can be calculated as $5818.73 \mathrm{~N}$. This reaction force represents the effect of both pretension load and the bending moment at the cross-section on the center plane of the bolt.

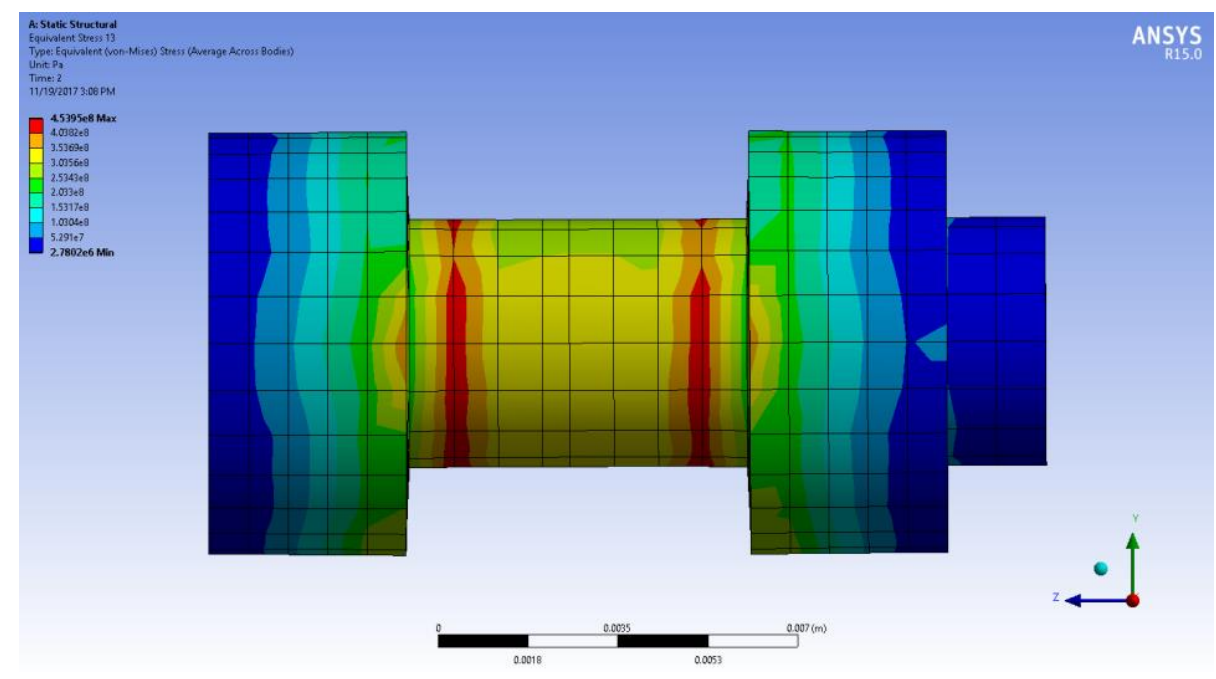

Figure 3.3: The equivalent von-Mises stress distribution on the bolt-nut geometry for DP1 configuration in Table 3.4 


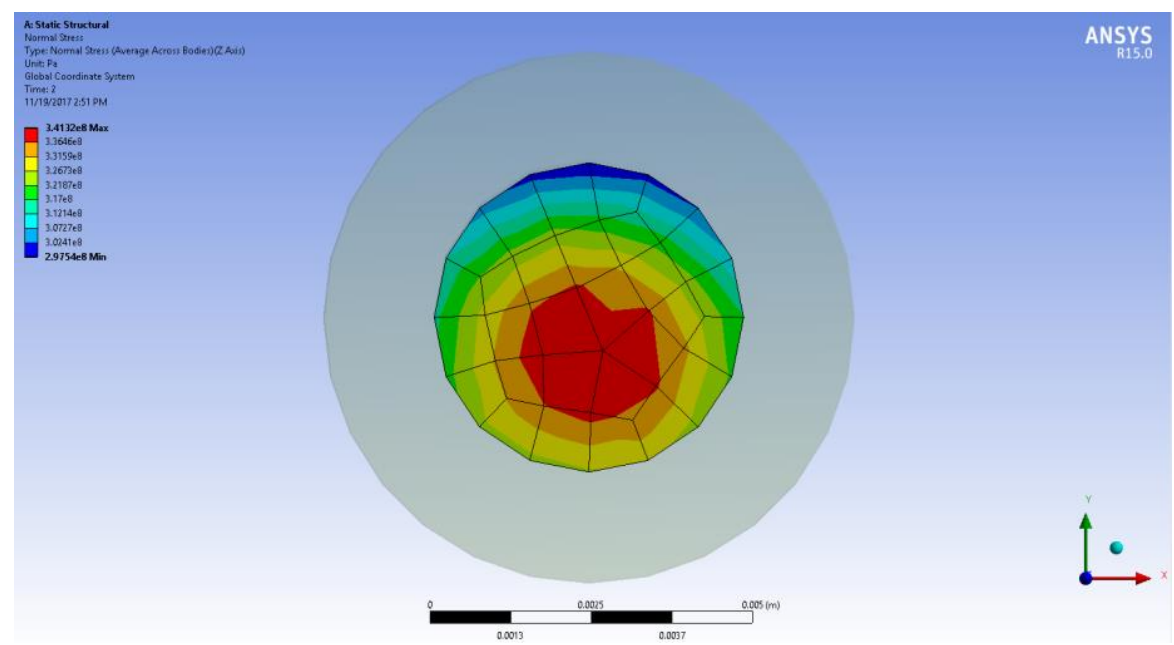

Figure 3.4: The normal stress distribution at the center cross-section of the bolt-nut geometry for DP1 configuration in Table 3.4

Figure 3.5 shows the equivalent von-Mises stress distribution for the bolted flange connection assembly for DP1 configuration in Table 3.4. The stress distribution at the center cross-section through the bolt on the $y-z$ plane is given in Figure 3.6. In order to clarify, the displacements are magnified in Figure 3.6.

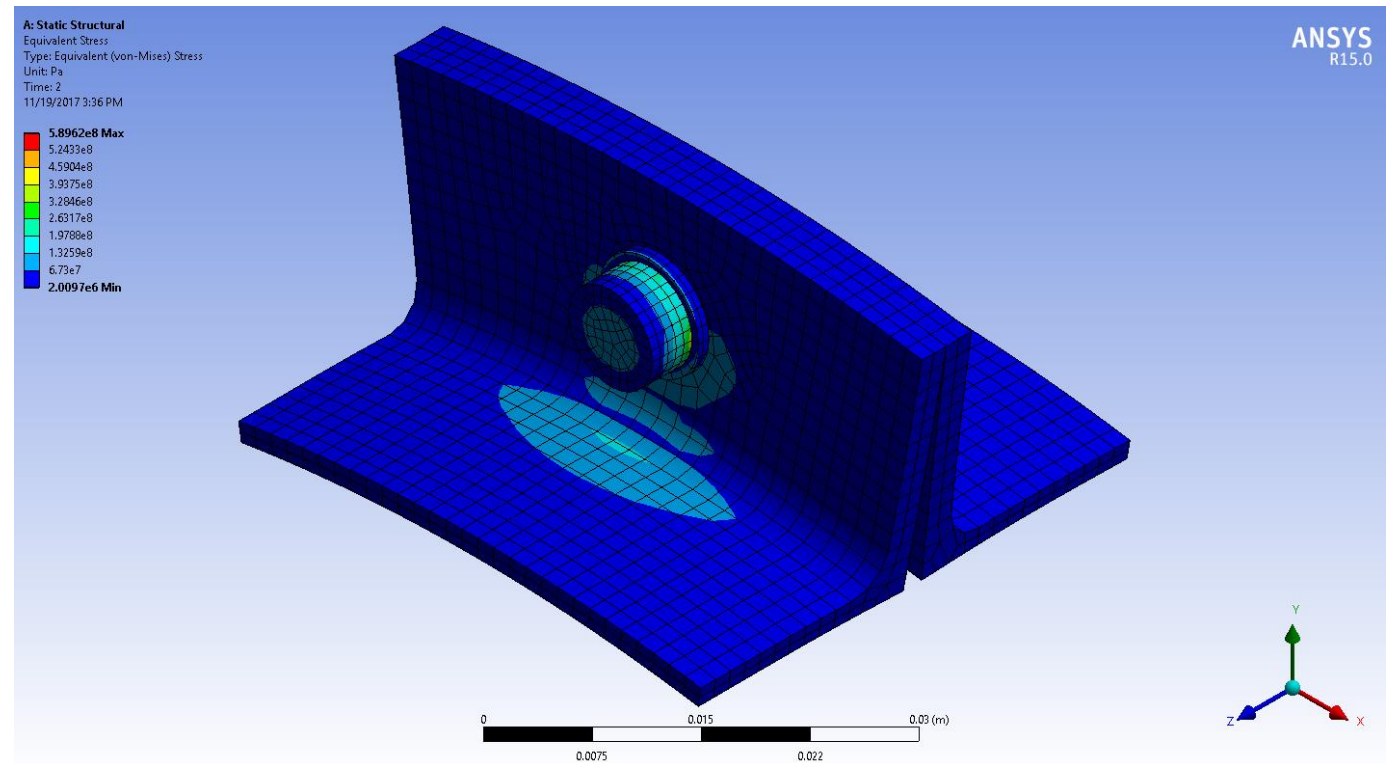

Figure 3.5: The equivalent von-Mises stress distribution of bolted flange connection assembly for DP1 configuration in Table 3.4 


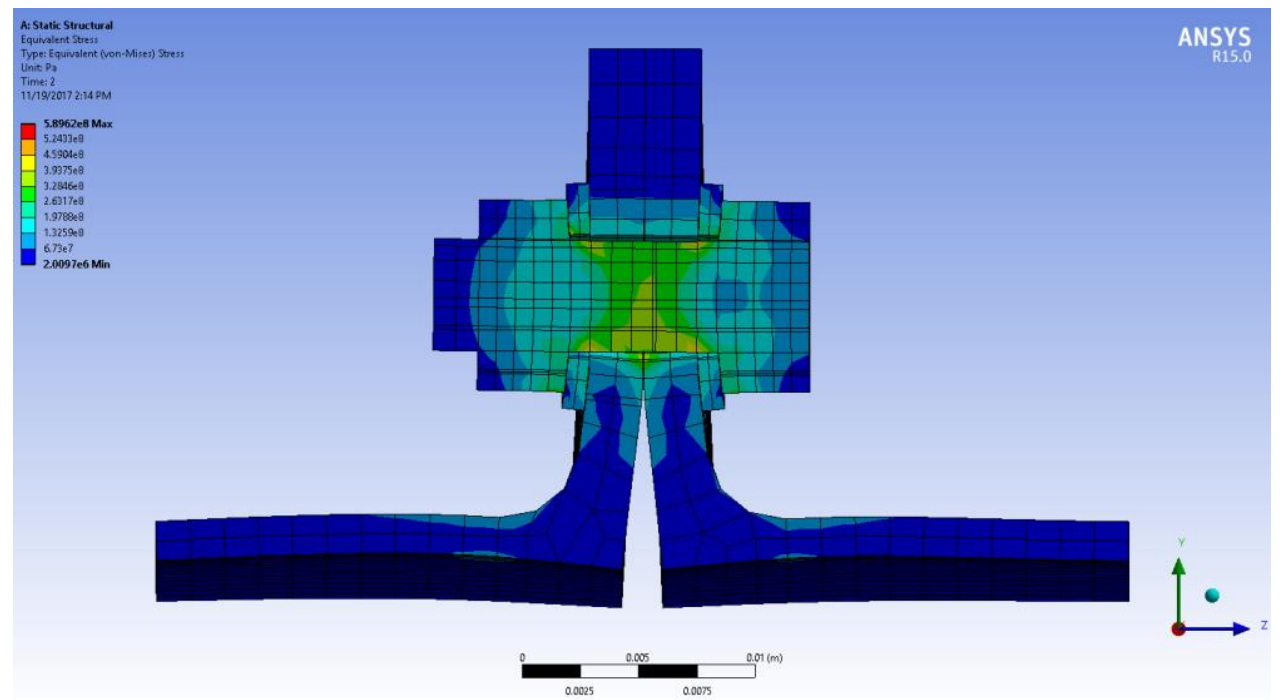

Figure 3.6: The equivalent von-Mises stress distribution at the $\mathrm{X}$ cross-section of the bolted flange connection assembly for DP1 configuration in Table 3.4

The initial finite element analyses clarified that the maximum equivalent von-Mises stress on the flange geometry appears on the corner of the bolt hole at the contact surface of the both flanges, as can be seen in Figure 3.2. However, this local peak stress concentrated at the hole corner contaminates the output data, due to the singular nature of the stress at the structural discontinuities. In order to avoid data pollution, a generalized data collection method is needed to be utilized on the geometry in order to be consistent for all the parametric analyses. Therefore, it is decided to take the average of the equivalent von-Mises stresses gathered from twelve data points on the contact surface of both flanges, as the final equivalent flange stress output. These data points are defined on the contact surface of the flanges, evenly spaced on the circle having a diameter of 1.75 times the bolt diameter. The diameter of the data collection circle is decided due to the contact status between the flanges. In Figure 3.7 contact status between the flanges is shown for a typical load scenario. From Figure 3.7, it can be seen that there is a specific region where the both flanges are in stick and slide status. The data collection circle is needed to be in the stick and slide region as well as being as far as possible from the hole corner in order not to feel the stress concentration effect. Thus, the largest possible circle is defined in the stick and slide region where the radius is roughly 
1.75 times the bolt diameter. The friction stress distribution at the contact surface of the flanges is presented in Figure 3.8. Figure 3.9 shows the defined data points on the flange geometry for the collection of Von-Mises stresses from the flange surface. Sample average stress calculation with the equivalent stresses collected from the given twelve data points is presented in the Table 3.5.

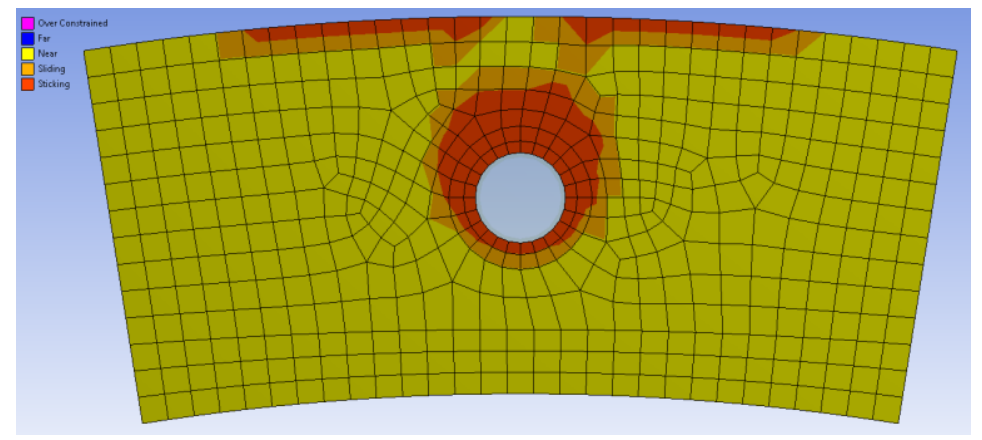

Figure 3.7: Contact status between the flanges

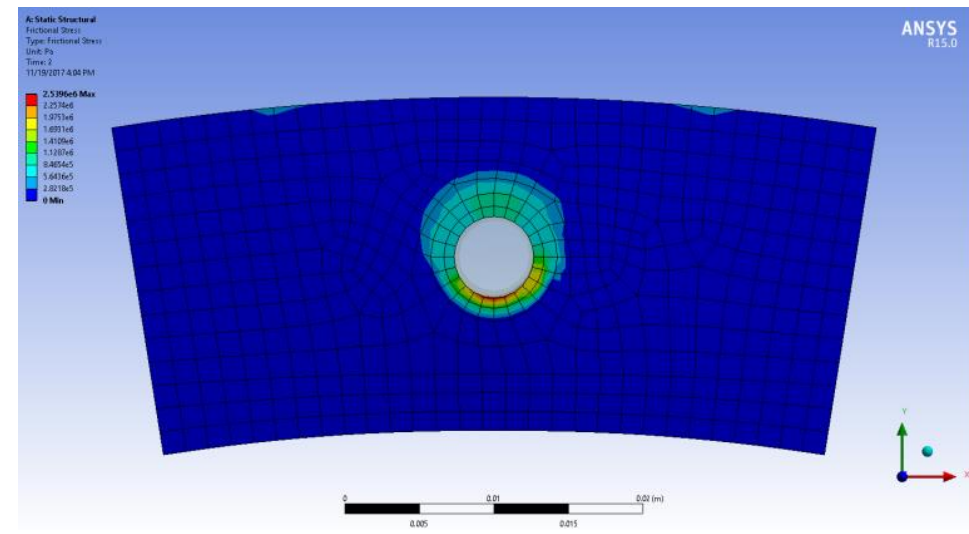

Figure 3.8: The frictional stress distribution on the contact surface of flanges

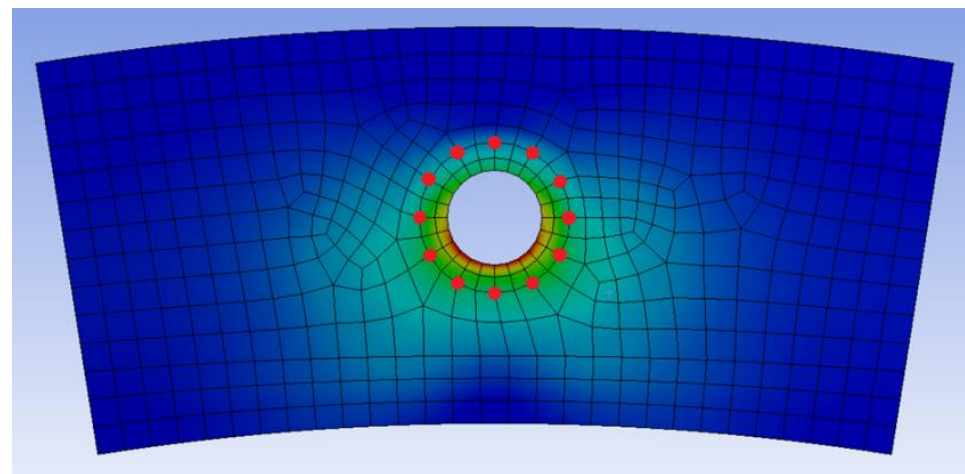

Figure 3.9: The equivalent von-Mises stress collection points 
Table 3.5: Sample average equivalent von-Mises stress calculation for DP1 in Table 3.4

\begin{tabular}{|c|c|c|c|c|c|c|}
\hline Point 1 & Point 2 & Point 3 & Point 4 & Point 5 & Point 6 & \multirow{2}{*}{$\begin{array}{c}\text { Avg. } \\
\text { Stress (MPa) }\end{array}$} \\
\cline { 1 - 5 } 70.4 & 82.3 & 115.3 & 153.2 & 174.3 & 171.1 & \multirow{2}{*}{134.5} \\
\hline Point 7 & Point 8 & Point 9 & Point 10 & Point 11 & Point 12 & \\
\hline 151.3 & 169.3 & 180.5 & 153.2 & 113.5 & 79.0 & \\
\hline
\end{tabular}

After the completion of all the finite element analyses parametrically for all twelve thousand design points organized as twenty four analysis set, the output data of bolt reaction force and the average flange stress along with the geometrical and load inputs are collected in four different MS Excel sheets. Each Excel sheet is constructed as to contain input and output values for previously mentioned bolt size groups, which consists of two similar bolt sizes loaded with the same pretension loads as given in Table 3.2. These MS Excel sheets, later, are used as database files for the artificial neural network training process.

\subsection{The Parametric Finite Element Analysis Results}

Sample finite element analysis results are given in Section 3.2 in Table 3.4. In addition to those results, some post comparisons are made, regarding the effect of pretension load on the bolt reaction force and on the equivalent von-Mises flange stress. The average bolt reaction forces and the average flange stresses are tabulated for each pretension load acting on each bolt group.

Table 3.6 shows the average bolt reaction forces occurring on the center plane of the bolts in each bolt group for different pretension load. Figure 3.10 represents the graphical visualization of the results given in Table 3.6. For all the pretension loads given in Table 3.6, the same axial force and the range of external bending moment, given in Table 3.3, acts on the geometry. From the Table 3.6, it is obvious that as the pretension load on the bolt increases, the reaction force occurring on the center plane also increases. However, with the higher pretension load acting on the bolt, the effect of the external forces tends to decrease, as the preload dominates the acting external 
loads. To clarify, the contribution of the external bending moment and the axial force to the bolt reaction force is around $300 \mathrm{~N}$ for the first bolt group which has relatively small bolt diameter and pretension load, while it is around $60 \mathrm{~N}$ for the bolts with the highest diameter. Although it is not very obvious, this can also be seen in Figure 3.10 , as the slope of each curve representing each bolt group increases to 45 degrees and tend to fit on $y=x$ curve on the graph as the bolt diameter increases.

Table 3.6: Average bolt reaction forces on each bolt group

\begin{tabular}{|c|c|c|}
\hline $\begin{array}{c}\text { Bolt } \\
\text { Groups }\end{array}$ & $\begin{array}{c}\text { Preload } \\
(\mathbf{N})\end{array}$ & $\begin{array}{c}\text { Average } \\
\text { Bolt Reaction } \\
\text { Force }(\mathbf{N})\end{array}$ \\
\hline \multirow{3}{*}{$4.83-5.00$} & 5700.00 & 6030.90 \\
\cline { 2 - 3 } & 6100.00 & 6400.76 \\
\cline { 2 - 3 } & 6500.00 & 6774.69 \\
\hline \multirow{3}{*}{$\mathbf{6 . 0 0 - 6 . 3 5}$} & 10000.00 & 10211.95 \\
\cline { 2 - 3 } & 11150.00 & 11325.07 \\
\cline { 2 - 3 } & 12300.00 & 12445.93 \\
\hline \multirow{3}{*}{$\mathbf{7 . 0 0 - 7 . 9 4}$} & 16000.00 & 16131.99 \\
\cline { 2 - 3 } & 19000.00 & 19091.88 \\
\cline { 2 - 3 } & 22000.00 & 22064.44 \\
\hline \multirow{3}{*}{$\mathbf{9 . 0 0 - 9 . 5 3}$} & 27000.00 & 27075.13 \\
\cline { 2 - 3 } & 29500.00 & 29561.81 \\
\cline { 2 - 3 } & 32000.00 & 32051.34 \\
\hline
\end{tabular}

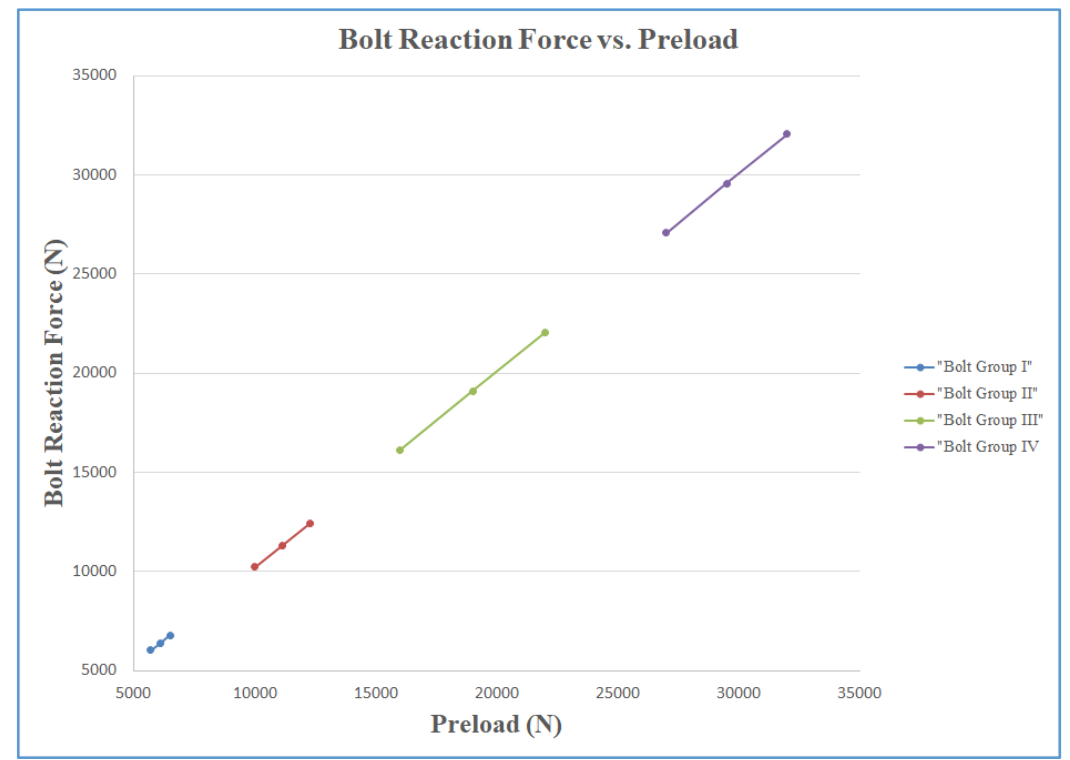

Figure 3.10: Average bolt reaction forces on each bolt group 
The tabulated average equivalent von-Mises flange stresses for each bolt group is given in Table 3.7. It is observed that within each bolt group, as the pretension load increases, the average equivalent flange stress also increases. However, as the bolt diameter increases, the effect of the external loads and the pretension load on the equivalent von-Mises flange stress decreases. This is believed to happen due to the increase in the friction force between the flange sections. Since the magnitude of the friction force rises with the increasing pretension load, the external loads tend to be carried by the bolt geometry, thus creates lower stress on the flange geometry.

Table 3.7: Average flange stresses for each bolt group

\begin{tabular}{|c|c|c|}
\hline $\begin{array}{c}\text { Bolt } \\
\text { Groups }\end{array}$ & $\begin{array}{c}\text { Preload } \\
(\mathbf{N})\end{array}$ & $\begin{array}{c}\text { Average } \\
\text { Flange } \\
\text { Stress }(\mathbf{M P a})\end{array}$ \\
\hline \multirow{3}{*}{$4.83-5.00$} & 5700.00 & 150.20 \\
\cline { 2 - 3 } & 6100.00 & 152.81 \\
\cline { 2 - 3 } & 6500.00 & 155.64 \\
\hline \multirow{3}{*}{$\mathbf{6 . 0 0 - 6 . 3 5}$} & 10000.00 & 131.26 \\
\cline { 2 - 3 } & 11150.00 & 137.61 \\
\cline { 2 - 3 } & 12300.00 & 144.40 \\
\hline \multirow{3}{*}{$\mathbf{7 . 0 0 - 7 . 9 4}$} & 16000.00 & 123.90 \\
\cline { 2 - 3 } & 19000.00 & 137.52 \\
\cline { 2 - 3 } & 22000.00 & 152.32 \\
\hline \multirow{3}{*}{$\mathbf{9 . 0 0 - 9 . 5 3}$} & 27000.00 & 118.39 \\
\cline { 2 - 3 } & 29500.00 & 126.15 \\
\cline { 2 - 3 } & 32000.00 & 134.16 \\
\hline
\end{tabular}

Table 3.8 presents the minimum, maximum and the average reaction forces occurring on the bolt geometries per each bolt size, and the maximum tensile stress for each bolt size. It should be noted that Equation 3.1 is used to calculate the tensile stress on the bolt cross-sections resulting from the bolt reaction forces. According to the calculations, the maximum tensile stress encountered on the bolt cross-sections is 583.36 MPa. As the tensile strength of the hexagonal steel bolt is around $800 \mathrm{MPa}$, the loads acting on the bolt geometries are carried safely without any failure. 
Table 3.8: Maximum tensile stresses on each bolt cross-section

\begin{tabular}{|c|c|c|c|c|}
\hline $\begin{array}{c}\text { Bolt Size } \\
(\mathbf{m m})\end{array}$ & $\begin{array}{c}\text { Min. Bolt } \\
\text { Reaction } \\
\text { Force (N) }\end{array}$ & $\begin{array}{c}\text { Max. Bolt } \\
\text { Reaction } \\
\text { Force (N) }\end{array}$ & $\begin{array}{c}\text { Avg. Bolt } \\
\text { Reaction } \\
\text { Force (N) }\end{array}$ & $\begin{array}{c}\text { Maximum Tensile } \\
\text { Stress } \\
(\mathbf{M P a})\end{array}$ \\
\hline 4.826 & 5705.88 & 7852.98 & 6393.52 & 429.31 \\
\hline 5 & 5707.31 & 7904.00 & 6410.71 & 402.55 \\
\hline 6 & 9991.00 & 13196.49 & 11318.40 & 466.73 \\
\hline 6.35 & 9992.85 & 13259.20 & 11336.91 & 418.68 \\
\hline 7 & 15979.98 & 22450.48 & 19079.80 & 583.36 \\
\hline 7.9375 & 15986.64 & 22550.19 & 19112.41 & 455.71 \\
\hline 9 & 26961.05 & 32343.71 & 29555.88 & 508.41 \\
\hline 9.525 & 26969.71 & 32379.66 & 29569.65 & 454.41 \\
\hline
\end{tabular}




\section{CHAPTER 4}

\section{SETUP OF ARTIFICIAL NEURAL NETWORK AND RESULTS}

\subsection{The Modeling of Artificial Neural Network}

Training of the artificial neural network with the results gathered from the parametric finite element analyses is the next important step in the development process of the bolted flange design tool. The success of the design tool is directly related to how well the artificial neural network is trained, as the ANN is the main element of the bolted flange design tool.

ANN Toolbox of the MATLAB software [3] is used in the training stage of the artificial neural network. For this study, the training process is conducted in four separate groups. Four distinct neural networks are trained for each bolt group given in Table 3.2. Each trained neural network is constructed with 3000 design points.

In order to perform the neural network training, data for each group is divided into three parts. Each distinct part is used for training, validating and testing the network. Training data set is used to train the artificial neural networks. Validation data set is included in the training process, such that at the end of every successful iteration in the training process, it verifies the network and determines if the termination criteria are met, and if so, it terminates the training process. Test data set, however, is not included in the training process. Test data set is used to test the neural network after it is successfully trained, and measure the performance of the trained neural network. For this study, it is decided to allocate $90 \%$ of the data for each group as the training data set in order to train each artificial neural network. The remaining $10 \%$ data are divided into two data sets. The first $5 \%$ of the data is utilized for the validation purpose of each neural network. The last remaining $5 \%$ of the data is in the test set in order to test the performances of the trained neural networks. The data divisions for each neural network are performed randomly by the ANN toolbox of Matlab. 
In the artificial neural network training process used in the current study, feedforward network structure is used for function fitting, with 6 input parameters and 2 output parameters. Figure 4.1 shows the structure of the artificial neural networks. The network structure is constructed with one hidden input layer and one output layer. Sigmoid transfer function is utilized in the hidden input layer, while the linear transfer function is used in the output layer.

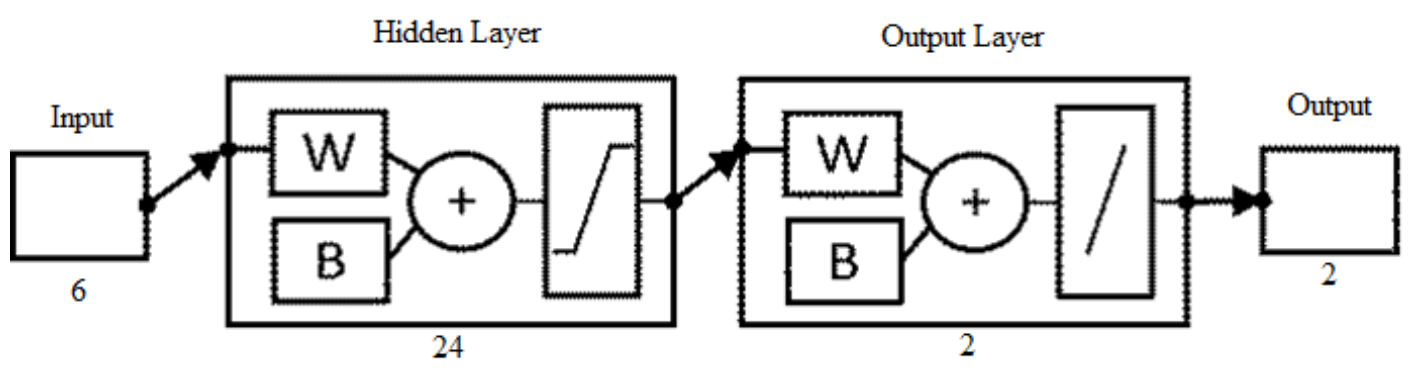

Figure 4.1: Artificial neural network structure

Levenberg-Marquardt back propagation method is used for training the artificial neural network. For each neural network, in the hidden input layer, the neuron number is set to twenty-four. The selection of the neuron number is made after trial and error. In the training process of the artificial neural network, the selection of the neuron number of the hidden input layer is one of the important steps. As a general rule, the networks with higher neuron number tend to give better results. On the other hand, if the number is set too high, over fitting problems start to occur. It means that instead of calculating the output values using the given database, the trained neural network starts to memorize the given output values. This way, the network seems to give perfect results for the given design points, however fails to be accurate for the intermediate values of the design points. As the performance metric, mean square error (MSE) is used in order to measure the performances of each trained neural network. Mean square error is calculated using the output values determined by both ANN and FEA. 
In the process of successful artificial neural network training, the selection of termination criteria is another important step. There are three criteria in general, in order to terminate the neural network training process. The first termination criterion is the so-called Epoch value. This value represents the total number of iterations which are used to update the weights in the artificial neural network. For this study, the Epoch number for each artificial neural network is set to 5000, which means that after 5000 successful iterations, the training process will stop whether the other criteria are met, or not. The performance criterion is another termination criteria. This criterion is set to zero for the present study, which means that the training of the neural network ends when the mean square error calculated using the given and estimated output values is zero. The last criterion of termination is the validation check limit. This limit is used to terminate the training process such that if the validation performance fails to decrease for the prescribed number of successful iterations, the training ends. In the current study, the validation check limit for each artificial neural network is defined as 300 successive iterations. It should be noted that the validation set which is allocated at the beginning of the trainig process is used for the validation check to terminate the training process.

\subsection{The Training Results of the Artificial Neural Network}

The training of the artificial neural network for each bolt group given in Table 3.2 is completed after approximately 2.5 minutes, with the mean square error performances of 1.53, 2.19, 3.42 and 2.45. Each training is ended around 2.5 minutes after 2361, 1715,1878 and 2012 successful iterations based on the validation check limit. The sample ANN training toolbox interface of the neural network trained for the first bolt group (4.826-5) is presented in Figure 4.2. It should be acknowledged that the performances of each network are the combined mean square errors of both bolt reaction forces and the average equivalent von-Mises flange stresses. In order to have a better understanding of the success of the trained networks, for each group, with the complete data including all the training, validation and test sets, the root mean square errors (RMSE) are calculated and given in Table 4.1, separately for bolt reaction forces and the average flange stresses, along with average bolt reaction force and flange stress. For the first bolt group given in Table 3.2, root mean square error 
of the bolt reaction forces is 1.45 , while the average bolt reaction force is around $6400 \mathrm{~N}$. In order to emphasize more, coefficient of determination $\left(\mathrm{R}^{2}\right)$ for each bolt group and for bolt reaction force and flange stress seperately is calculated as 0.999 , which shows the accuracy of the trained ANN compared to the FE results.

Table 4.1: RMSE for each bolt group and combined RMSE for all bolt groups along with average bolt reaction force and flange stress

\begin{tabular}{|l|c|c|c|c|c|c|}
\hline & \multicolumn{6}{|c|}{ Root Mean Square Error } \\
\cline { 4 - 7 } & \multirow{2}{*}{$\begin{array}{c}\text { Bolt } \\
\text { Reaction }\end{array}$} & Flange & \multicolumn{4}{|c|}{ Bolt + Flange } \\
\cline { 4 - 7 } & 1.45 & 1.03 & 1.24 & 1.63 & 1.21 & 1.26 \\
\hline $\mathbf{4 . 8 2 6 - 5}$ & 1.93 & 0.88 & 1.48 & 1.58 & 1.78 & 1.50 \\
\hline $\mathbf{6 - 6 . 3 5}$ & 2.47 & 0.91 & 1.85 & 1.98 & 2.00 & 1.86 \\
\hline $\mathbf{7 - 7 . 9 3 7 5}$ & Training & Test & Validation & All \\
\hline $\mathbf{9 - 9 . 5 2 5}$ & 2.06 & 0.89 & 1.57 & 1.88 & 1.64 & 1.59 \\
\hline All & 2.01 & 0.93 & - & - & - & 1.57 \\
\hline
\end{tabular}

\begin{tabular}{|l|l|l|}
\hline & $\begin{array}{c}\text { Average } \\
\text { Bolt } \\
\text { Reaction } \\
(\mathbf{N})\end{array}$ & $\begin{array}{c}\text { Average } \\
\text { Flange } \\
\text { Stress } \\
\text { (Mpa) }\end{array}$ \\
\hline $\mathbf{4 . 8 2 6 - 5}$ & 6402.12 & 152.89 \\
\hline $\mathbf{6 - 6 . 3 5}$ & 11327.70 & 137.76 \\
\hline $\mathbf{7 - 7 . 9 3 7 5}$ & 19096.10 & 137.92 \\
\hline $\mathbf{9 - 9 . 5 2 5}$ & 29562.80 & 126.23 \\
\hline All & 16597.20 & 138.70 \\
\hline
\end{tabular}

Error histograms of the trained artificial neural networks suggests that there is a great agreement between the artificial neural network and the finite element analysis results. To illustrate, Figure 4.3 acquired from the finished ANN training process of the first bolt group (4.826-5) presents the comparison of target values, which are obtained by the finite element analyses and provided to the ANN, and the outputs, which are calculated by the trained network using the given target values. This comparison is conducted for the training, validation and test sets separately, as well as the overall database. 


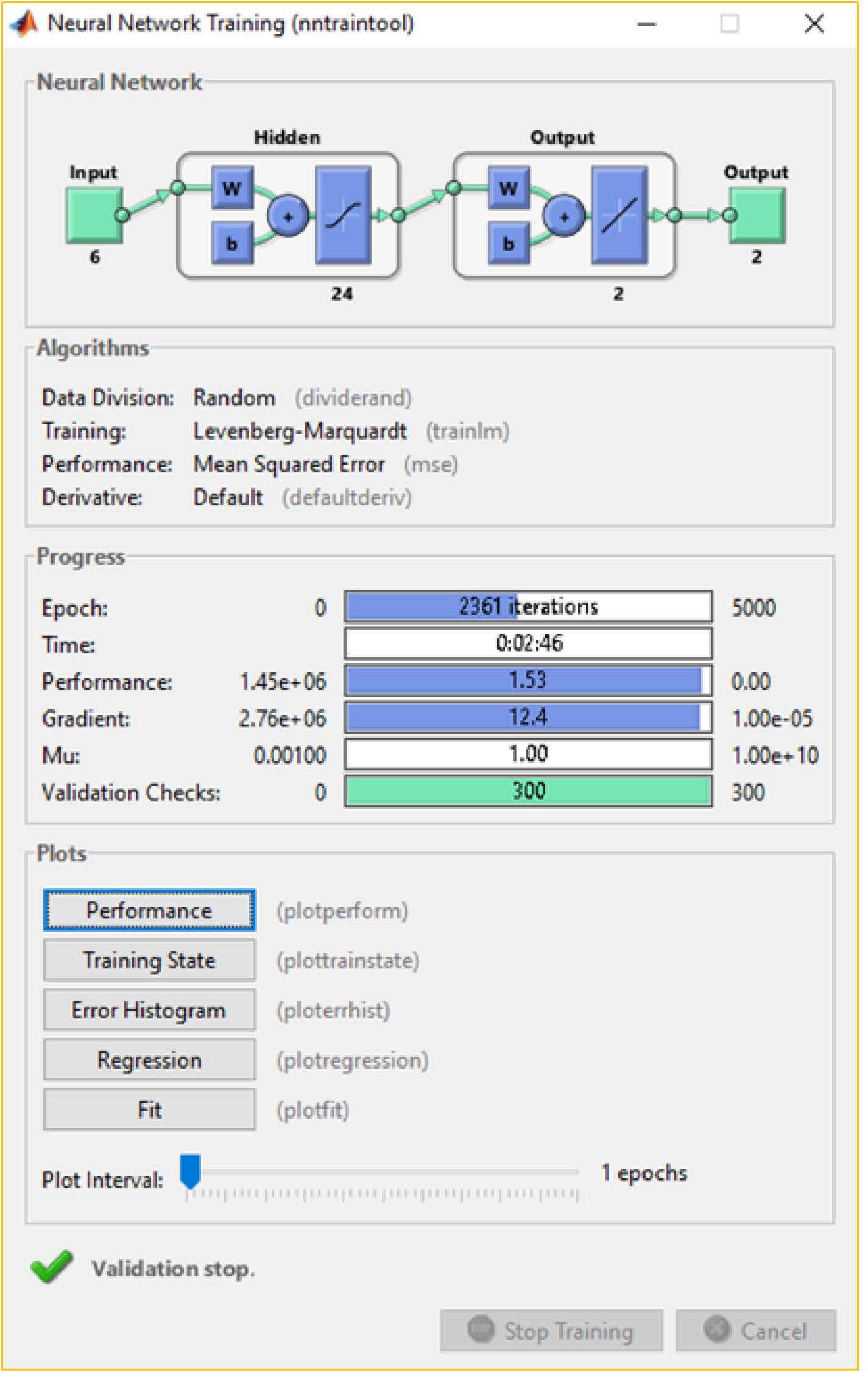

Figure 4.2: ANN training toolbox interface 


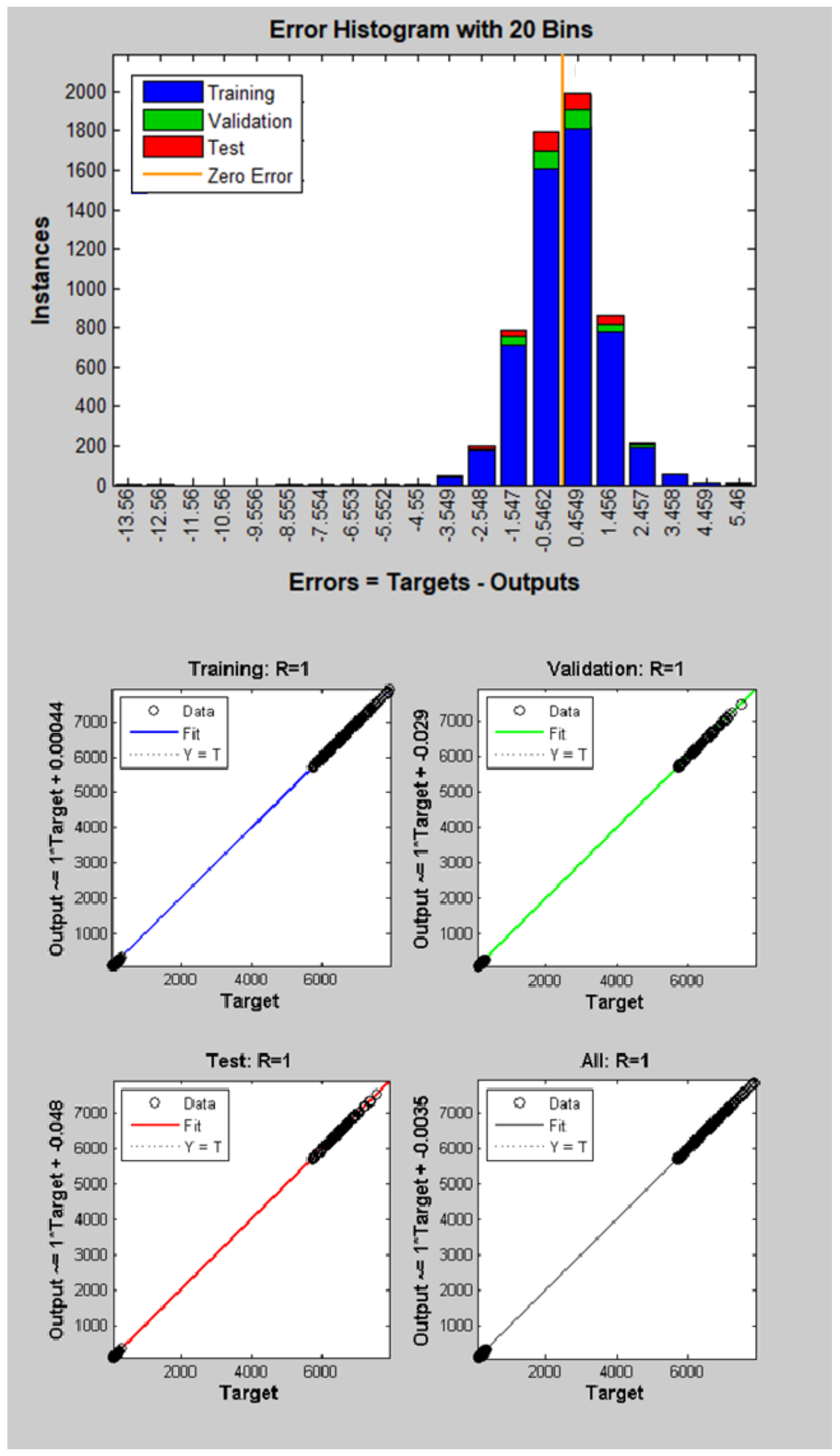

Figure 4.3: Error histogram comparing ANN and FEA results of the (4.826-5) bolt group 
The first part of the Figure 4.3 shows that for all the design points in the first bolt analysis group, the majority of the errors between the artificial neural network results, which are named as outputs, and finite element analysis results, which are named as targets, are near zero error line, while the maximum error is about 5.5. The second part shows the plots for target values with respect to the output values for the training, validation and test sets, as well as all data combined. For all separate and combined sets, it can be seen that target and output data points fit almost perfectly on the $x=y$ line where the output is equal to the target. The similar results are observed for the other bolt groups, as well.

\subsection{Comparison of Artificial Neural Network and Finite Element Analysis Results}

Mean square errors along with the error histogram charts suggest that there is a great agreement between the results computed by the artificial neural network and the results calculated with the finite element models, which are used in the training process of the artificial neural network. In order to justify the agreement between the results, an additional comparison is conducted between the results of the artificial neural network and finite element results. For the comparison, several design points are selected. The selection is done manually and randomly among the complete set of twelve thousand design points which are modeled with finite element method. Those selected design points and their related geometrical and load input variables are given in Table 4.2. In order to be able to show that the results agree for all the design points in the whole analysis set, the selection is made such that all the different input parameters are represented.

Table 4.3 presents the comparison of the ANN and finite element results for the design points given in Table 4.2. As can be seen in Table 4.3, the trained artificial neural network successfully calculates the bolt reaction force using the database created with finite element analysis results, and agrees with the FEA results with a maximum error of $0.041 \%$. Apart from the bolt reaction force, the artificial neural network accurately estimates the results for the average equivalent von-Mises flange stress with a maximum error of $0.858 \%$. 
Table 4.2: Random design points used in the training of the ANN

\begin{tabular}{|c|c|c|c|c|c|c|}
\hline $\begin{array}{c}\text { Design } \\
\text { Point }\end{array}$ & $\begin{array}{c}\text { Bolt } \\
\text { Size } \\
(\mathrm{mm})\end{array}$ & $\begin{array}{c}\text { \# of } \\
\text { Bolts } \\
(-)\end{array}$ & $\begin{array}{c}\text { Shaft } \\
\text { Thick. } \\
(\mathrm{mm})\end{array}$ & $\begin{array}{c}\text { Flange } \\
\text { Thick. } \\
(\mathrm{mm})\end{array}$ & $\begin{array}{c}\text { Bending } \\
\text { Moment } \\
(\mathrm{Nmm})\end{array}$ & $\begin{array}{c}\text { Preload } \\
(\mathrm{N})\end{array}$ \\
\hline DP1 & 4.83 & 20 & 2.10 & 3.60 & 3378554.88 & 6500.00 \\
\hline DP2 & 5.00 & 24 & 2.52 & 3.30 & 1689277.44 & 6100.00 \\
\hline DP3 & 5.00 & 30 & 2.52 & 2.70 & 3378554.88 & 6500.00 \\
\hline DP4 & 6.00 & 24 & 1.89 & 3.60 & 2252369.92 & 12300.00 \\
\hline DP5 & 6.35 & 20 & 1.89 & 3.60 & 3378554.88 & 10000.00 \\
\hline DP6 & 6.35 & 36 & 1.68 & 2.70 & 1689277.44 & 12300.00 \\
\hline DP7 & 7.00 & 36 & 1.89 & 3.30 & 1126184.96 & 19000.00 \\
\hline DP8 & 7.94 & 20 & 1.68 & 2.70 & 3378554.88 & 16000.00 \\
\hline DP9 & 9.00 & 36 & 1.89 & 2.40 & 2815462.40 & 27000.00 \\
\hline DP10 & 9.53 & 24 & 2.31 & 3.60 & 1689277.44 & 27000.00 \\
\hline
\end{tabular}

Table 4.3: Comparison of the ANN and the FEA results for the selected design points given in Table 4.2

\begin{tabular}{|c|c|c|c|c|c|c|}
\hline \multirow[b]{2}{*}{$\begin{array}{c}\text { Design } \\
\text { Point }\end{array}$} & \multicolumn{2}{|c|}{ ANN Results } & \multicolumn{2}{|c|}{ FEA Results } & \multirow[b]{2}{*}{$\begin{array}{c}\text { Bolt } \\
\text { Reaction } \\
\text { Force } \\
\text { Error } \\
\%\end{array}$} & \multirow[b]{2}{*}{$\begin{array}{c}\text { Flange } \\
\text { Stress } \\
\text { Error } \\
\%\end{array}$} \\
\hline & $\begin{array}{l}\text { Bolt } \\
\text { Reaction } \\
\text { Force } \\
(\mathrm{N})\end{array}$ & $\begin{array}{l}\text { Flange } \\
\text { Stress } \\
(\mathrm{MPa})\end{array}$ & $\begin{array}{l}\text { Bolt } \\
\text { Reaction } \\
\text { Force } \\
(\mathrm{N})\end{array}$ & $\begin{array}{l}\text { Flange } \\
\text { Stress } \\
(\mathrm{MPa})\end{array}$ & & \\
\hline DP1 & 7222.90 & 216.80 & 7222.20 & 216.70 & 0.01 & 0.05 \\
\hline DP2 & 6189.40 & 111.80 & 6189.30 & 111.40 & 0.00 & 0.44 \\
\hline DP3 & 6982.10 & 184.30 & 6984.30 & 184.80 & 0.03 & 0.26 \\
\hline DP4 & 12370.90 & 139.80 & 12371.20 & 140.70 & 0.00 & 0.67 \\
\hline DP5 & 10650.20 & 173.60 & 10652.80 & 173.20 & 0.03 & 0.20 \\
\hline DP6 & 12323.80 & 116.50 & 12321.90 & 116.30 & 0.02 & 0.16 \\
\hline DP7 & 18989.10 & 133.80 & 18990.90 & 133.50 & 0.01 & 0.19 \\
\hline DP8 & 16739.70 & 187.10 & 16746.50 & 185.50 & 0.04 & 0.86 \\
\hline DP9 & 27100.20 & 128.90 & 27099.90 & 129.70 & 0.00 & 0.61 \\
\hline DP10 & 27006.10 & 103.10 & 27005.20 & 103.30 & 0.00 & 0.19 \\
\hline
\end{tabular}

Although the trained network successfully calculates the results for the given design points, design tool has to be tested for intermediate design points . The reason for this 
additional work is to make sure that the trained network does not have an over-fitting problem, thus can be efficiently used for any intermediate design point. In order to conduct this comparison, 20 additional design points are created, each having random intermediate values for any geometrical or load input variables, except for the bolt size parameter as the bolt sizes are industrial standards and cannot have intermediate values. For the intermediate design points bolted flane connections are modeled and finite element analyses are performed. After the finite element analyses, the same geometrical and load values corresponding to the intermediate design points are given as input to the already trained artificial neural network. Table 4.4 gives the intermediate design points with random geometrical and load inputs.

Table 4.4: Input variables of intermediate design points

\begin{tabular}{|c|c|c|c|c|c|c|}
\hline $\begin{array}{c}\text { Design } \\
\text { Point }\end{array}$ & $\begin{array}{c}\text { Bolt } \\
\text { Size } \\
(\mathrm{mm})\end{array}$ & $\begin{array}{c}\text { \# of } \\
\text { Bolts } \\
(-)\end{array}$ & $\begin{array}{c}\text { Shaft } \\
\text { Thick. } \\
(\mathrm{mm})\end{array}$ & $\begin{array}{c}\text { Flange } \\
\text { Thick. } \\
(\mathrm{mm})\end{array}$ & $\begin{array}{c}\text { Bending } \\
\text { Moment } \\
(\mathrm{Nmm})\end{array}$ & $\begin{array}{c}\text { Preload } \\
(\mathrm{N})\end{array}$ \\
\hline DP1 & 4.83 & 21 & 2.16 & 2.50 & 1250000.00 & 6250.00 \\
\hline DP2 & 4.83 & 22 & 1.75 & 3.12 & 1980000.00 & 5800.00 \\
\hline DP3 & 4.83 & 26 & 1.90 & 2.30 & 2850000.00 & 6100.00 \\
\hline DP4 & 4.83 & 33 & 1.75 & 3.10 & 2385000.00 & 5820.00 \\
\hline DP5 & 5.00 & 32 & 1.80 & 3.45 & 1760000.00 & 5920.00 \\
\hline DP6 & 5.00 & 27 & 2.49 & 2.90 & 3160000.00 & 6370.00 \\
\hline DP7 & 6.00 & 34 & 2.35 & 2.84 & 1350000.00 & 12150.00 \\
\hline DP8 & 6.00 & 22 & 1.97 & 3.40 & 2645000.00 & 10850.00 \\
\hline DP9 & 6.35 & 29 & 2.49 & 2.81 & 3075000.00 & 12250.00 \\
\hline DP10 & 6.35 & 34 & 1.85 & 3.20 & 1368000.00 & 11700.00 \\
\hline DP11 & 6.35 & 31 & 1.93 & 3.50 & 2010000.00 & 10210.00 \\
\hline DP12 & 6.35 & 23 & 2.22 & 2.60 & 2746000.00 & 10950.00 \\
\hline DP13 & 7.00 & 22 & 1.79 & 3.12 & 1985000.00 & 16350.00 \\
\hline DP14 & 7.00 & 31 & 2.06 & 2.80 & 1325000.00 & 18500.00 \\
\hline DP15 & 7.94 & 34 & 2.36 & 2.55 & 2465000.00 & 17300.00 \\
\hline DP16 & 7.94 & 25 & 1.81 & 3.50 & 3260000.00 & 21600.00 \\
\hline DP17 & 9.00 & 22 & 2.38 & 3.25 & 1530000.00 & 30250.00 \\
\hline DP18 & 9.00 & 35 & 1.93 & 2.90 & 3054000.00 & 28500.00 \\
\hline DP19 & 9.53 & 32 & 1.80 & 3.55 & 1168000.00 & 29300.00 \\
\hline DP20 & 9.53 & 29 & 2.19 & 3.10 & 2048000.00 & 31000.00 \\
\hline & & & & & & \\
\hline
\end{tabular}


Table 4.5 shows the results of comparison between the artificial neural network and finite element analysis results for the given 20 additional intermediate design points given in Table 4.4. The correlation between both results shows that the trained neural network still successfully manages to calculate the bolt reaction force and the average equivalent von-Mises flange stress, although the intermediate design points are not among the initially given twelve thousand design points used in the training process of the ANN. It can be seen from the results that the trained artificial neural network estimates the bolt reaction force with a maximum error of $1.422 \%$ for the selected random intermediate design points, while it approximates the average flange stress with a maximum error of $3.009 \%$. Even though the maximum errors for both bolt reaction force and the average flange stress for the intermediate design points seem to be higher than the calculation errors for the design points represented in Table 4.2, they are still considered to be low enough, making the trained neural network a reliable design tool for the geometrical and load inputs variables in the determined input variable margin. Additionally, root mean square errors are calculated using the results given for the intermediate design points in Table 4.5, in order to be able have better understanding of the results. Considering the bolt reaction force, the root mean square error is calculated as $37.45 \mathrm{~N}$, and for the average flange stress, RMSE is determined as $1.31 \mathrm{MPa}$. These root mean square error values for the bolt reaction force and the average equivalent von-Mises flange stress are quite admissible, since the range of magnitudes of the bolt reaction force and the flange stress are considerably high compared to RMSE values. This, again, proves that the trained artificial neural network is an efficient tool of design for any input variable within the upper and lower bounds of the initially prescribed geometrical and load input variables.

Further studies comparing the artificial neural network and finite element analysis results showed that the error between the both results is inclined to increase when the input variables are selected outside the margins of initially determined input variables. Therefore, the trained artificial neural network should not be used as a design tool for the geometrical and load input variables selected beyond the limits of the design variable margins. In case an analysis is needed for such a case when the input variables are outside the given boundaries, a new database should be created 
with new input variable intervals containing the design point. After that, a new artificial neural network should be trained, and therefore a new design tool should be constructed.

Table 4.5: Comparison of the ANN and the FEA results for the intermediate design points given in Table 4.4

\begin{tabular}{|c|c|c|c|c|c|c|}
\hline \multirow[b]{2}{*}{$\begin{array}{c}\text { Design } \\
\text { Point }\end{array}$} & \multicolumn{2}{|c|}{ ANN Results } & \multicolumn{2}{|c|}{ FEA Results } & \multirow[b]{2}{*}{$\begin{array}{c}\text { Bolt } \\
\text { Reaction } \\
\text { Force } \\
\text { Error } \\
\%\end{array}$} & \multirow[b]{2}{*}{$\begin{array}{c}\text { Flange } \\
\text { Stress } \\
\text { Error } \\
\% \\
\end{array}$} \\
\hline & $\begin{array}{c}\text { Bolt } \\
\text { Reaction } \\
\text { Force } \\
(\mathrm{N})\end{array}$ & $\begin{array}{l}\text { Flange } \\
\text { Stress } \\
(\mathrm{MPa})\end{array}$ & $\begin{array}{c}\text { Bolt } \\
\text { Reaction } \\
\text { Force } \\
(\mathrm{N})\end{array}$ & $\begin{array}{l}\text { Flange } \\
\text { Stress } \\
(\mathrm{MPa})\end{array}$ & & \\
\hline DP1 & 6416.10 & 132.00 & 6336.60 & 131.30 & 1.25 & 0.50 \\
\hline DP2 & 5993.80 & 154.60 & 6056.10 & 155.30 & 1.03 & 0.47 \\
\hline DP3 & 6758.00 & 233.40 & 6759.70 & 234.40 & 0.02 & 0.43 \\
\hline DP4 & 5928.10 & 137.80 & 5996.30 & 139.10 & 1.14 & 0.92 \\
\hline DP5 & 5894.10 & 102.30 & 5979.10 & 103.20 & 1.42 & 0.91 \\
\hline DP6 & 6909.70 & 178.80 & 6838.40 & 177.90 & 1.04 & 0.55 \\
\hline DP7 & 12156.10 & 118.80 & 12151.60 & 118.70 & 0.04 & 0.10 \\
\hline DP8 & 11078.00 & 154.80 & 11074.10 & 154.30 & 0.04 & 0.33 \\
\hline DP9 & 12473.90 & 148.50 & 12481.00 & 146.40 & 0.06 & 1.44 \\
\hline DP10 & 11701.40 & 104.30 & 11702.00 & 104.90 & 0.01 & 0.59 \\
\hline DP11 & 10263.20 & 101.40 & 10264.10 & 101.20 & 0.01 & 0.19 \\
\hline DP12 & 11329.40 & 165.90 & 11325.10 & 165.30 & 0.04 & 0.37 \\
\hline DP13 & 16389.70 & 136.10 & 16409.00 & 136.20 & 0.12 & 0.03 \\
\hline DP14 & 18486.60 & 130.00 & 18499.10 & 131.20 & 0.07 & 0.93 \\
\hline DP15 & 17389.10 & 110.40 & 17393.40 & 109.10 & 0.03 & 1.19 \\
\hline DP16 & 21750.30 & 146.00 & 21742.40 & 145.10 & 0.04 & 0.65 \\
\hline DP17 & 30240.00 & 124.60 & 30237.60 & 128.50 & 0.01 & 3.01 \\
\hline DP18 & 28571.40 & 134.30 & 28572.90 & 133.00 & 0.01 & 1.01 \\
\hline DP19 & 29281.80 & 106.90 & 29292.50 & 108.40 & 0.04 & 1.46 \\
\hline DP20 & 31022.10 & 117.40 & 31028.80 & 118.00 & 0.02 & 0.51 \\
\hline
\end{tabular}




\subsection{The Graphical User Interface of the Bolted Flange Design Tool}

The ANN and FEA comparisons and results showed that the trained artificial neural network can be used as a verified, efficient bolted flange design tool. However, the use of the artificial network requires a licenced MATLAB software as well as the basic MATLAB user skills. In order to be able to convert the available neural network into a design tool that is more user-friendly and which requires little to no computer skills, a simple graphical user interface is created. With the help of the graphical user interface, the artificial neural network is turned into a standalone executable program that does not need any additional software to run and give results. The graphical user interface is created with the MATLAB software, using the Graphical User Interface (GUI) toolbox. Theuser interface simply requires the user to enter the desired design inputs in order to run them through the built-in artificial neural network and provide the results. The user is guided through the whole process. The input data is supplied to the program by writing into the corresponding input boxes and choosing from available drop-down menu. The lower and upper bounds of the geometrical and load inputs are given underneath the boxes to guide the user to remain in the design margins of the artificial neural network. After entering the input data, a simple run command enables the program to give the bolt reaction force and average equivalent von-Mises flange stress, corresponding to the supplied design point, as an output of the design tool. Figure 4.4 shows the graphical user interface created for the standalone bolted flange design tool program. 


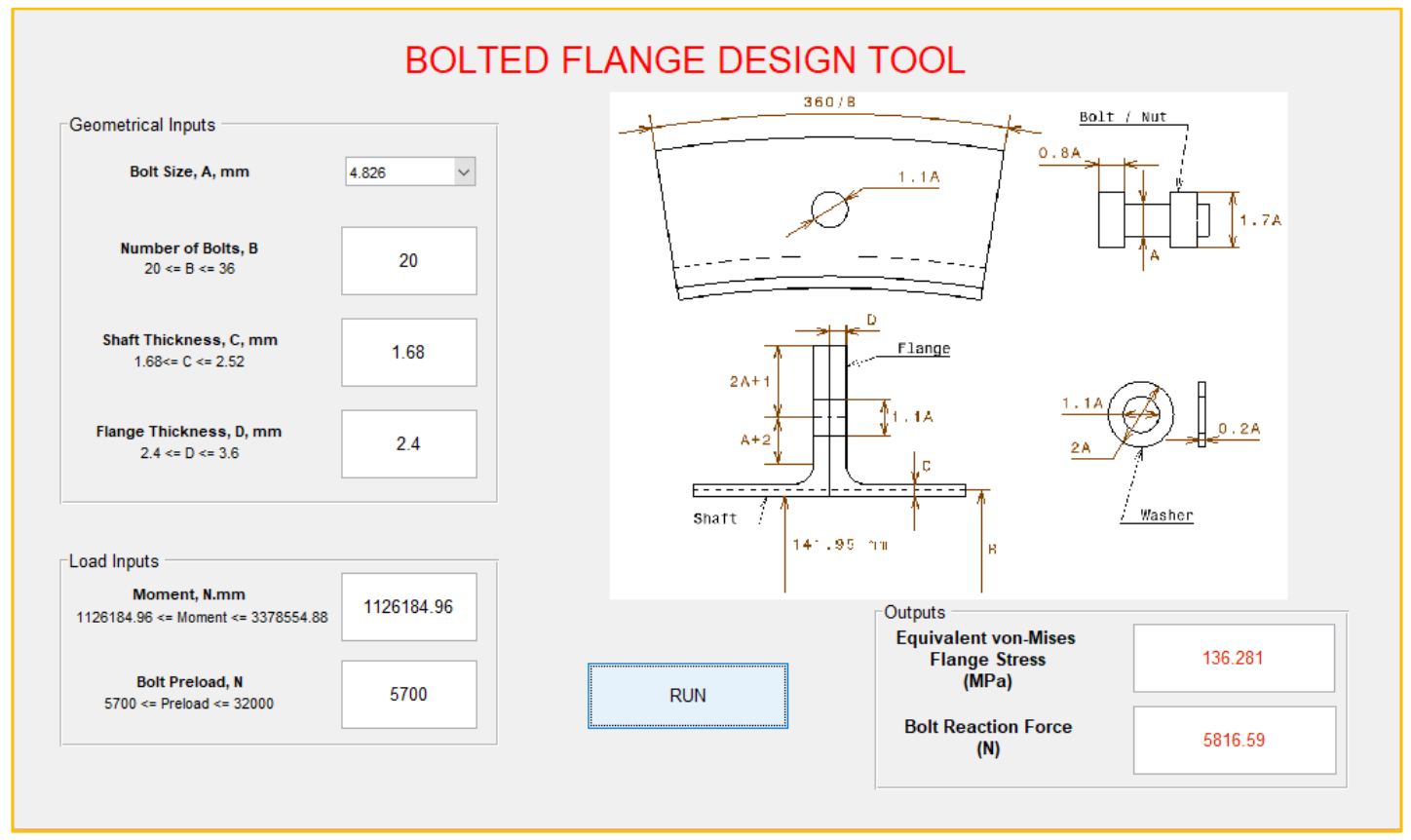

Figure 4.4: Graphical user interface of the bolted flange design tool 


\section{CHAPTER 5}

\section{CONCLUSION}

As one of the most used connection types in the aerospace industry, the analysis of the bolted flange connections is very important. The accuracy of the analysis is directly related to the integrity of the structure. An optimum analysis should supply the designer with enough information that is needed to keep the structure together as well as to make it as light as possible. Furthermore, the accurate connection analysis affects the efficiency of the load transfer between the mating part, thus affects the remaining structure, as well. Apart from the accuracy, an optimum structural analysis is also needed to be as fast as possible. Due to the fact that any design process usually requires many trials, if the response time of a single analysis process takes too much time, the total process is also affected, too. Current methods used in the industry often fails to meet both requirements. For example, as one of the most common analysis methods, the finite element method supplies very accurate results but it requires too much computational effort, while another common method, theoretical calculation, gives rather fast response with the handicap of inaccuracy. Therefore, it is needed to create a new analysis and design method combining both good aspects of the current methods, which requires less computational effort without sacrificing the accuracy of the results.

The current thesis study is on finding and developing a method for analyzing the bolted flange connection of a typical aircraft engine loaded with combined bending moment and axial loads. The proposed solution is to develop a bolted flange design tool for connections under combined loads which depends on an artificial neural network. The reason for the choice of artificial neural network is that it meets both requirements for the new design tool, which is fast and accurate in case repetitive analyses are needed. In order to train such neural network, a database is needed to be created. The database is formed by the results of series of finite element analysis 
conducted on the bolted flange geometry. In order to determine the suitable analysis geometry, some initial investigations are carried out. First, partial model assumption is made, and a segment model representing the full model is developed. Using the suitable boundary conditions and transforming the bending moment to an axial force acting on the segment model, it is proven that the segment model working under the carefully adjusted axial force can succesfully represent the full bolted flange connection model loaded with the bending moment. After that, another study comparing different application zones for the shear load is conducted. While this study showed the most suitable load zone for the shear force, it also drew attention to the effect of shear force on the bolt reaction force and the flange stress. After an additional study on the effect of the shear force on the outputs, it is seen that the shear load has almost no effect on the bolt reaction force and the flange stress, therefore it is eliminated. Following the finalization of analysis geometry, load and boundary conditions, mesh comparison study is conducted examining the effect of different mesh densities on the mesh quality, computational time and the output parameters. As a result of the comparison study, medium-fine mesh size is decided to be used. Total number of 12000 analyses are conducted on final analysis geometry in order to form a database for the training of the artificial neural network. The use of the partial model in forming the database significantly reduced the time needed for the creation of the database, and therefore the training of the artificial neural network. Using the database created, four artificial neural networks are trained, for bolt groups loaded with the same preload range. With the help of appropriate adjustments on the hidden layer and neuron numbers, very low root mean square errors are achieved for each group of bolts. The final product of the study, the artificial neural network, is proven to be effective in terms of the speed and the accuracy. In order to clarify the computational effort, while the full model of a bolted flange tool created for this study gives results within hours, due to the contact definitions and boundary conditions, and the partial model representing the full model, although it saves some time, takes minutes to compute results, the design tool based on the artificial neural network manages to give an answer to any design configuration almost instantly with the same accuracy of a complicated finite element model. 
It is decided that, in order to maintain the integrity of the bolted flange connection typically used in the aircraft engines, the bolt reaction and the average flange stress have to be monitored. Thus, the bolt reaction force and the average equivalent vonMises flange stress are taken as the outputs of the design tool developed.

Major conclusions drawn from this thesis study can be summarized as;

- Using suitable boundary conditions, it is possible to represent the full model of a bolted flange connection with a segment model. Approximate relation equation is reliable for the conversion of the bending moment to an axial force. It is possible to get the same results using a segment model loaded with an axial force, calculated with the approximate relation equation, instead of the full model loaded with the bending moment, in order to save computational effort.

- When the full model is loaded with only shear loads and the pretension loads, shear stress on the flanges are not affected by the friction coefficient between the both flange geometries; therefore the materials of the flanges. Only the pretension load affects the flange stresses in a linear fashion. On the other hand, the shear stress on the bolt geometries are only affected by the friction coefficient between the flanges, and not affected by the amplitude of the pretension load applied on them. It is seen that, when the pretension load is decreased, the shear stress on the bolt section increases in an exponential fashion.

- The artificial neural network is very successful in calculating the results based on the given database. It is proven that artificial neural network based design tool developed for a bolted flange connection, which is one of the most common type of connections encountered in an aircraft engine, is an effective analysis tool for a design process where many repeating analyses are needed. The ANN based tool can give instant results, while it almost takes an hour to compete a single analysis with the full model of the bolted flange connection, and the analysis of the segment model gives results within 10 to 15 minutes. 


\subsection{Future Work}

It is ascertained that such design tool can be used in the future process of optimization in order to keep the weight of the structure, which is one of the most critical elements in an aircraft, minimum without sacrificing the integrity. Later on, in order to make the results more realistic, the artificial neural network of such a design tool can be trained with a database formed by the outputs of series of structural tests. Also, the design tool can be improved such that it includes leakage control over the bolted flange connection. The usage of artificial neural network method can also be implemented to any structure in the future as it surpasses the weak sides of common analysis methods. 


\section{REFERENCES}

[1] Kumar, N., Brahamanandam, P. \& Papa Rao, B., 2011. 3-D Finite Element Analysis of Bolted Flange Joint of Pressure Vessel. MIT International Journal of Mechanical Engineering, 1(1), 35-40.

[2] Coro, A., 2004, "Flange-Designer : A New Flange Design Methodology Based on Finite Element Analysis", In International Ansys Conference. Retrieved from http://www.ansys.com/staticassets/ANSYS/staticassets/resourcelibrary/confpape r/2004-Int-ANSYS-Conf-107.PDF

[3] ASME, 2004, "2004 ASME Boiler and Pressure Vessel Code, Section VIII, Division I", New York: American Society of Mechanical Engineers.

[4] The Institution of Mechanical Engineers., 2012, “Analysis of pretensioned bolted joints subject to tensile (separating) forces”, (978 0856795275 ).

[5] Gomes, H. M., \& Awruch, A. M., 2004. Comparison of response surface and neural network with other methods for structural reliability analysis. Structural safety, 26(1), 49-67.

[6] Gosavi, A., 2003. Simulation Based Optimization., 57-92.

[7] Graupe, D. (2013). "Principles of Artificial Neural Networks (3rd Edition)". Singapore: World Scientific Publishing Company

[8] Muliana, A., Haj-Ali, R. M., Steward, R., \& Saxena, A. (2002). Artificial neural network and finite element modeling of nanoindentation tests. Metallurgical and Materials Transactions A, 33(7), 1939-1947.

[9] Budynas, R. G., Nisbett, J. K., 2008, “Shigley’s Mechanical Engineering Design (8th ed.)", New York, NY: McGraw-Hill, Chap. 8.

[10] Schaaf, M., Bartonicek, J., 2003, "Calculation of Bolted Flange Connections of Floating and Metal-To-Metal Contact Type”, Proceedings of PVP2003. 
[11] Azim, R., 2013, "An Analytical Investigation On Bolt Tension Of A Flanged Steel Pipe Joint Subjected to Bending Moments", International Journal of Engineering and Applied Sciences, 2(3), 71-81.

[12] Couchaux, M., Ryan, I., Hijaj, M., Alain, B., 2011, Bolted circular flange connections: bending and axial static resistances, Proceedings of EUROSTEEL August 31-September 2, 2011, Budapest, Hungary.

[13] Couchaux, M., 2010. Behaviour of bolted circular flange joints, $\mathrm{PhD}$ Thesis, INSA of Rennes, (in French).

[14] Stamatopoulos, G.N. Int J Steel Struct (2014) 14: 255. https://doi.org/10.1007/s13296-014-2006-0

[15] Tafheem, Z., Amanat, K., 2011. Investigation on bolt tension of a flanged pipe joint subjected to bending, 4th Annual Paper Meet and 1st Civil Engineering Congress, At IEB, Dhaka, Bangladesh.

[16] Fei, Y., Pengdong, G., Yongquan, L., 2016, "Bolt force prediction using simplified finite element model and back propagation neural networks", Proceedings of 2016 IEEE Information Technology, Networking, Electronic and Automation Control Conference, ITNEC 2016, 7560415, pp. 520-523.

[17] Y1ld1rım, A., 2015. Development of bolted flange design tool based on finite element analysis and artificial neural network. Yayınlanmış yüksek lisans tezi, Orta Doğu Teknik Üniversitesi Fen Bilimleri Enstitüsü, Ankara, Türkiye.

[18] Yıldırım,A., Akay, AA., Gülaşık H., Çoker D., Gürses, E, Kayran, A., Development of bolted flange design tool based on finite element analysis and artificial neural network, Proceedings of the ASME 2015 International Mechanical Engineering Congress \& Exposition IMECE2015 November 13-19, 2015, Houston, Texas.

[19] ANSYS Workbench Version: 15.0.0, 2013

[20] MATLAB Version: 7.14.0.739, 2012 
[21] "Reference Tables - Coefficient of Friction", 2015, April 4. Retrieved from http://www.engineershandbook.com/Tables/frictioncoefficients.htm

[22] Akay, A. A., Gülaşık, H., Yıldırım, A., Çöker, D., Kayran, A. \& Gürses, E., 2015. Modelling of a circular double flange joint including contact and friction effects. 8. Ankara Uluslararası Havac1l1k ve Uzay Konferans1, Ankara, Türkiye 


\section{APPENDIX A}

\section{JUSTIFICATION OF EQUATION FOR AXIAL FORCE DUE TO MOMENT}

This section shows the justification of the Equation 2.1, given in the Section 2.2. For simplification, the formula is derived on shaft section with 8-bolt configuration.

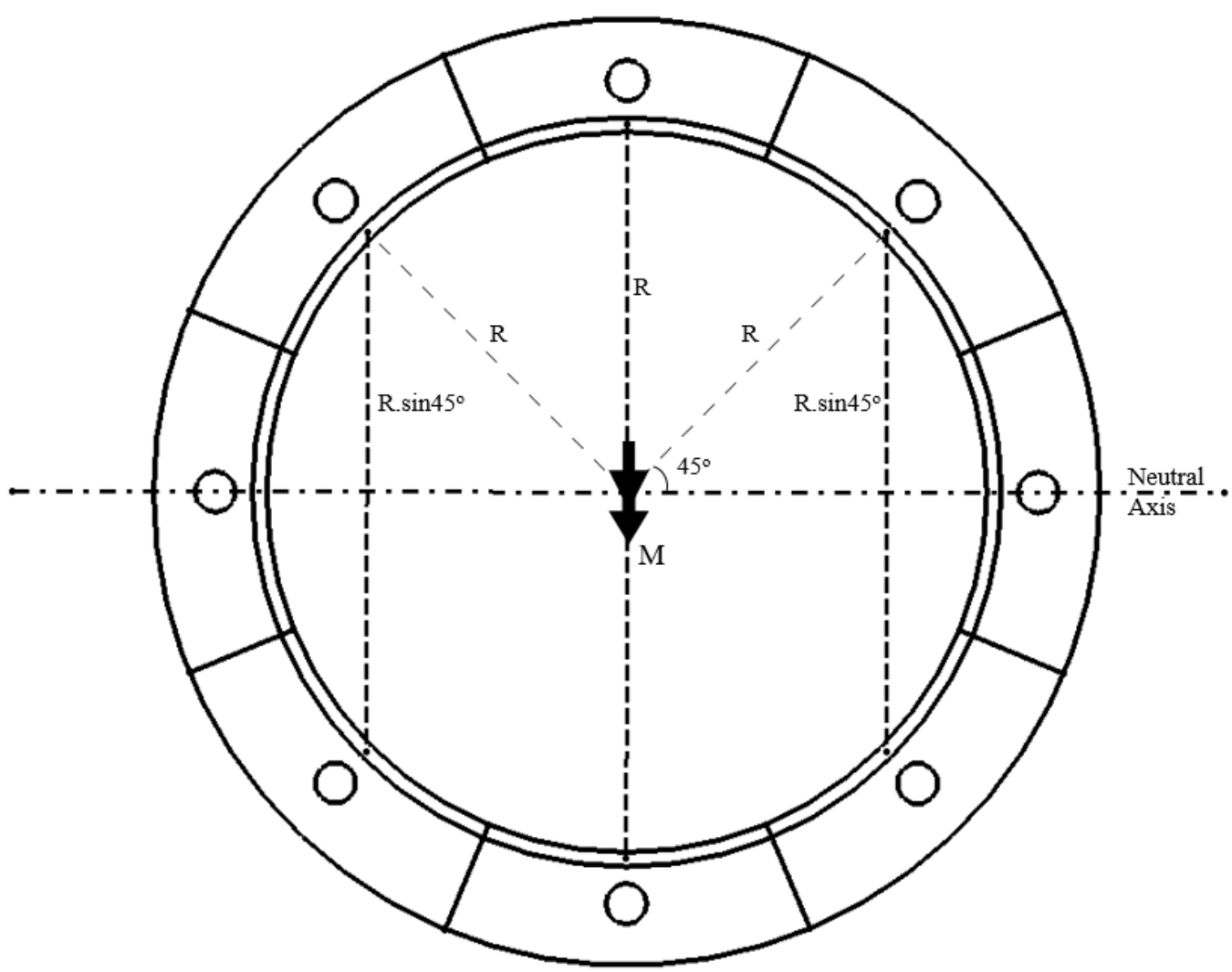

Figure A.1: Shaft section with 8-bolt configuration

The shaft is divided into 8 equal sections containing one bolt. For the top section, where the moment creates maximum tensile load, the axial stress is calculated with Equation A.1 and A.2, where $\mathrm{M}$ is the acting bending moment, $\mathrm{y}$ is the distance of 
the center of gravity from the neutral axis, I is the moment of inertia, A is the crosssectional area of each equal section and $d$ is the distance of center of gravity of each section from the neutral axis.

$$
\sigma_{\text {axial }}=\frac{M y}{I} ; \quad I=\sum A d^{2}
$$

The same tensile stress is also equal to the stress caused by the axial force due to the applied bending moment, which is calculated with Equation A.3.

$$
\sigma_{\text {axial }}=\frac{F_{\text {axial }}}{A}
$$

Equating both stress formulas for the top section where $\mathrm{y}$ is equal to $\mathrm{R}$, and inserting the moment of inertia calculation into the equation gives us;

$$
\begin{gathered}
\frac{F_{\text {axial }}}{A}=\frac{M R}{I} \\
F_{\text {axial }}=\frac{M R A}{2 A R^{2}+4 A R^{2} \sin ^{2} 45+2 x 0} \\
F_{\text {axial }}=\frac{M R A}{A R^{2}\left(2+4 x \frac{1}{2}\right)} \\
F_{\text {axial }}=\frac{M}{4 R} \\
F_{\text {axial }}=\frac{2 M}{N R}
\end{gathered}
$$

where $\mathrm{N}$ is the total number of bolts and the $\mathrm{R}$ is the average radius of the axial cross-sectional surface of the shaft. 


\section{APPENDIX B}

\section{ARTIFICIAL NEURAL NETWORK TRAINING CODE}

This section shows the code compiled for the training of one of the artificial neural networks. This code assumes that the inputs and outputs are gather in two separate Excel sheets, named 'A1_MOMENT.xlsx' and 'B1.xlsx', in order to train 'net1'. The trained artificial neural network, 'netl', is then saved under the name 'ANN1.mat' for future use.

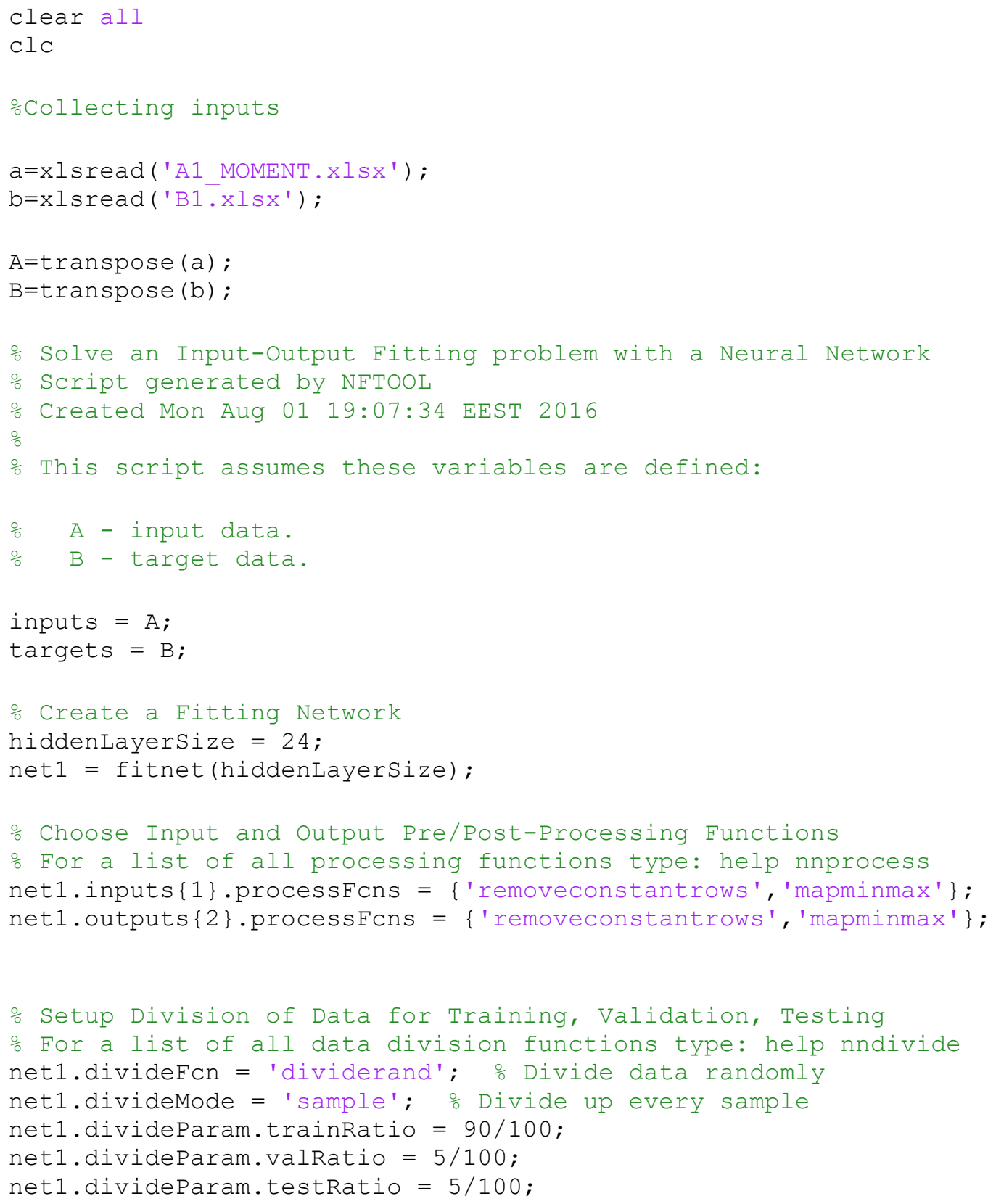


\% For help on training function 'trainlm' type: help trainlm \% For a list of all training functions type: help nntrain net1.trainFcn = 'trainlm'; $\frac{\circ}{\circ}$ Levenberg-Marquardt

\% Choose a Performance Function

\% For a list of all performance functions type: help nnperformance net 1 .performFcn = 'mse'; 응 Mean squared error

net1.trainParam.max fail = 300;

net1.trainParam.epochs $=5000$;

o net.trainParam.time = inf;

\% net.trainParam.lr $=0.01$;

\% net.trainParam.min grad $=1.0000 e-010 ;$

\% net.trainParam.mu $\overline{\text { dec }}=0.1000$;

onet.trainParam.mu inc $=10$;

\% Choose Plot Functions

\% For a list of all plot functions type: help nnplot net1.plotFcns $=$ \{'plotperform', 'plottrainstate', 'ploterrhist', ... 'plotregression', 'plotfit'\};

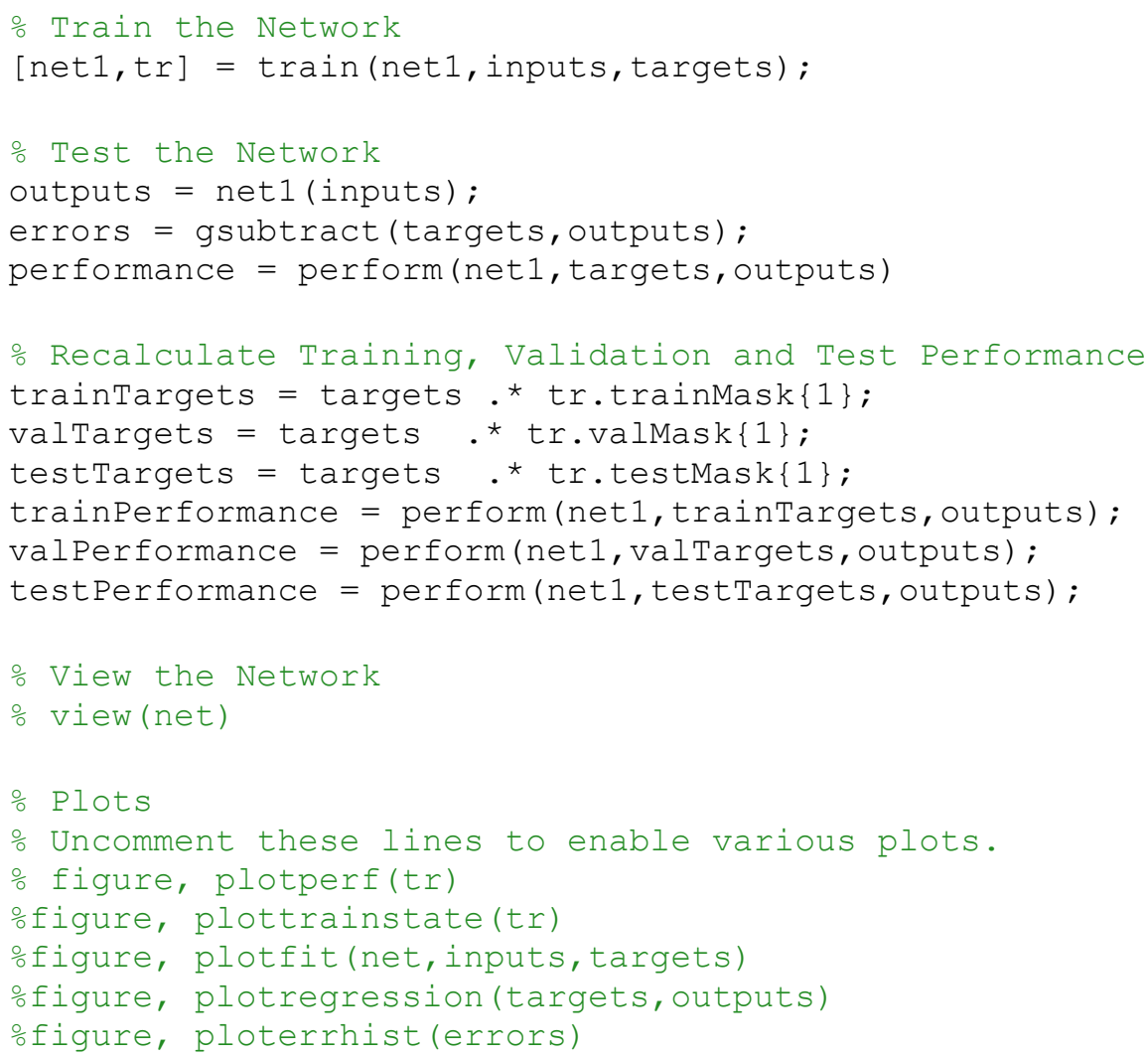




\section{APPENDIX C \\ CREATING THE GRAPHICAL USER INTERFACE}

This section describes the process of creating the graphical user interface for the developed bolted flange connection design tool.

The graphical user interface is created using the GUI toolbox of the MATLAB software. In order to create an empty graphical user interface 'guide' command is run in the MATLAB Command Window in order to access 'GUIDE Quick Start' window. In the new window, 'Blank GUI' option is selected under the 'Create New GUI' tab, as can be seen in Figure C.1, which creates an empty '*.fig' file where the main lay-out of the GUI is created as required, by dragging and dropping the elements, such as push button, listbox or pop-up menu. The empty '*.fig' file and the elements which can be used are shown in Figure C.2.

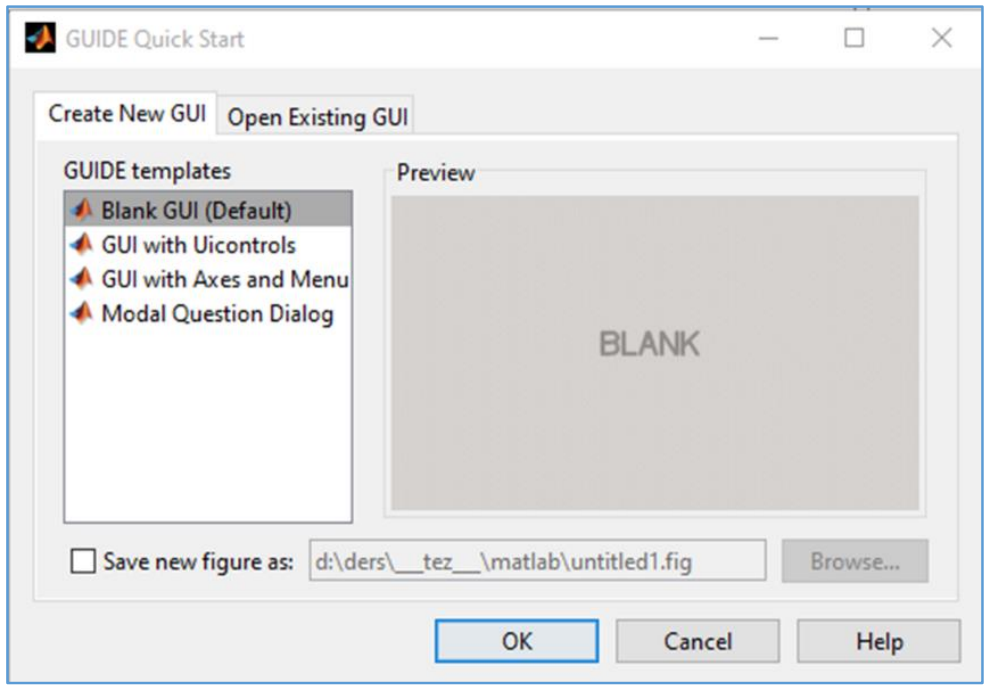

Figure C.1: GUIDE Quick Start window 


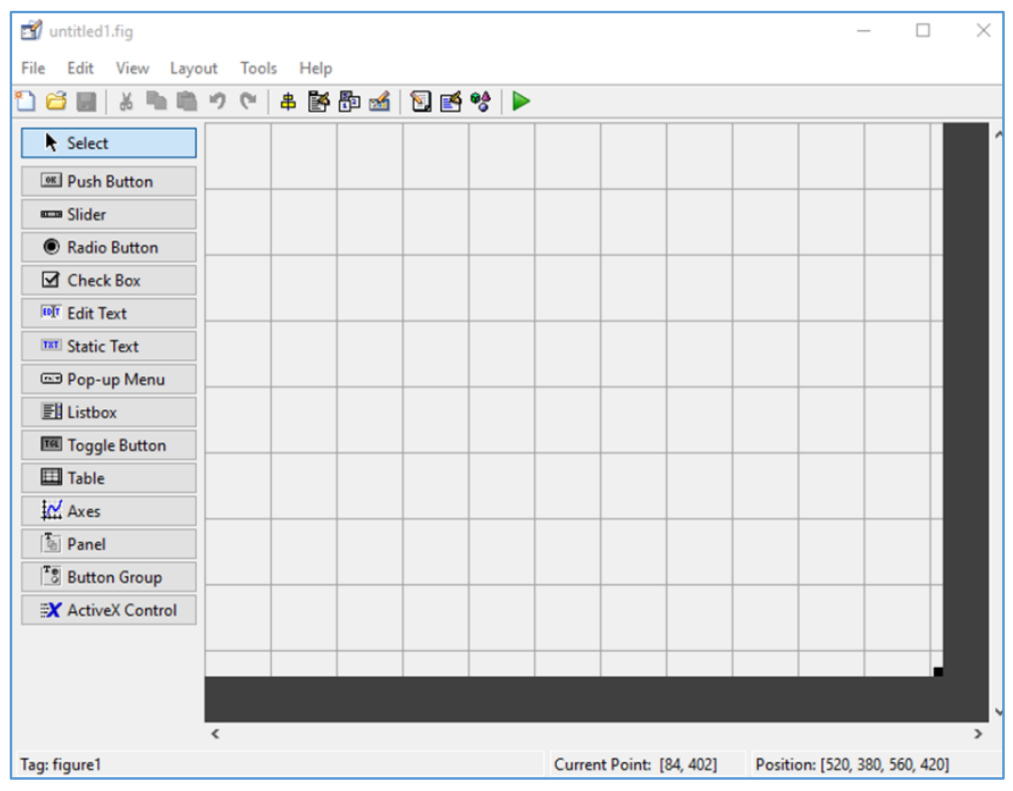

Figure C.2: Empty fig file and the main GUI elements

The contents of the added elements are edited through the string line in the property inspector window which is activated by double-clicking the elements. The property inspector window also enables the user to change the visual settings of the element. Figure C. 3 shows the property inspector window.

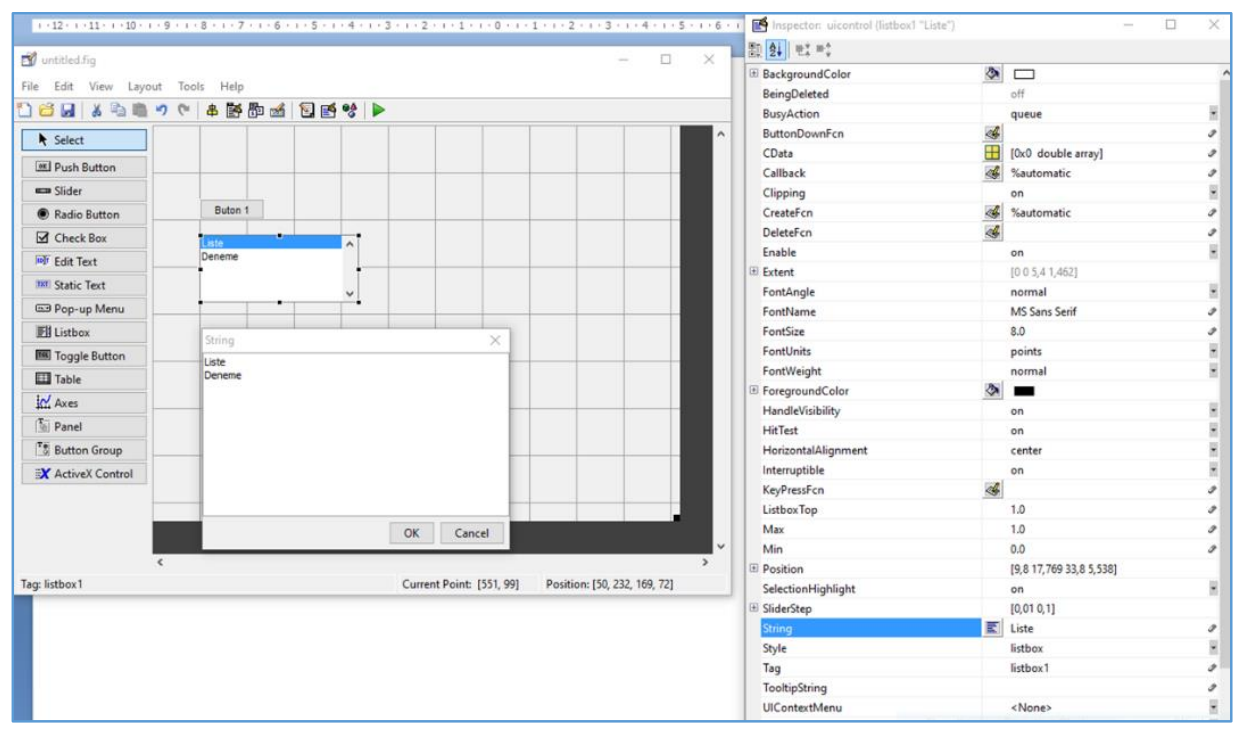

Figure C.3: Property inspector window of an element 
After the main lay-out of the graphical user interface is created, the '*.fig' file is run in order to display the graphical user interface and create an '*.m' file for the GUI. The sample graphical user interface with various elements is shown in Figure C.4.

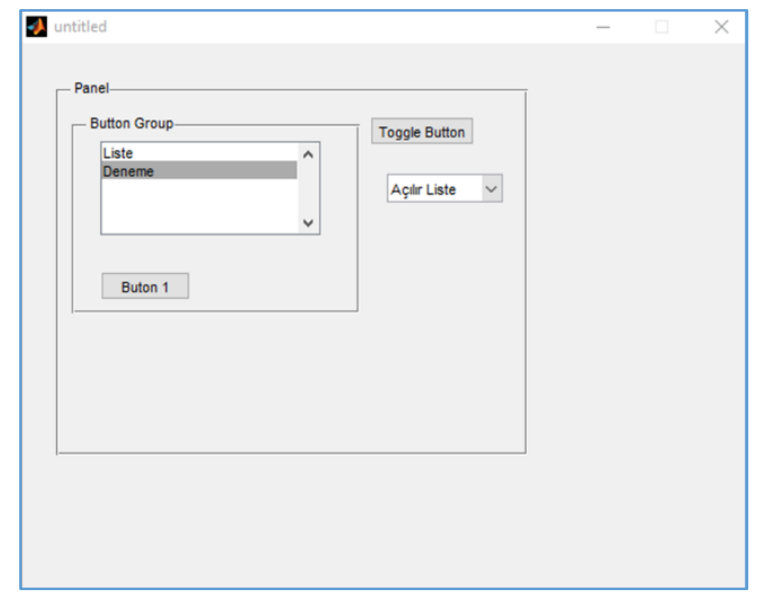

Figure C.4: Sample graphical user interface

Within the created '*.m' file, sub-functions, called callback function, exist for each element added to the lay-out. The function of each element is assigned through these callback functions. Figure C.5 shows empty callback functions for some of the elements added to the interface.

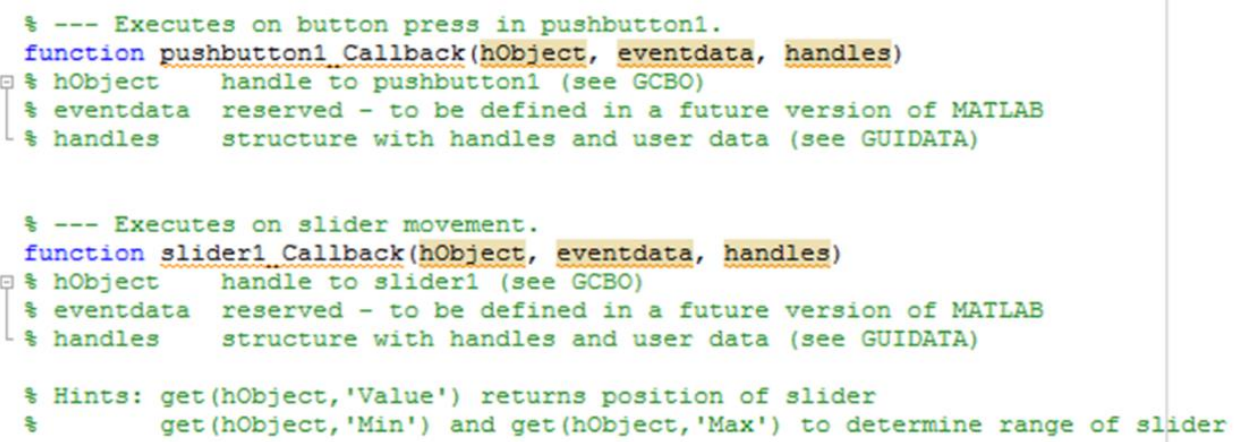

Figure C.5: Empty callback function samples 
The preliminary graphical user interface for the developed bolted flange design tool is shown if Figure C.6. The elements which are used to enter the input text is called edittext element. The callback function of the edittext box is edited as below in order to store the input data for future use in the execution step.

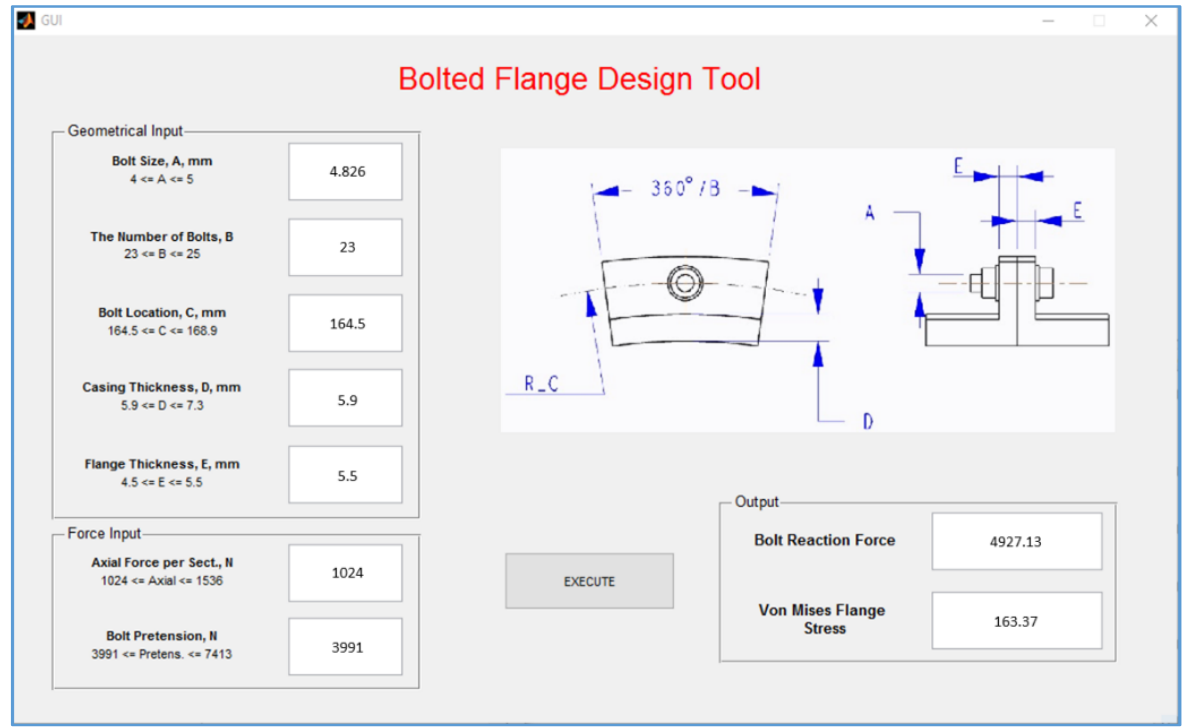

Figure C.6: Preliminary GUI for bolted flange design tool

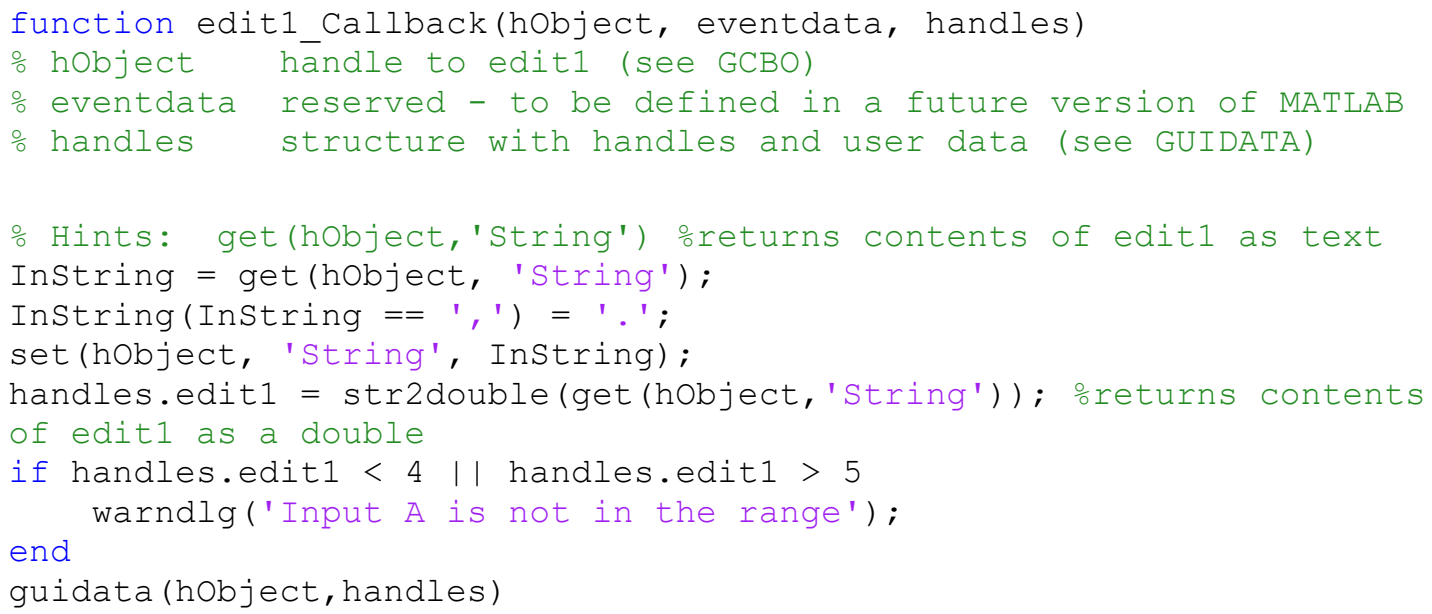

In this sub-function, first, ',' is changed to '.', in case it is entered in the text box, for MATLAB to recognize the input as number. After that, input text (hObject) is stored 
under handles as edit1. At the end, a warning message is added in order to warn the user when the input is out of the input parameter margin.

Explanatory figure is added to the GUI with axes element, and the opening subfunction of the '*.m' file of the GUI is edited such that it loads the figure from corresponding file location.

The input parameter texts entered in the corresponding text boxes are processed through trained neural network with a pushbutton element. The callback function of the pushbutton element is edited as shown in Figure C.7. In this sub-function, trained neural networks, saved as'*.mat' (See Appendix B) file is loaded. Stored input parameters are called and run through the loaded neural network. The outputs of the neural network are stored separately and displayed in the corresponding text boxes.

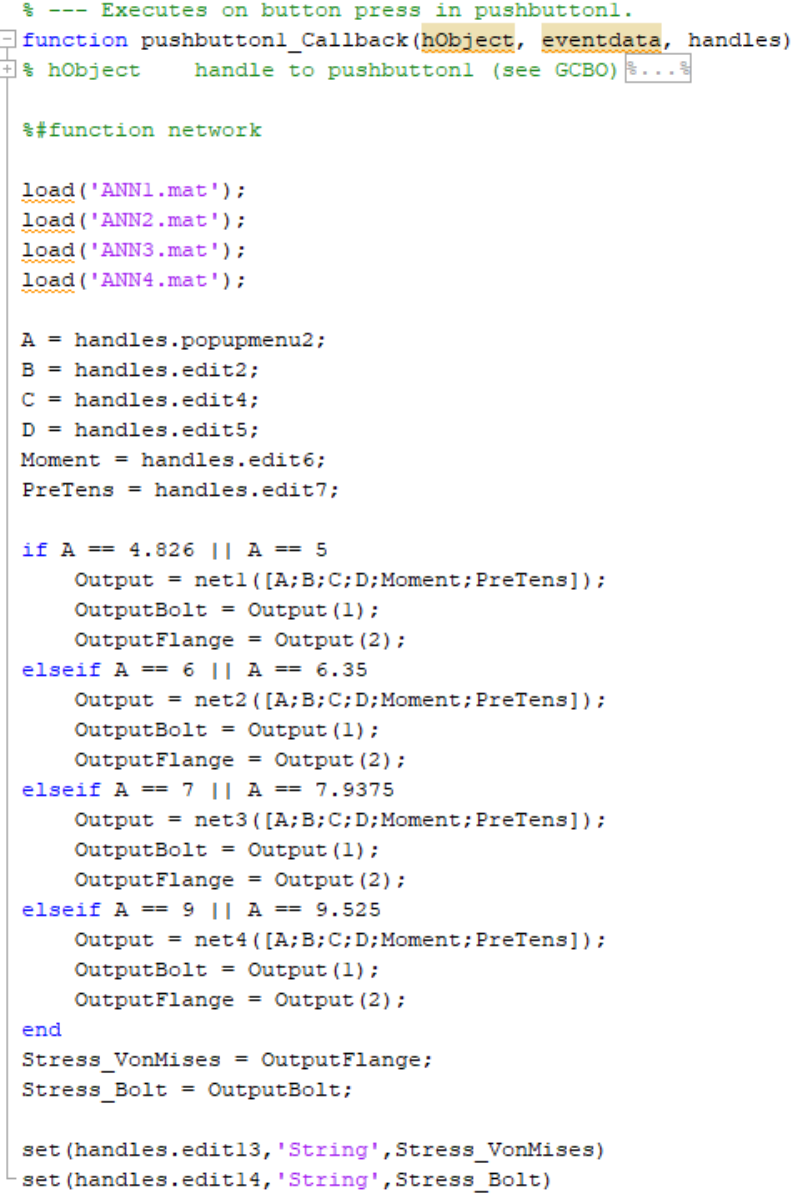

Figure C.7: Execute pushbutton callback function 


\section{APPENDIX D}

\section{BOLTED FLANGE DESIGN TOOL GRAPHICAL USER INTERFACE MAIN CODE}

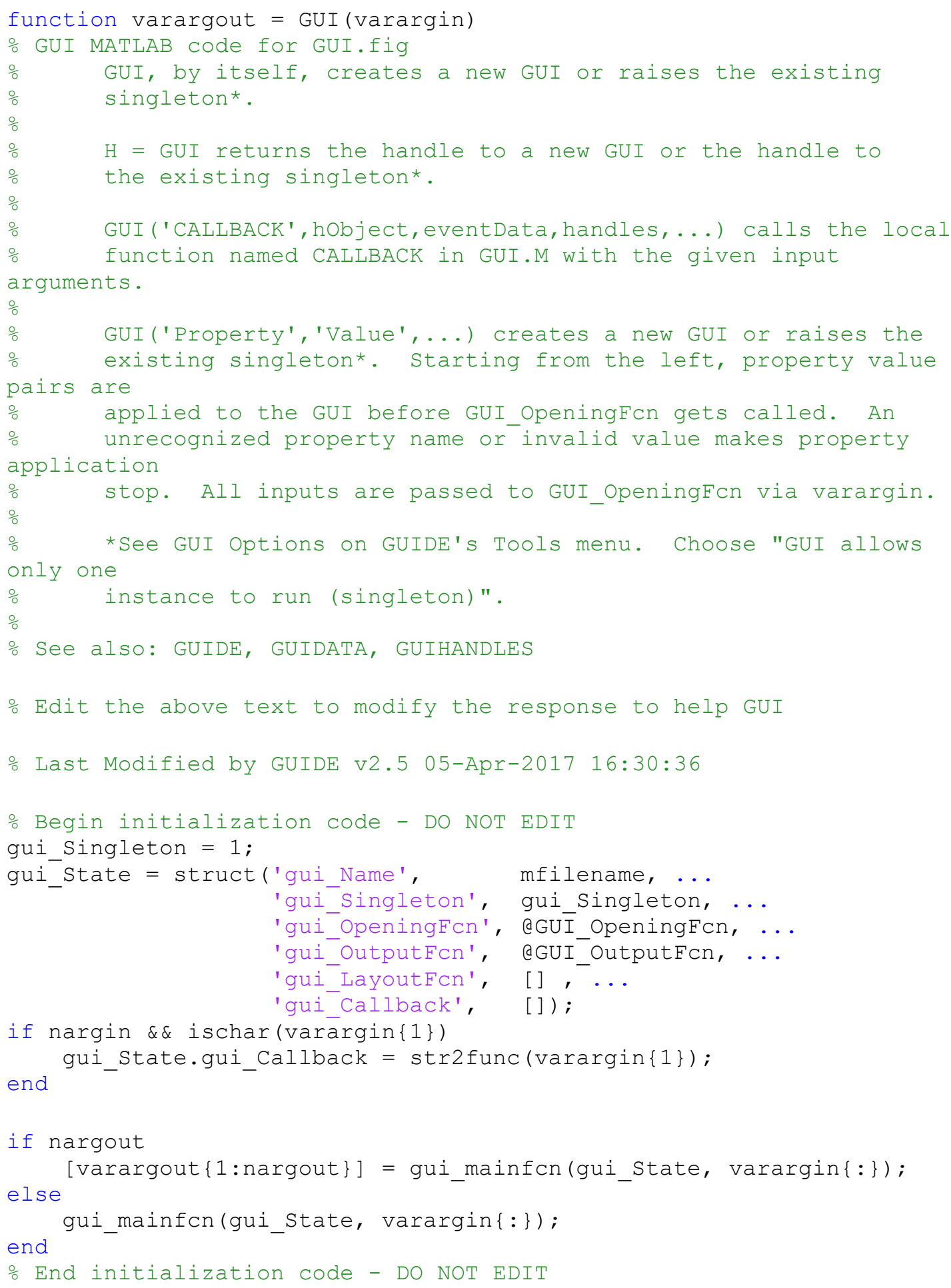




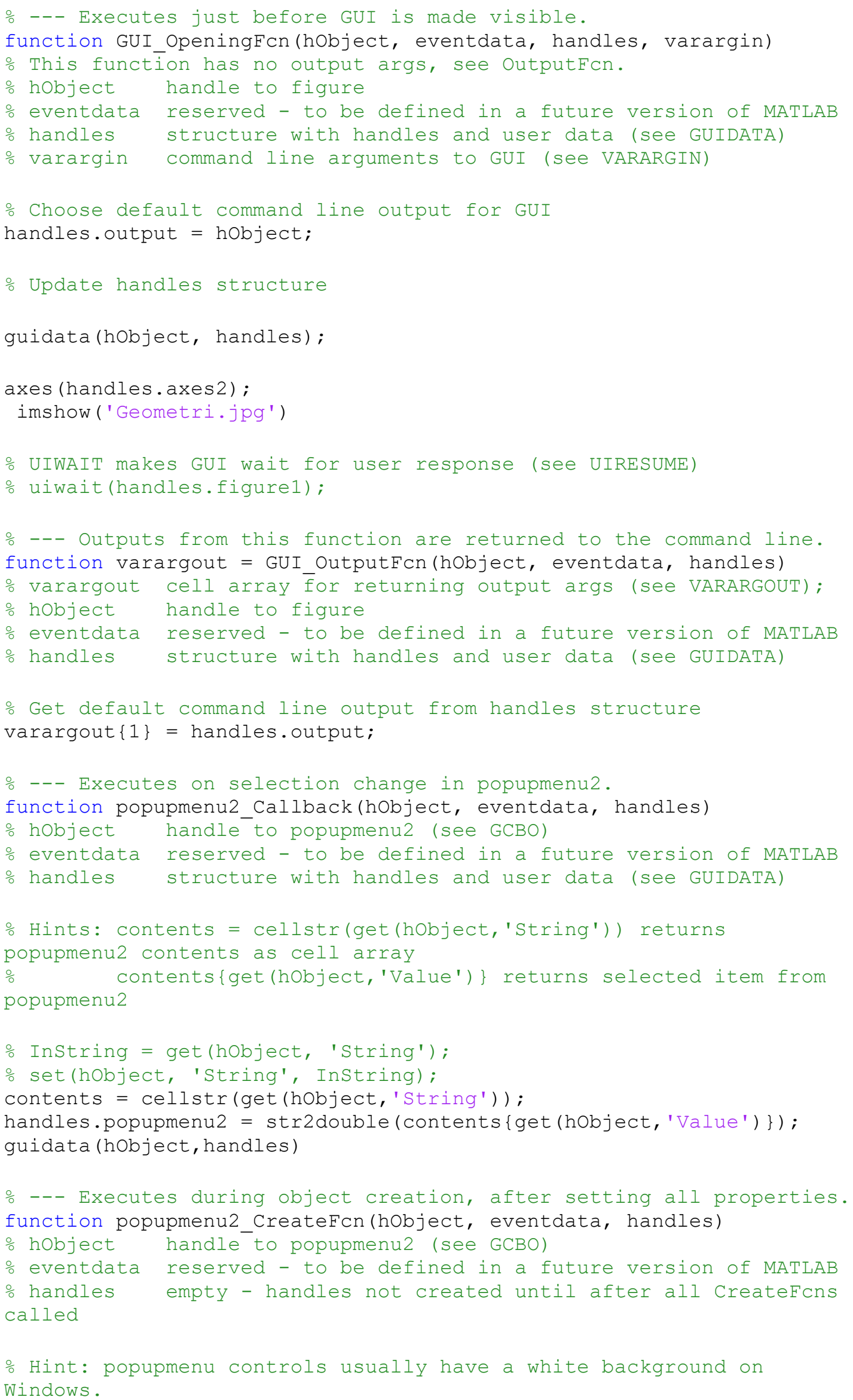




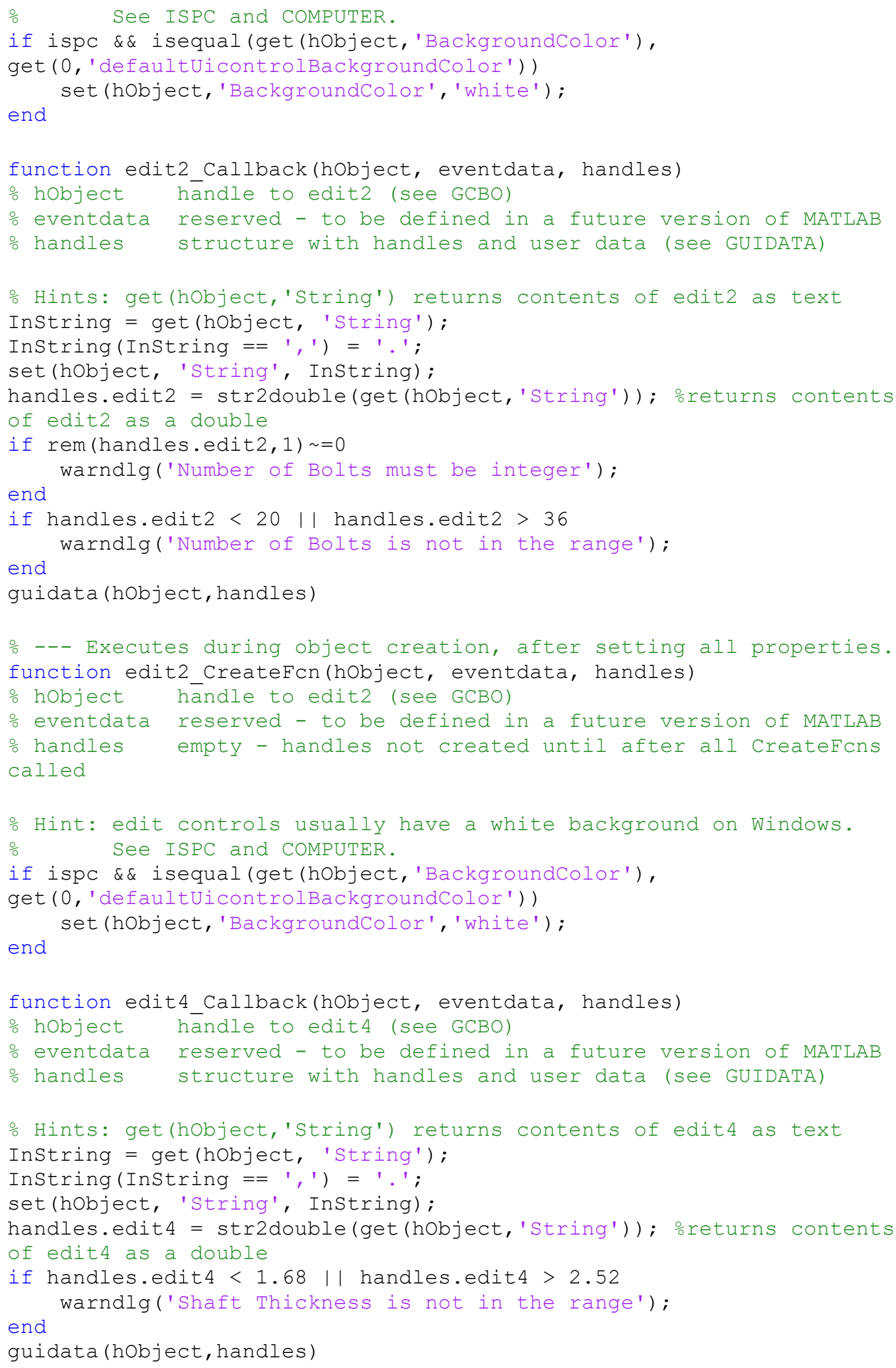




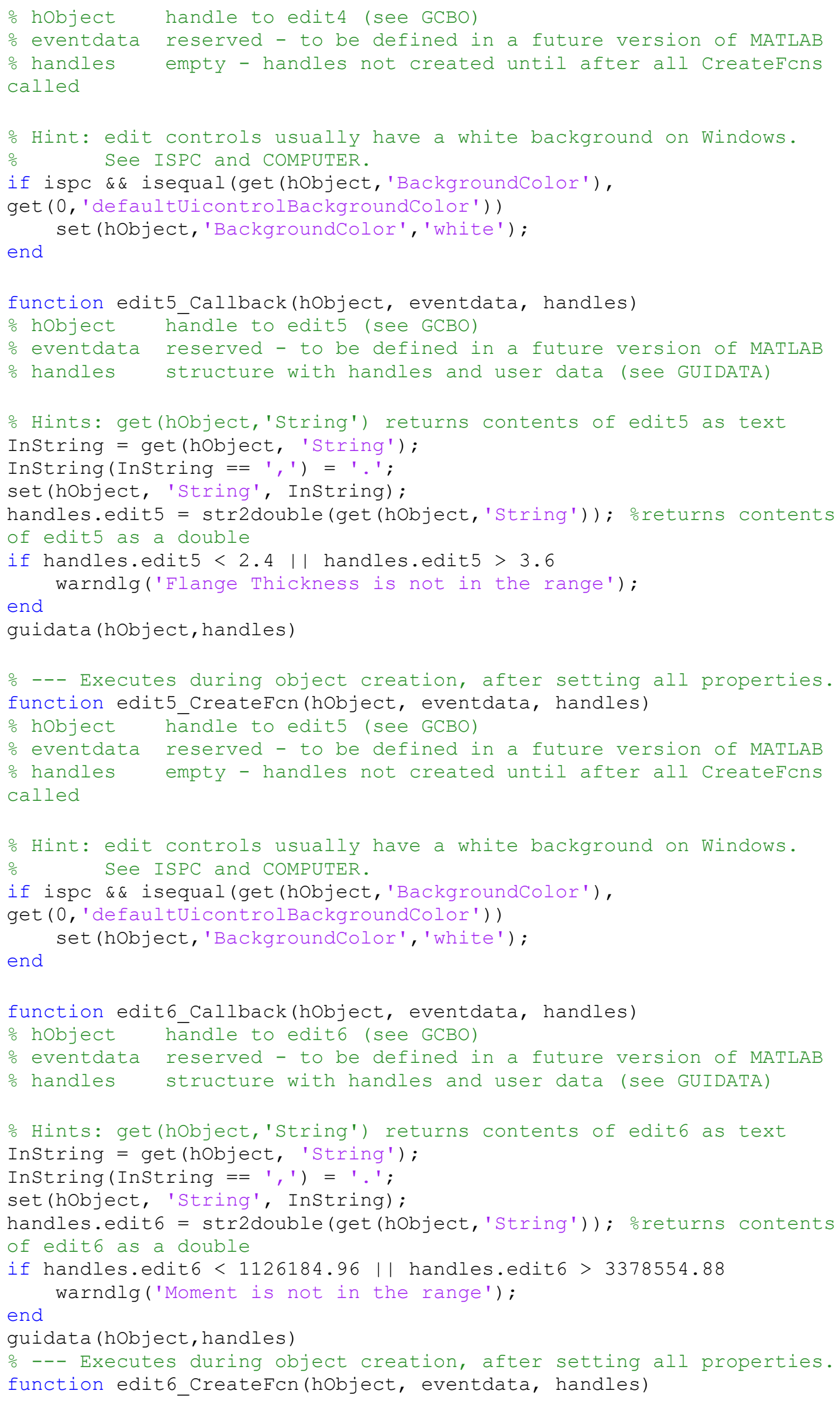




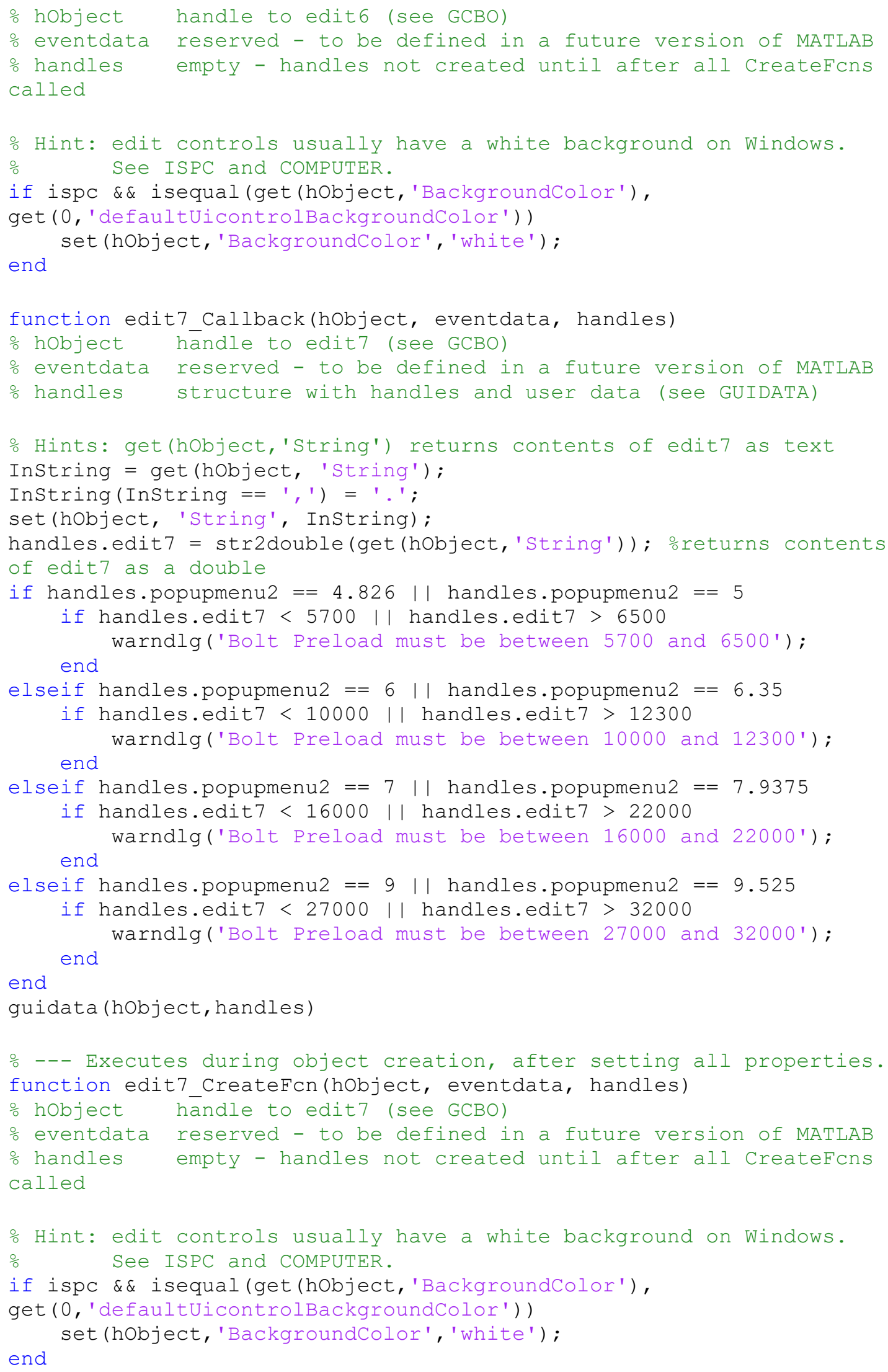




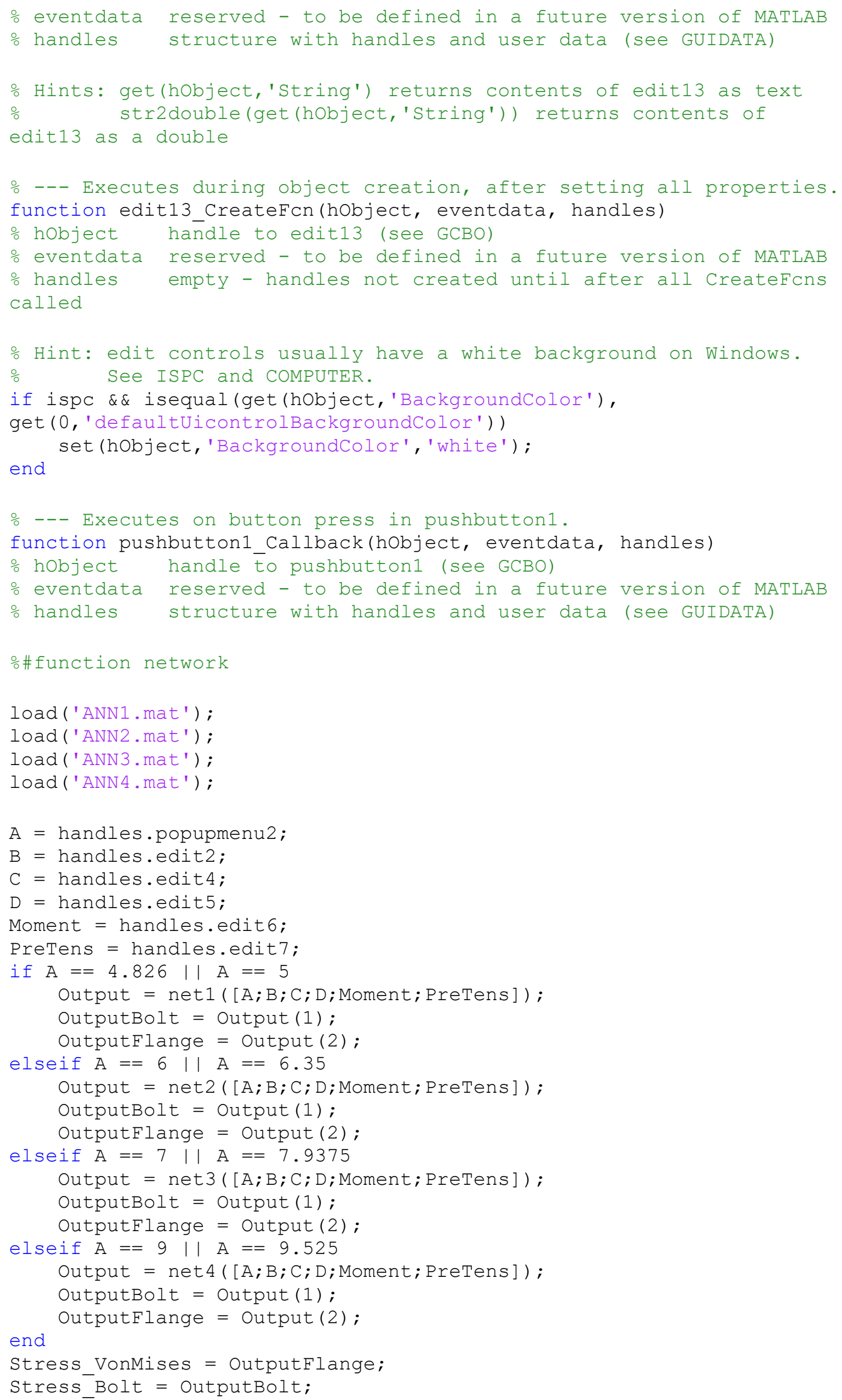




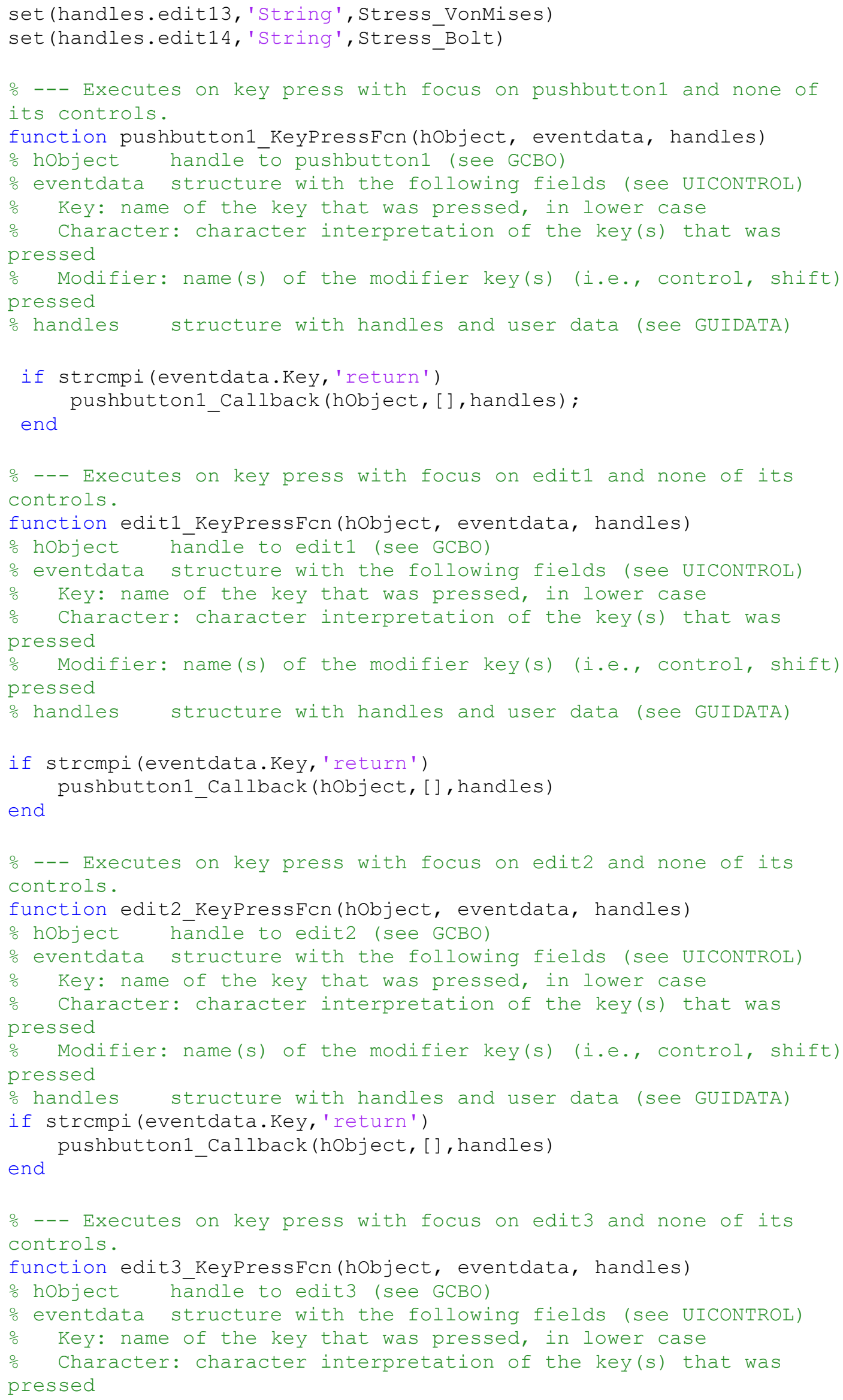




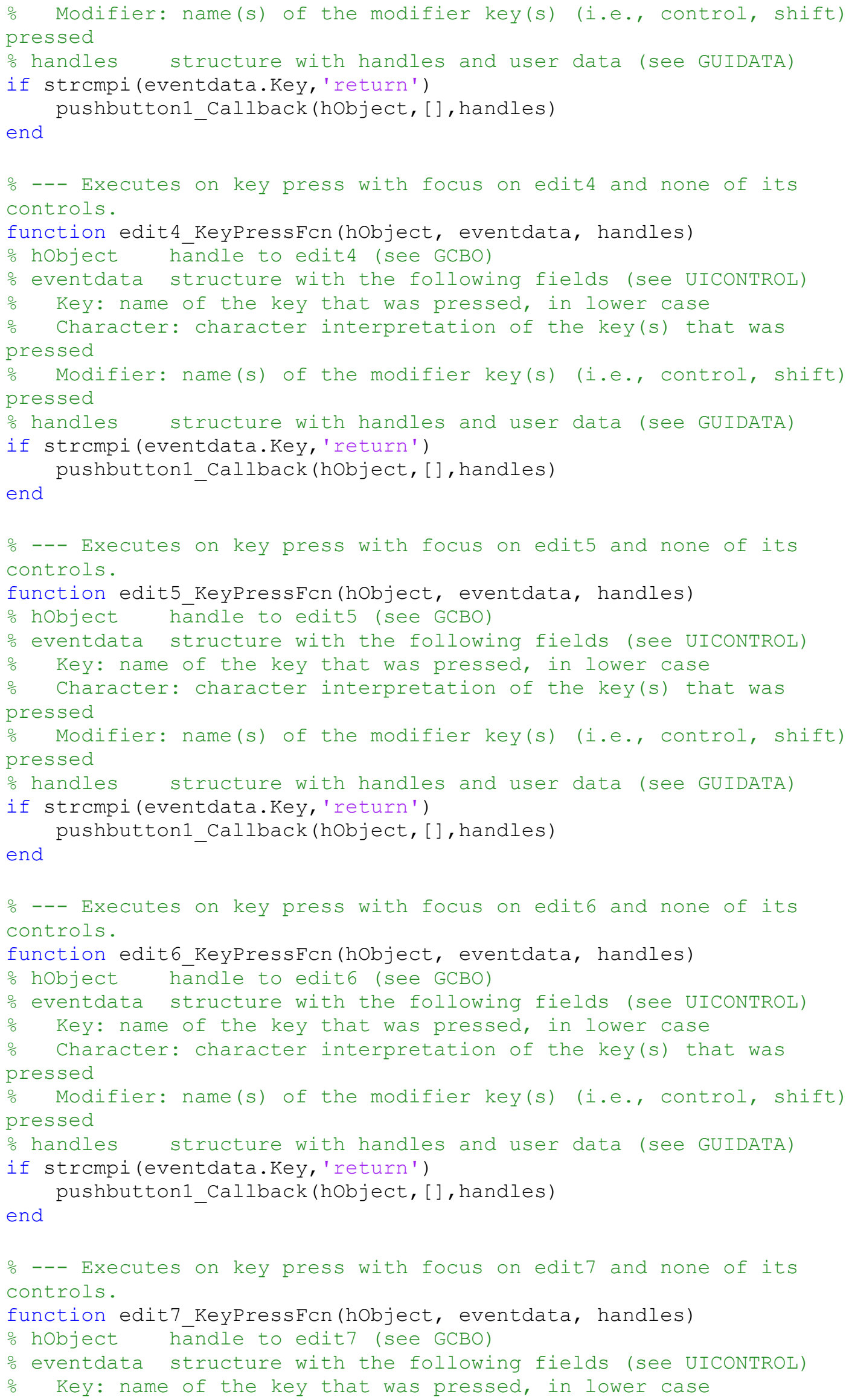




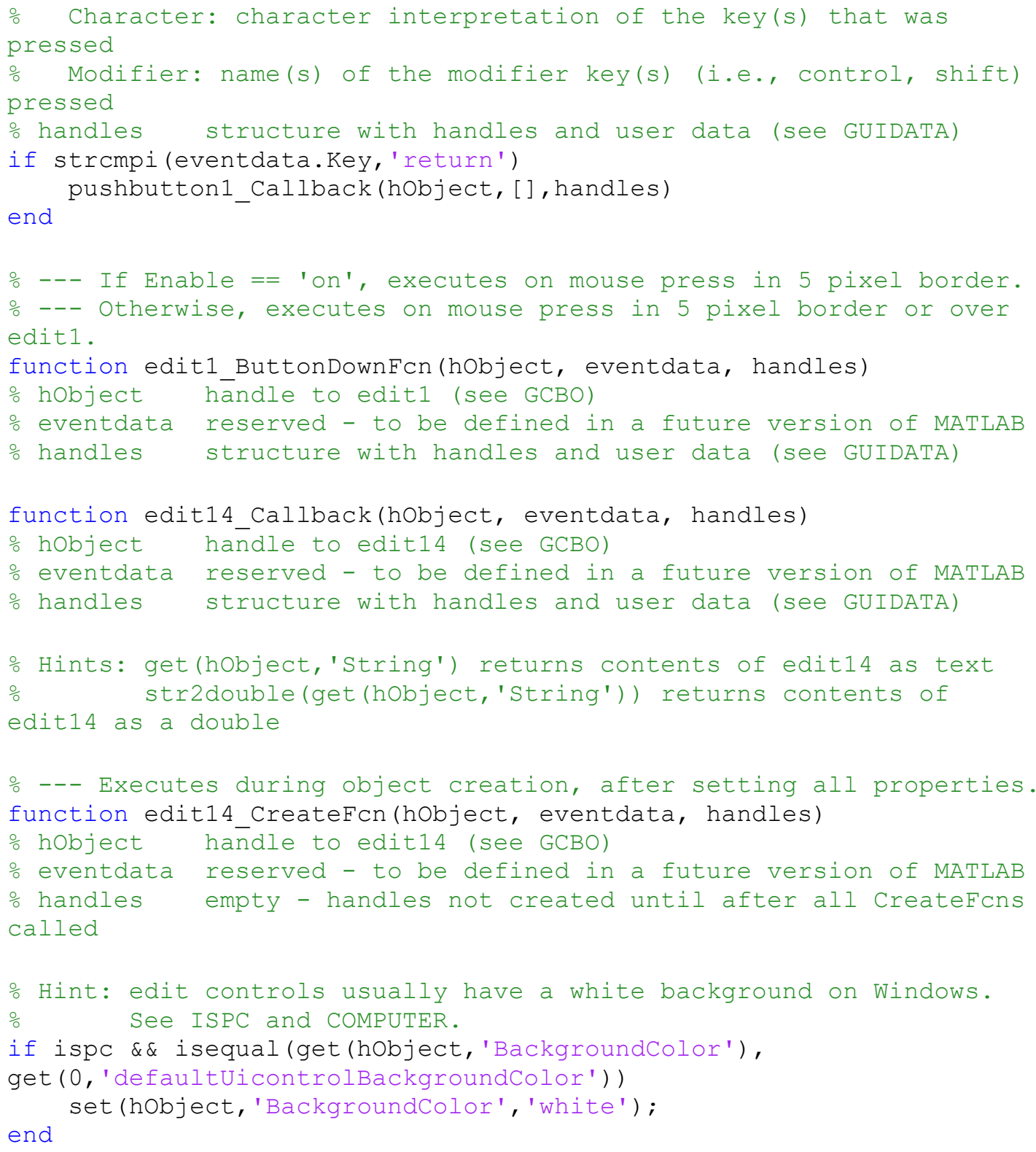




\section{APPENDIX E}

\section{BOLTED FLANGE DESIGN TOOL GRAPHICAL USER INTERFACE USER MANUEL}

This section describes the usage of the graphical user interface for the developed bolted flange connection design tool.

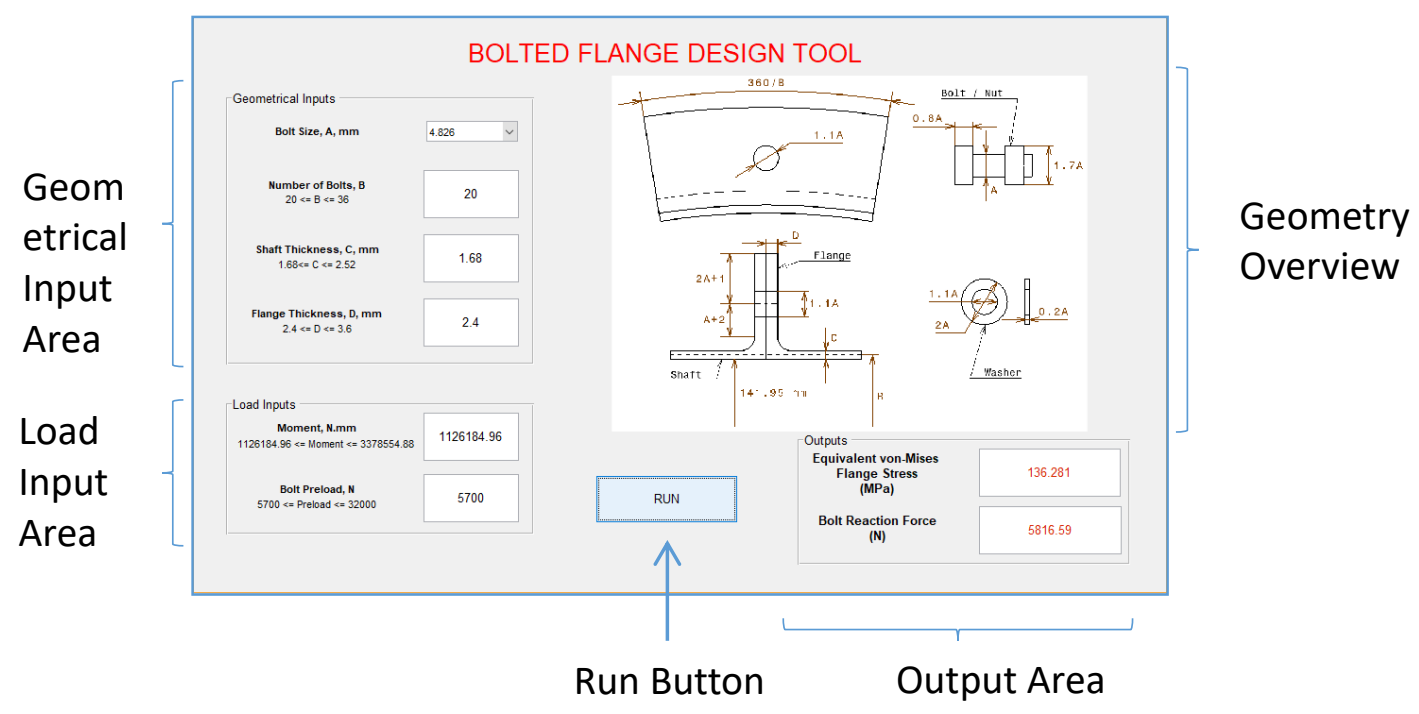

Figure E.1: Graphical user interface sections

- Input values are written in the input area

- Hitting "RUN" button or simply pressing "ENTER" runs the program

- Outputs are displayed in the output area

- If any input is needed to be changed, writing new value and pressing "ENTER" runs the program with new value 


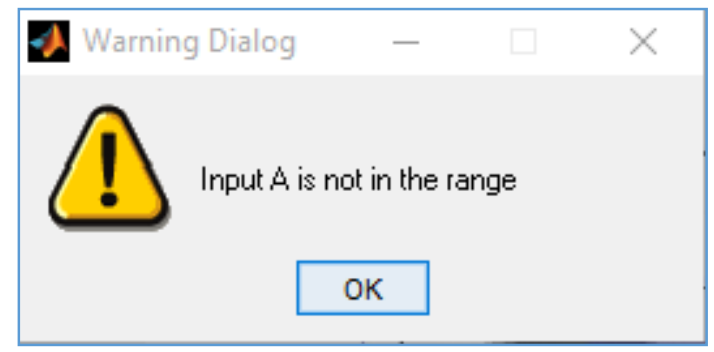

Figure E.2: Range warning dialog box

- If any input written is outside the corresponding range, a warning dialog box is displayed.

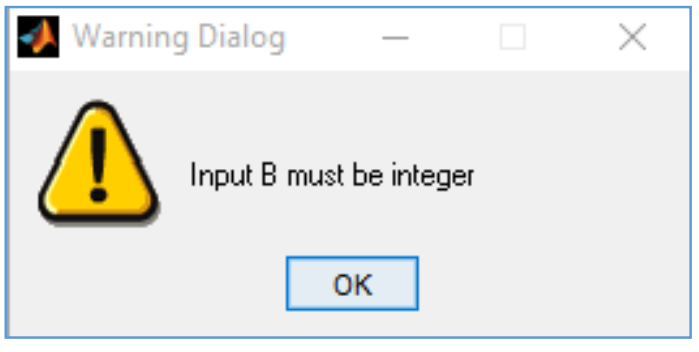

Figure E.3: Integer warning dialog box

- If input B is not integer, a warning dialog box is displayed. 


\section{APPENDIX F \\ THEORETICAL BOLT STRESS CALCULATION CODE - ESDU}

This section describes the code segment used for calculating the theoretical bolt stress based on the source, ESDU 85021.

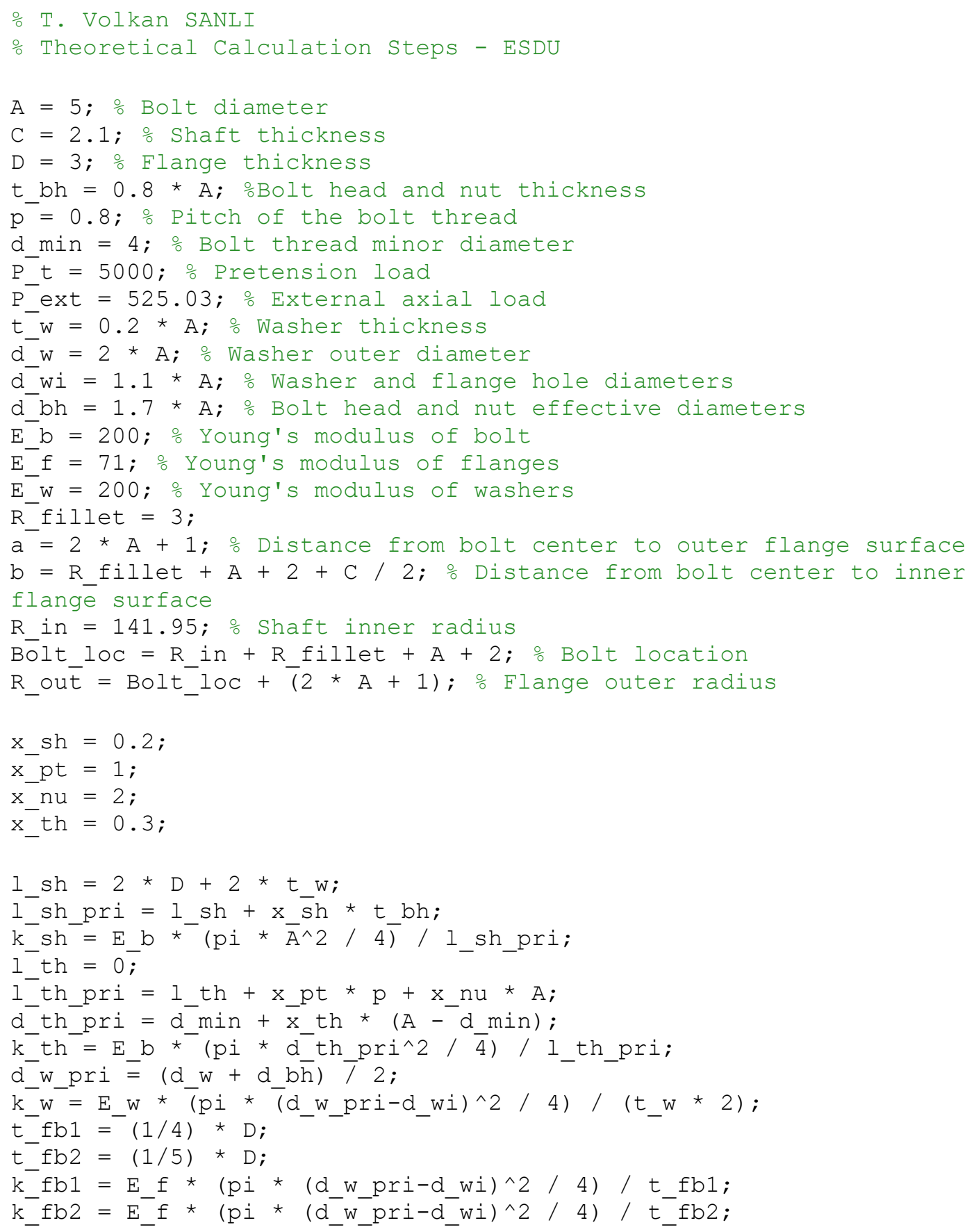




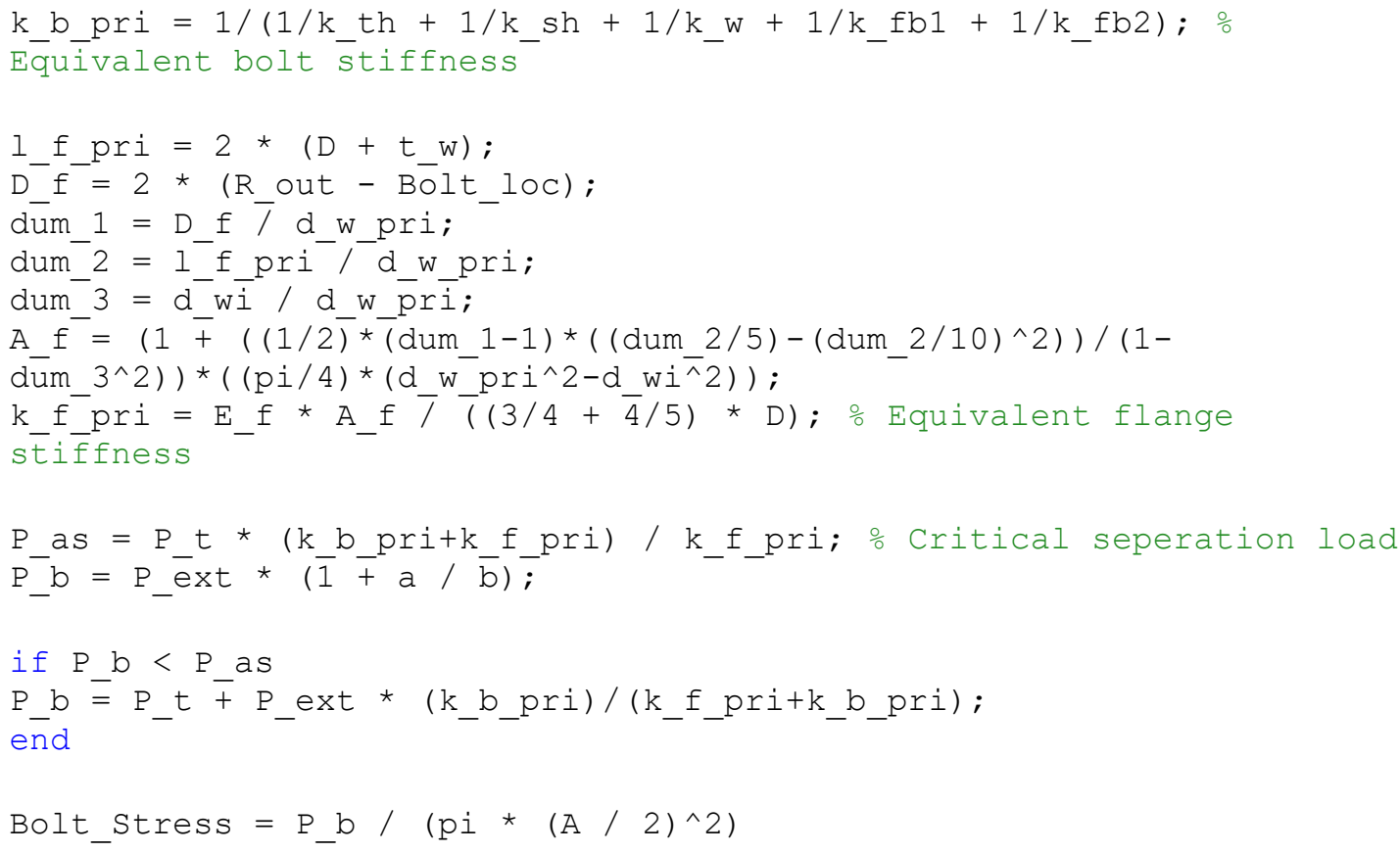

